\title{
Targeted Protein Acetylation in Cells Using Heterobifunctional Molecules
}

Wesley W. Wang ${ }^{1, a}$, Li-Yun Chen ${ }^{1, a}$, Jacob M. Wozniak ${ }^{2}$, Appaso M. Jadhav ${ }^{1}$, Hayden Anderson ${ }^{1}$, Taylor E. Malone ${ }^{1}$, Christopher G. Parker ${ }^{1,2^{*}}$

${ }^{1}$ Department of Chemistry, The Scripps Research Institute, Jupiter, FL 33458, USA

${ }^{2}$ Department of Chemistry, The Scripps Research Institute, La Jolla, CA, 92037, USA

a These authors contributed equally

*To whom correspondence should be addressed: cparker@scripps.edu 


\section{TABLE OF CONTENTS}

\section{Supplementary Figures}

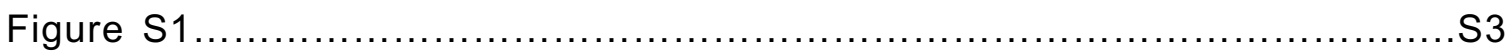

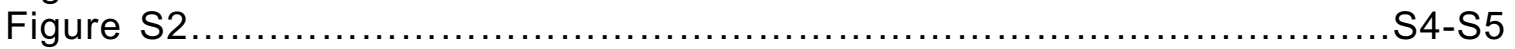

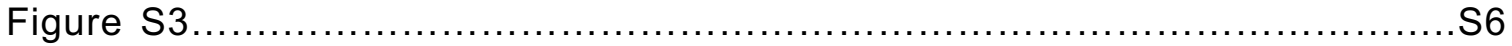

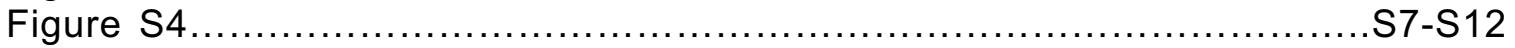

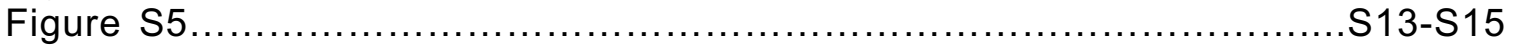

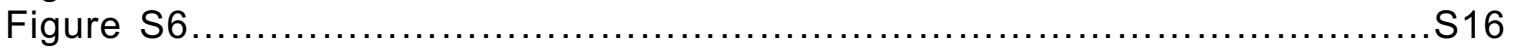

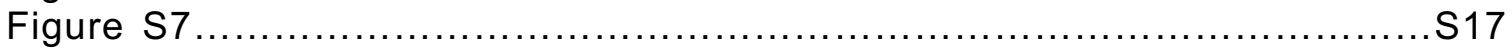

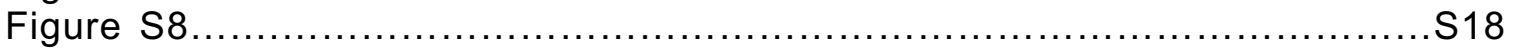

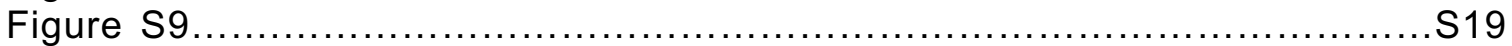

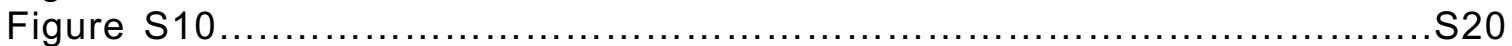

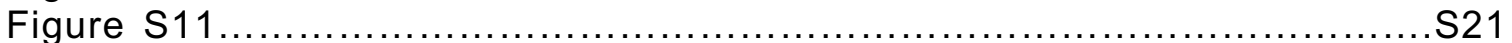

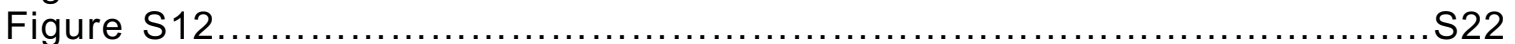

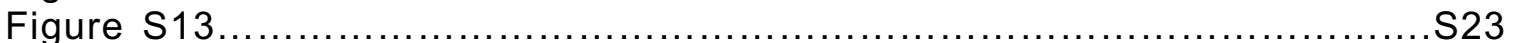

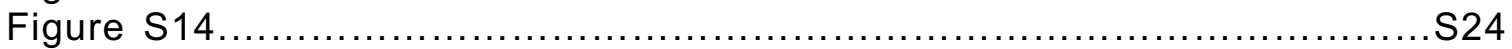

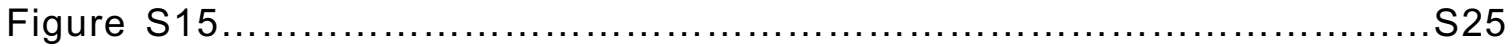

\section{Materials and Methods}

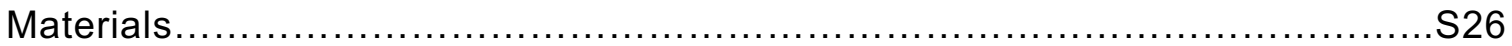

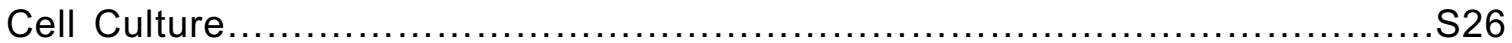

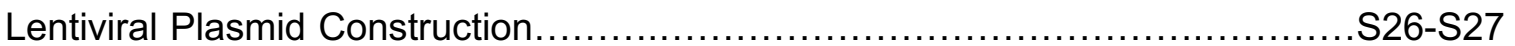

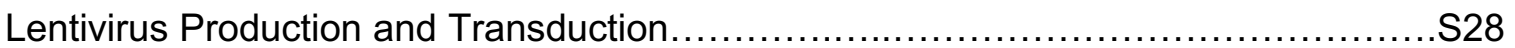

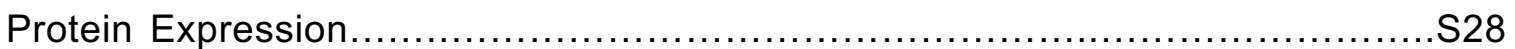

GST- FKBP12 ${ }^{336 V} /$ His-P300-BRD AlphaScreen Assay.............................. 28 -S29

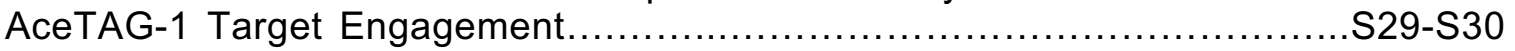

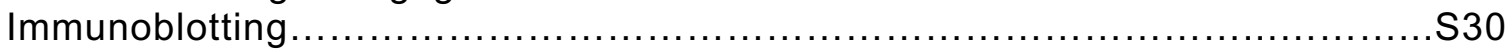

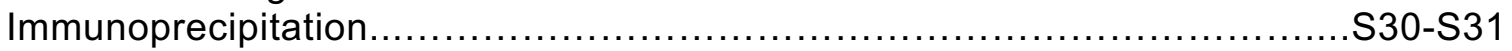

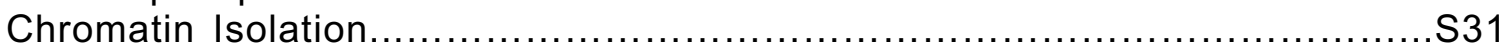

Quantitative Proteomic Analysis of H3.3 Acetylation.................................S31-S33

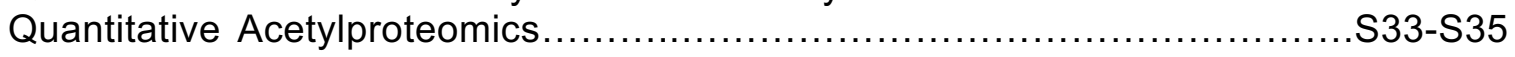

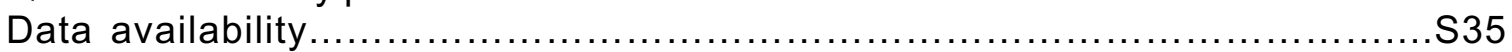

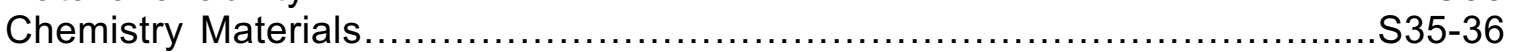

\section{Compound Synthesis and Characterization}

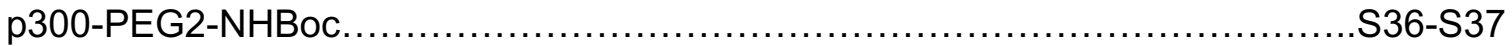

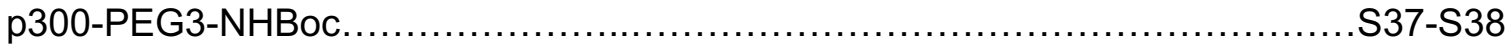

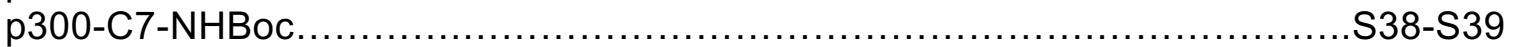

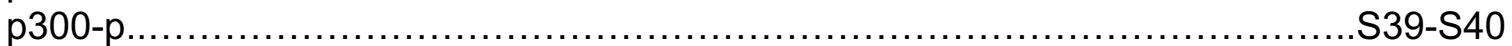

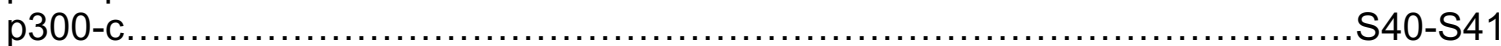

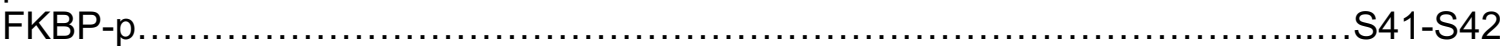

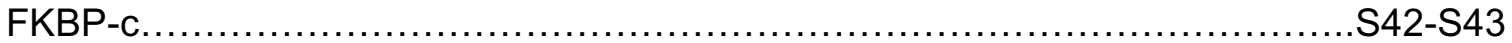

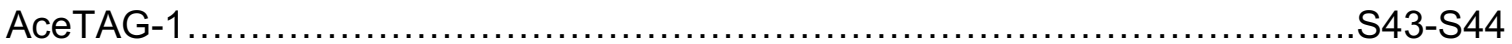

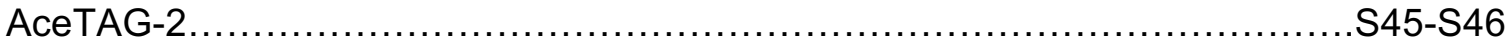

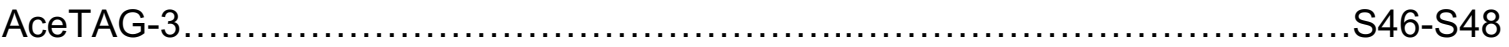




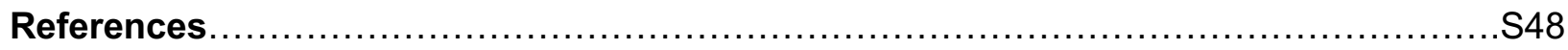

\section{Spectra}

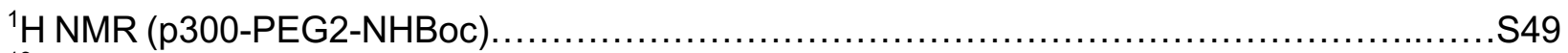

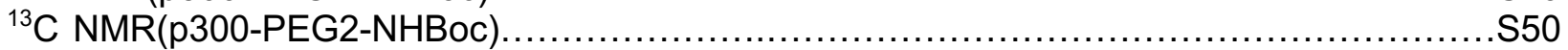

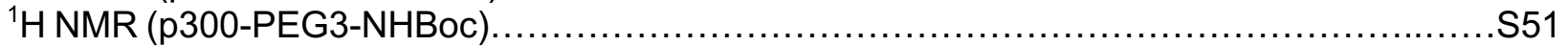

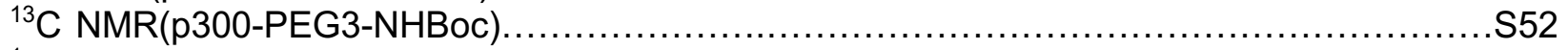

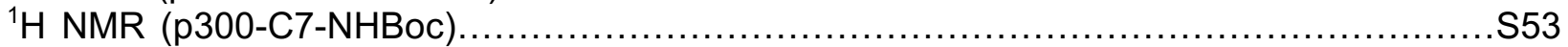

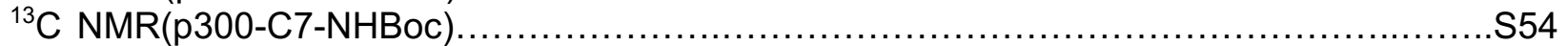

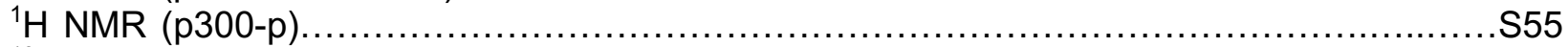

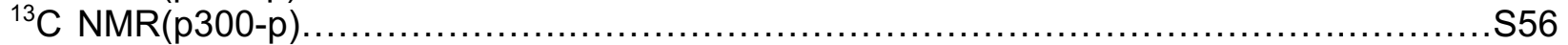

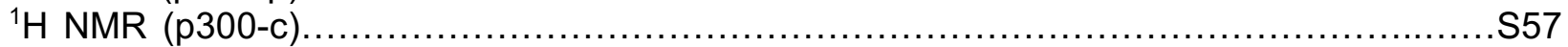

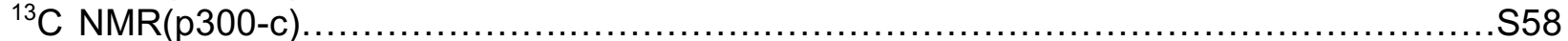

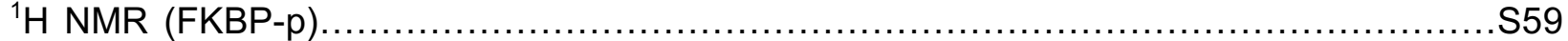

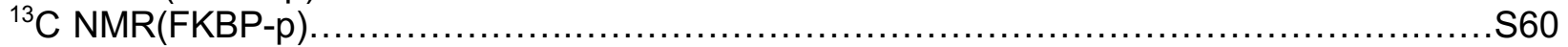

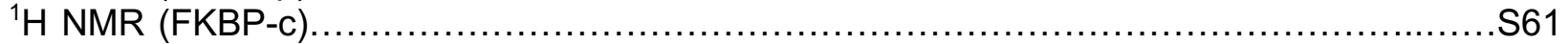

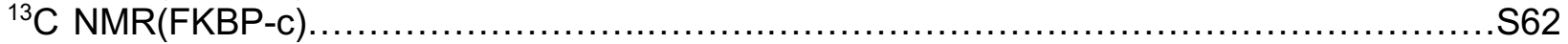

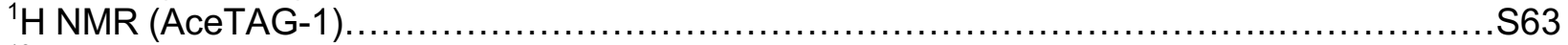

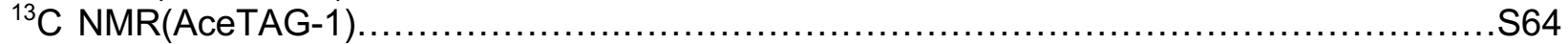

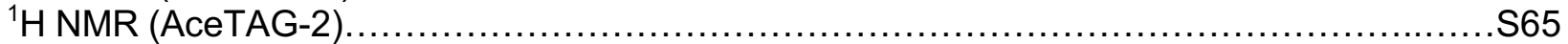

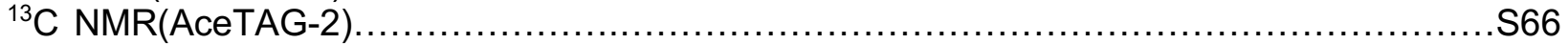

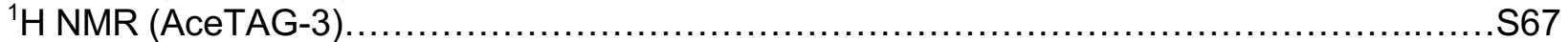

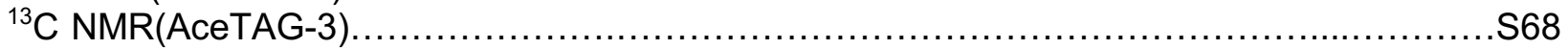


a
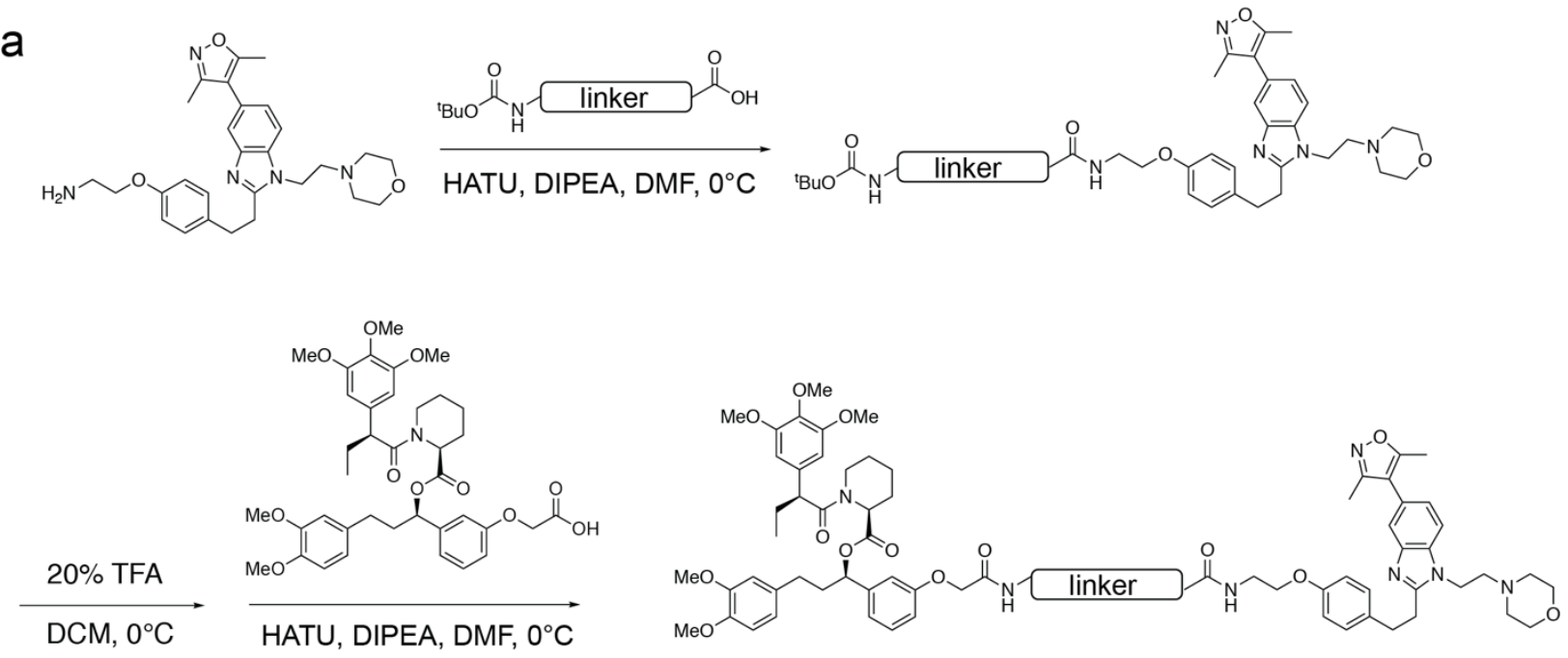

$$
\text { AceTAG-2 }
$$

b

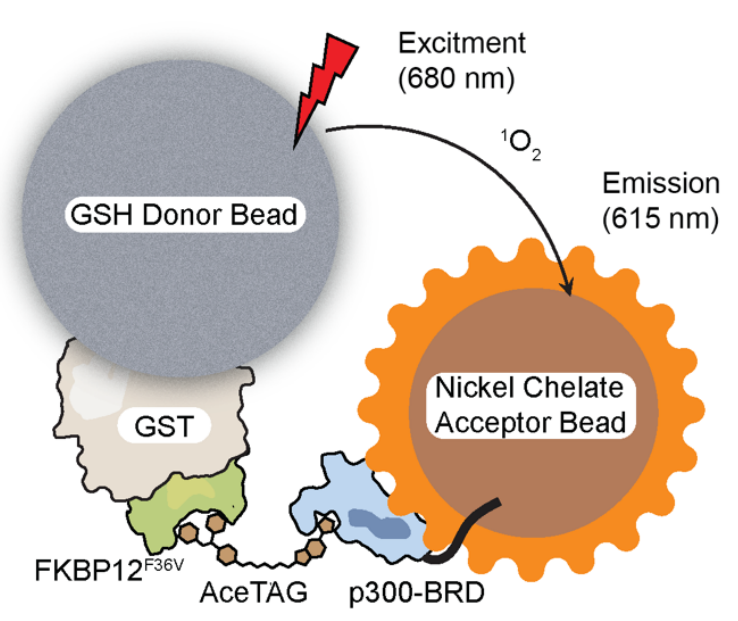

C
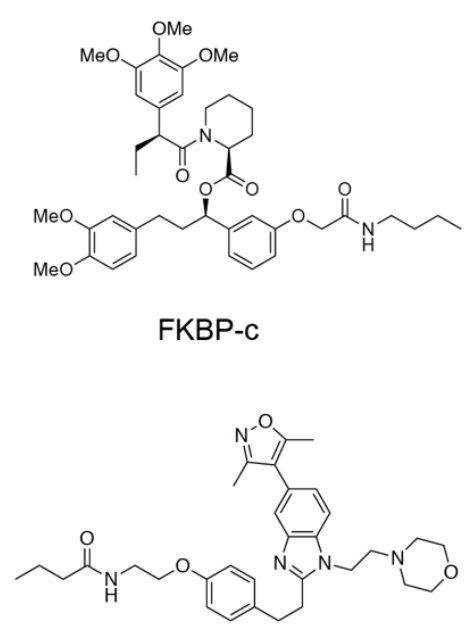

p300-c

Supplementary Figure 1. Chemical structures of indicated molecules and AlphaScreen assay design. a, General synthetic route of AceTAG molecules. b. Schematic depiction of a luminescence-based AlphaScreen assay, in which AceTAG molecules induce dimerization of GST-FKBP12 ${ }^{\mathrm{F} 36 \mathrm{~V}}$ and His-p300BRD. c, Chemical structures of terminal binding molecules. FKBP-C is used as a competitive binder for FKBP $12^{\mathrm{F} 36 \mathrm{~V}}$ and $\mathrm{p} 300-\mathrm{c}$ is used as a competitive binder for $\mathrm{p} 300 / \mathrm{CBP}$. 

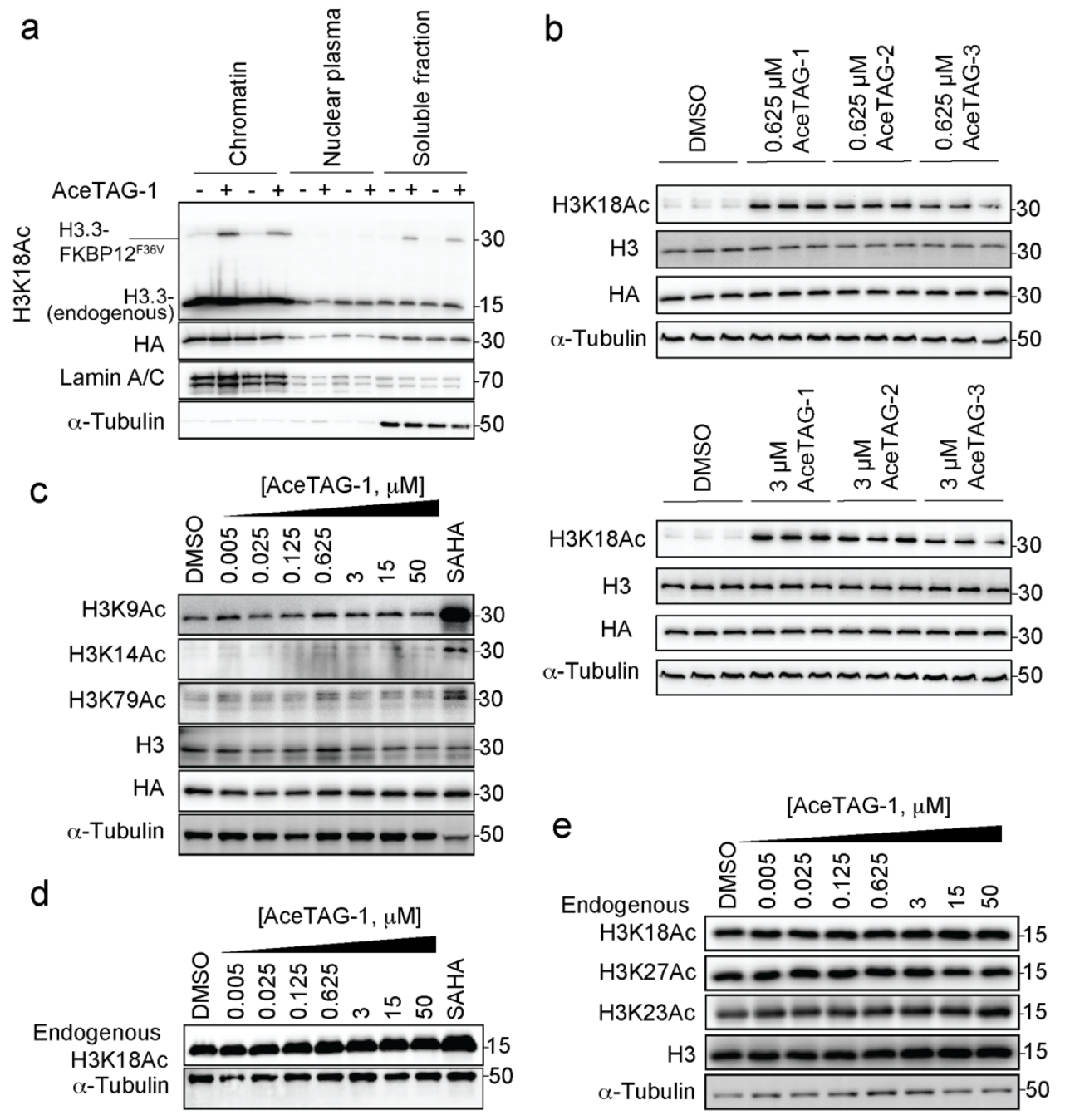

d

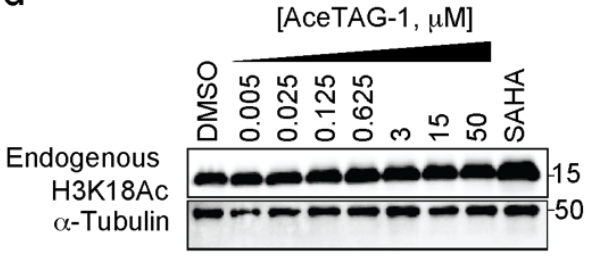

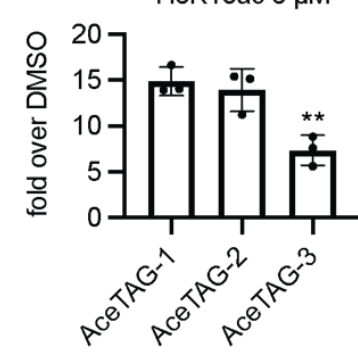
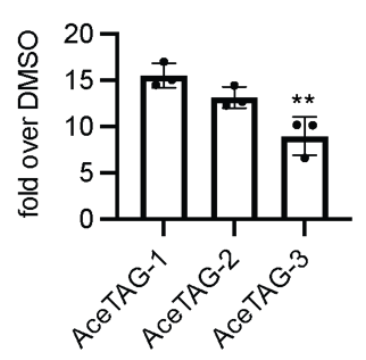

H3K18ac $3 \mu \mathrm{M}$

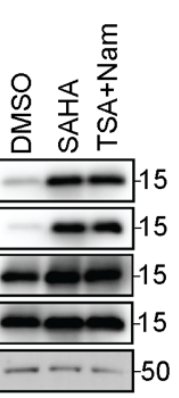

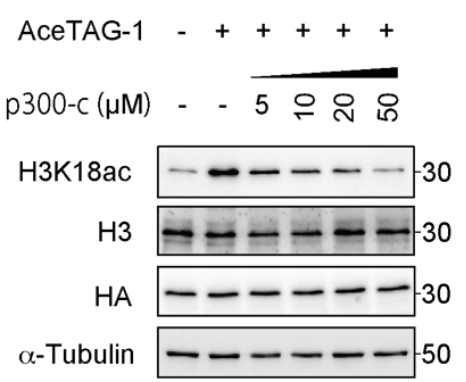

H3K18ac

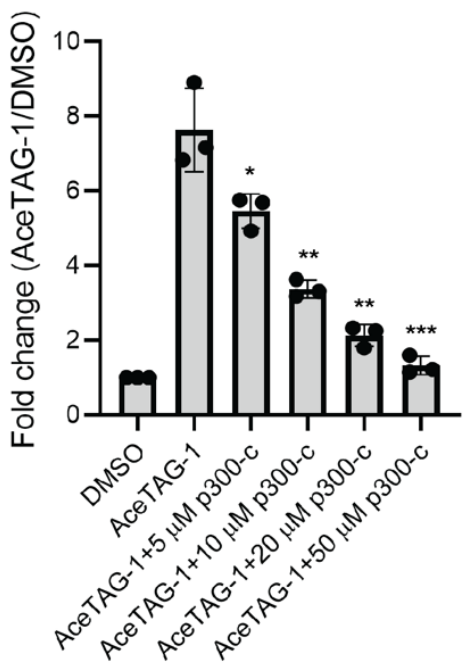


Supplementary Figure 2. Confirmation of Histone H3.3-FKBP12 ${ }^{\mathrm{F} 36 \mathrm{~V}}$ acetylation induced by AceTAGs. a, Cell fractionation confirms localization of Histone H3.3-FKBP12 ${ }^{\mathrm{F} 36 \mathrm{~V}}$ to chromatin. H3.3-FKBP12 ${ }^{\mathrm{F} 36 \mathrm{~V}} \mathrm{HeLa}$ cells were treated with AceTAG-1 $(625 \mathrm{nM})$ or DMSO for $2 \mathrm{~h}$. Acetylation of $\mathrm{K} 18$ was monitored by immunoblot. b, Comparison of K18ac level induced by different AceTAGs. H3.3-FKBP12 ${ }^{\mathrm{F} 36 \mathrm{~V}}$ HeLa cells were treated with $625 \mathrm{nM}$ or $3 \mu \mathrm{M}$ AceTAG1-3 for $2 \mathrm{~h}$. Acetylation of K18 was monitored by immunoblot analysis of lysate. Shown in the right panel is quantitation of immunoblot signal of K18Ac relative to $\alpha$ tubulin as the mean \pm s.e.m. of $n=3$ biologically independent experiments. Statistical significance was calculated with unpaired two-tailed Student's t-tests comparing AceTAG-3 to AceTAG-1-treated samples. ${ }^{*} p<0.05$; ${ }^{* *} p<0.01$; ${ }^{* * *} p<0.001$; ${ }^{* * * *} p<0.0001$. c, Acetylation of K9, K14 and K79 were not induced by AceTAG-1. H3.3-FKBP12 $2^{\mathrm{F} 36 \mathrm{~V}} \mathrm{HeLa}$ cells were treated with increasing concentrations of AceTAG-1 for $2 \mathrm{~h}$. Acetylation of K9, K14 and K79 were monitored by immunoblot analysis of lysate. d, Endogenous Histone H3K18 acetylation was not affected by AceTAG-1 in H3.3-FKBP12 $2^{\mathrm{F} 36 \mathrm{~V}}$ HeLa cells. Cells were treated with increasing concentrations of AceTAG-1 for $2 \mathrm{~h}$. Acetylation of $\mathrm{K} 18$ was monitored by immunoblot analysis of lysate. e, Endogenous Histone H3K18, H3K23, and H3K27 acetylation was not affected by AceTAG-1 in WT HeLa cells. Cells were treated with increasing concentrations of AceTAG-1, SAHA $(5 \mu \mathrm{M})$, or TSA $(2 \mu \mathrm{M})$ and Nicotinamide $(\mathrm{Nam} ; 10 \mathrm{mM})$ for $2 \mathrm{~h}$. Acetylation of Histones were monitored by immunoblot analysis of lysate. f, Acetylation of H3K18 induced by $625 \mathrm{nM}$ AceTAG-1 was competed by $\mathrm{p} 300-\mathrm{c}$ in dose-dependent fashion. Hela cells expressing H3.3-FKBP12 ${ }^{\mathrm{F} 36 \mathrm{~V}}$ were incubated with corresponded molecules for 2 hours. Acetylation of K18 was monitored by immunoblot analysis of lysate. Shown in the right panel is quantitation of immunoblot signal of K18Ac relative to $\alpha$-tubulin as the mean \pm s.e.m. of $n=3$ biologically independent experiments. Statistical significance was calculated with unpaired two-tailed Student's t-tests comparing AceTAG-1+p300-c to AceTAG-1-treated samples. ${ }^{*} p<0.05 ;{ }^{* *} p<0.01 ;{ }^{* * *} p<0.001 ;{ }^{* * * *} p<0.0001$. See Supplementary Figure 12 and 13 for full blot images. 
a

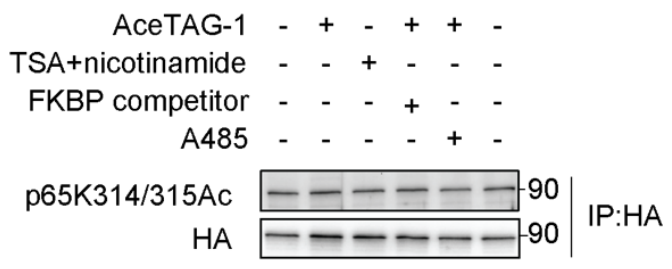

C

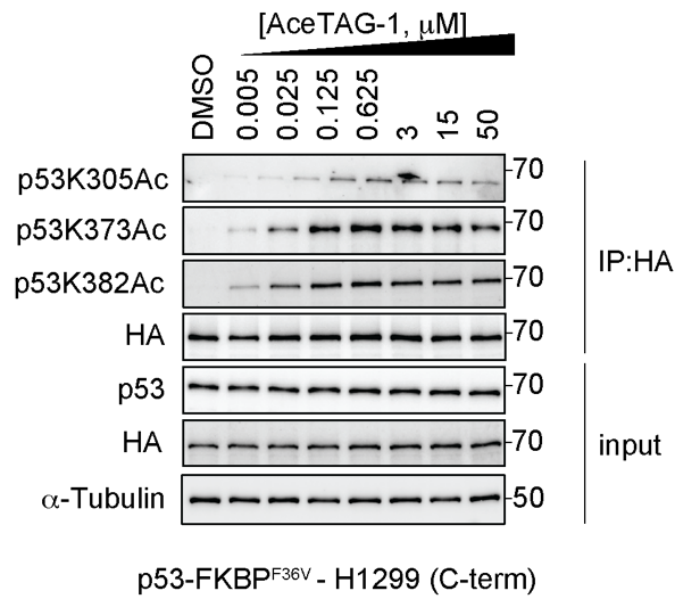

b

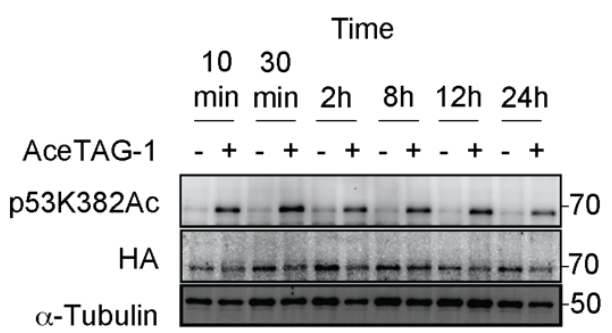

Supplementary Figure 3. AceTAG-1 p53 kinetics and induction of acetylation of C-terminally tagged p53. a, Immunoblot analysis of controls for AceTAG-mediated acetylation of RelA. Cells were treated with TSA $(2 \mu \mathrm{M})$ and nicotinamide $(10 \mathrm{mM})$ as a positive control for p65 acetylation or co-treated with AceTAG$1(625 \mathrm{nM})$ and DMSO, an FKBP12 ${ }^{\mathrm{F} 36 \mathrm{~V}}$ binding ligand (50 $\mu \mathrm{M}$, Supplementary Figure 1c), or the p300/CBP KAT domain inhibitor A485 $(1 \mu \mathrm{M})$ for $2 \mathrm{~h}$ which block AceTAG-1-induced acetylation. b, Kinetics of AceTAG-1 induced acetylation on FKBP12 ${ }^{\mathrm{F} 36 \mathrm{~V}}-\mathrm{p} 53$. FKBP12 ${ }^{\mathrm{F} 36 \mathrm{~V}}-\mathrm{p} 53 \mathrm{H} 1299$ cells were treated with AceTAG-1 (625 nM) or DMSO for indicated time. Acetylation of K382 was monitored by immunoblot analysis of cell lysate. c, AceTAG-1 induces dose-dependent acetylation on K382, K373 and K305 of p53FKBP12 ${ }^{\mathrm{F} 36 \mathrm{~V}}$. p53-FKBP12 ${ }^{\mathrm{F} 36 \mathrm{~V}} \mathrm{H} 1299$ cells were treated with increasing concentrations of AceTAG-1 for $2 \mathrm{~h}$, lysed and p53-FKBP12 $2^{\mathrm{F} 36 \mathrm{~V}}$ was enriched and blotted with noted antibodies. The results in a-c are representative of two independent biological replicates $(n=2)$. See Supplementary Figure 14 for full blot images. 
a

H3.3-FKBP12 $2^{\mathrm{F} 36 \mathrm{~V}} \mathrm{HeL}$ cells

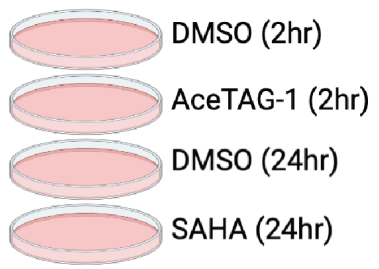

MS2-Identification

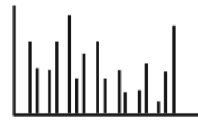

MS3-Quantification

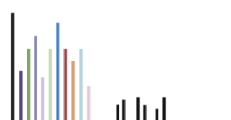

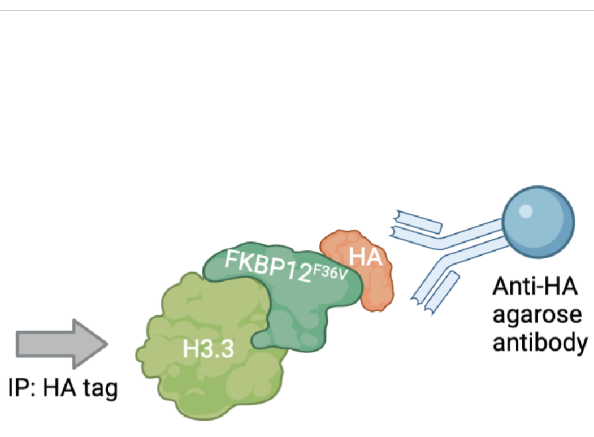
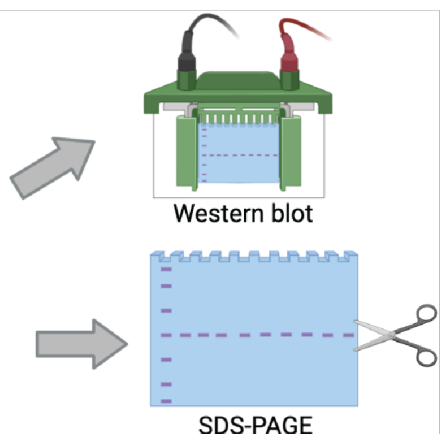

\{

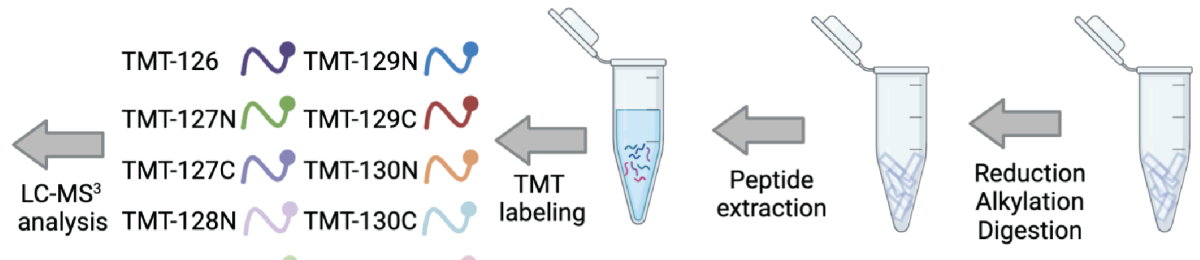

b

H3.3 K9ac_14ac peptide

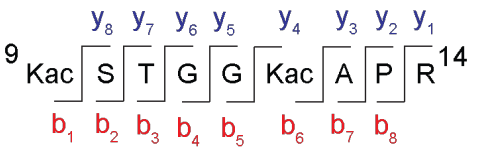

20210507_AC127_5_1.raw \#12790 RT: 37.6865 min

ITMS, 607.8560@cid30.00, $z=+2$, Mono m/z=607.85691 Da, MH+=1214.70654 Da, Match Tol.=0.8 D

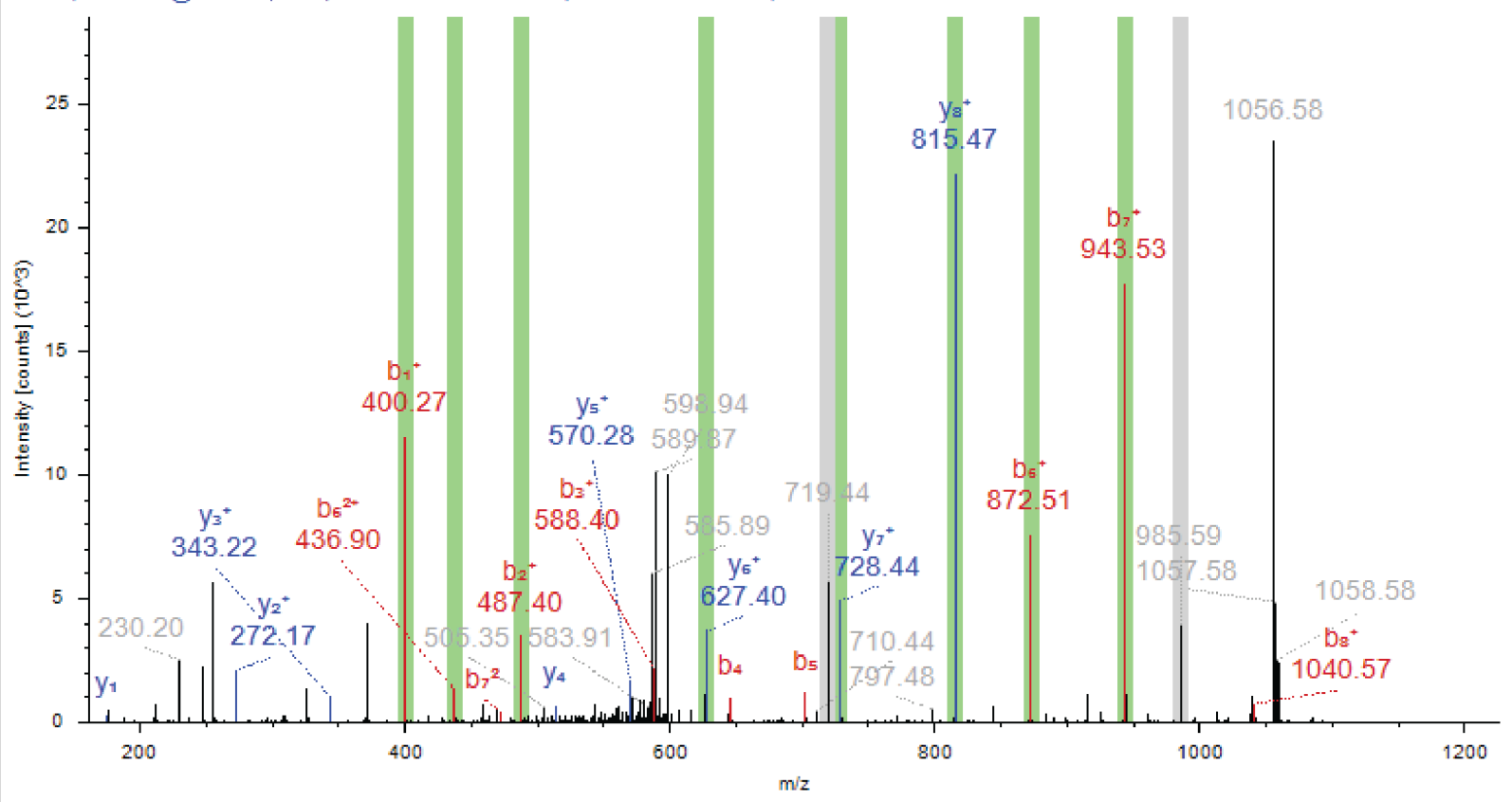


C

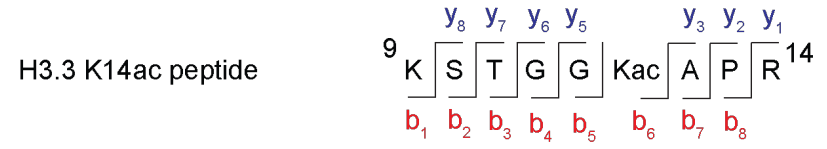

021721_AC102_H3_1.raw \#13017 RT: $37.1612 \mathrm{~min}$

ITMS, 467.9551@cid 30.00, $z=+3$, Mono m/z=467.95764 Da, MH+=1401.85836 Da, Match Tol.=0.8 Da

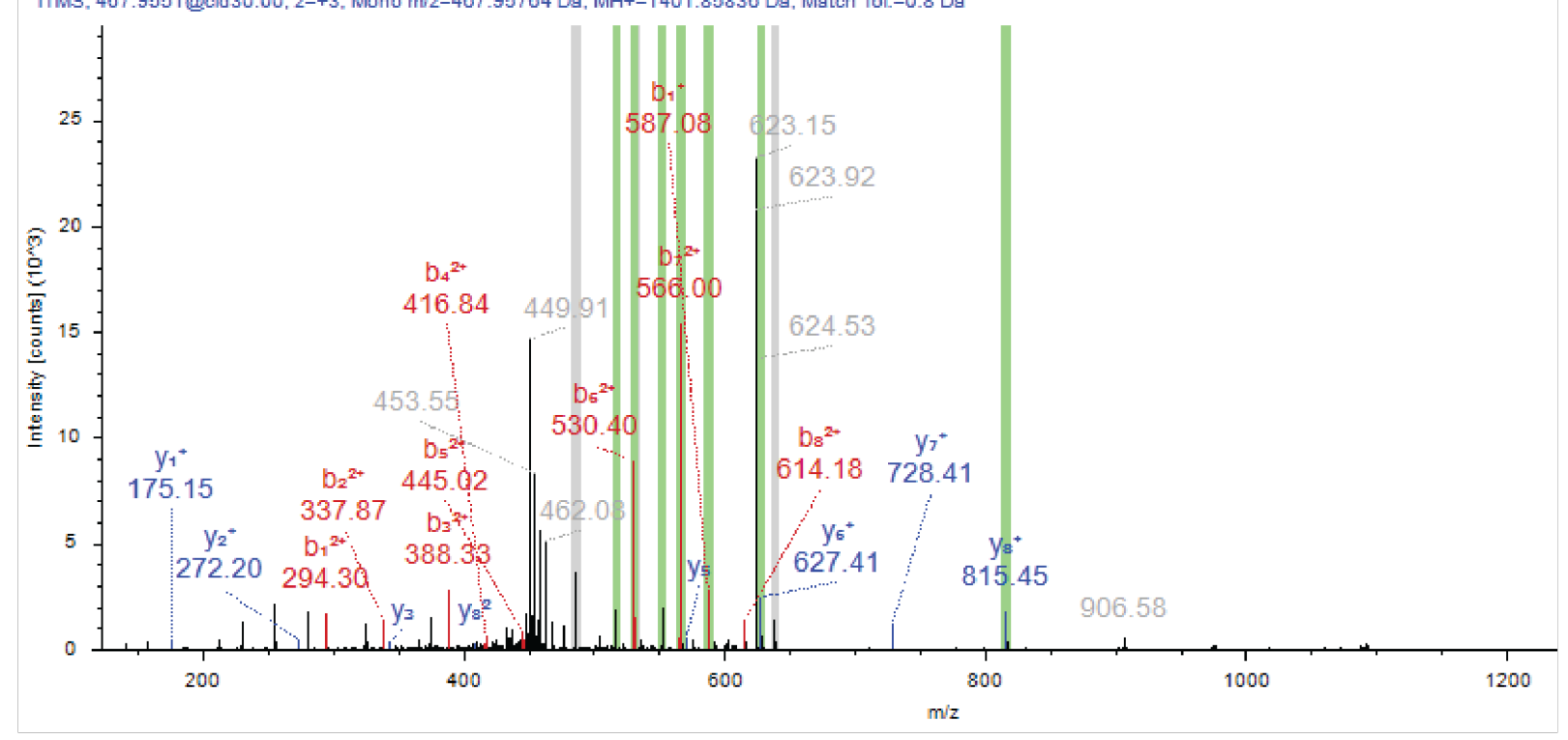

d

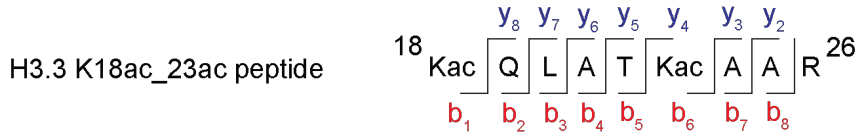

021721_AC102_H3_1.raw \#22134 RT: 58.0955 min

ITMS, 650.3979@cid30.00, $z=+2$, Mono $m / z=650.40149 \mathrm{Da}, \mathrm{MH}+=1299.79570 \mathrm{Da}$, Match ToL=0.8 Da

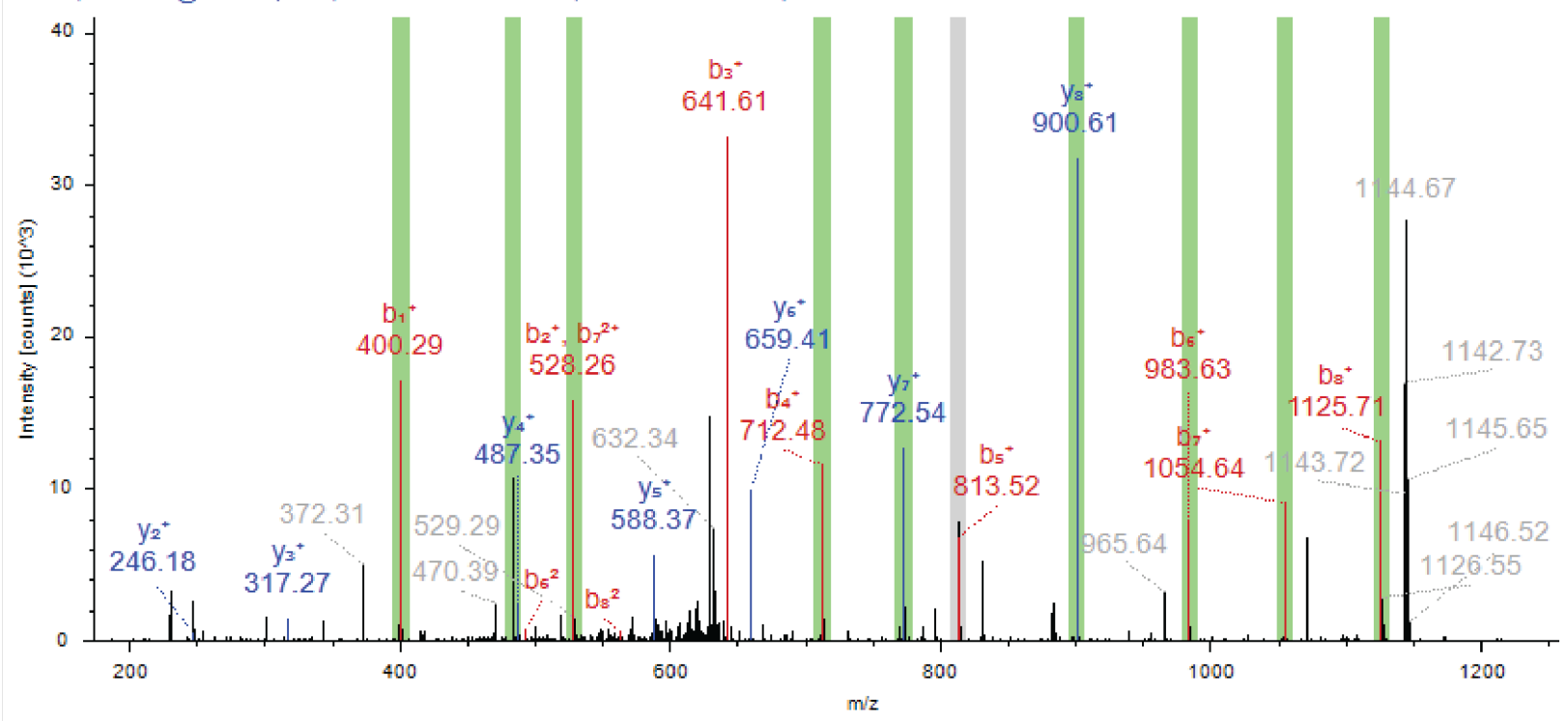


e

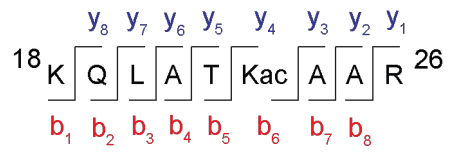

021721_AC102_H3_2.raw \#18497 RT: $51.9198 \mathrm{~min}$

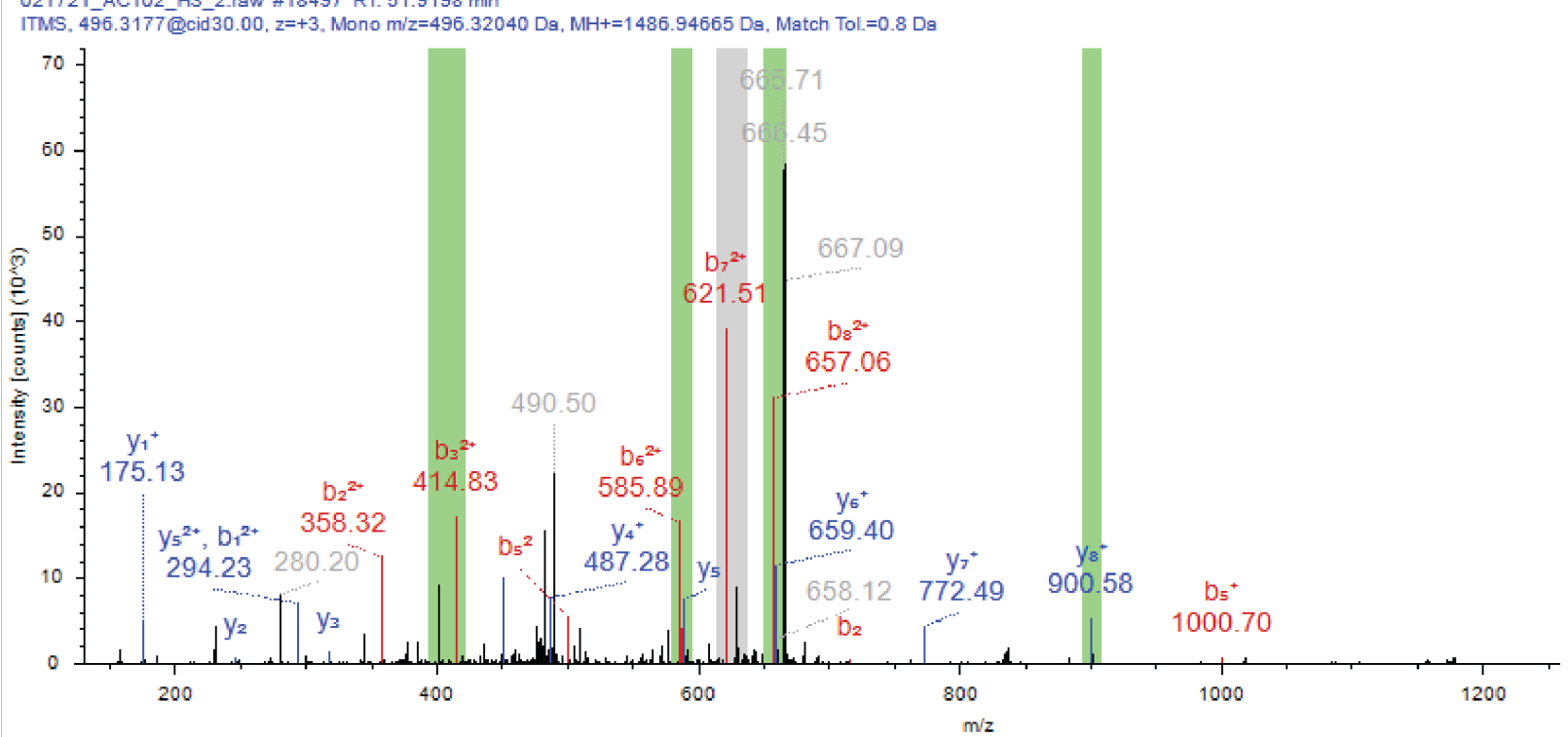

f

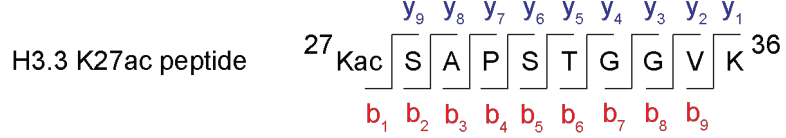

20210507_AC127_1_1.raw \#19967 RT: 56.0154 min

ITMS, 716.4321 @cid 30.00, $z=+2$, Mono $\mathrm{m} / \mathrm{z}=716.43329 \mathrm{Ds}, \mathrm{MH}+=1431.85930 \mathrm{Da}$, Match Tol.=0.8 Da

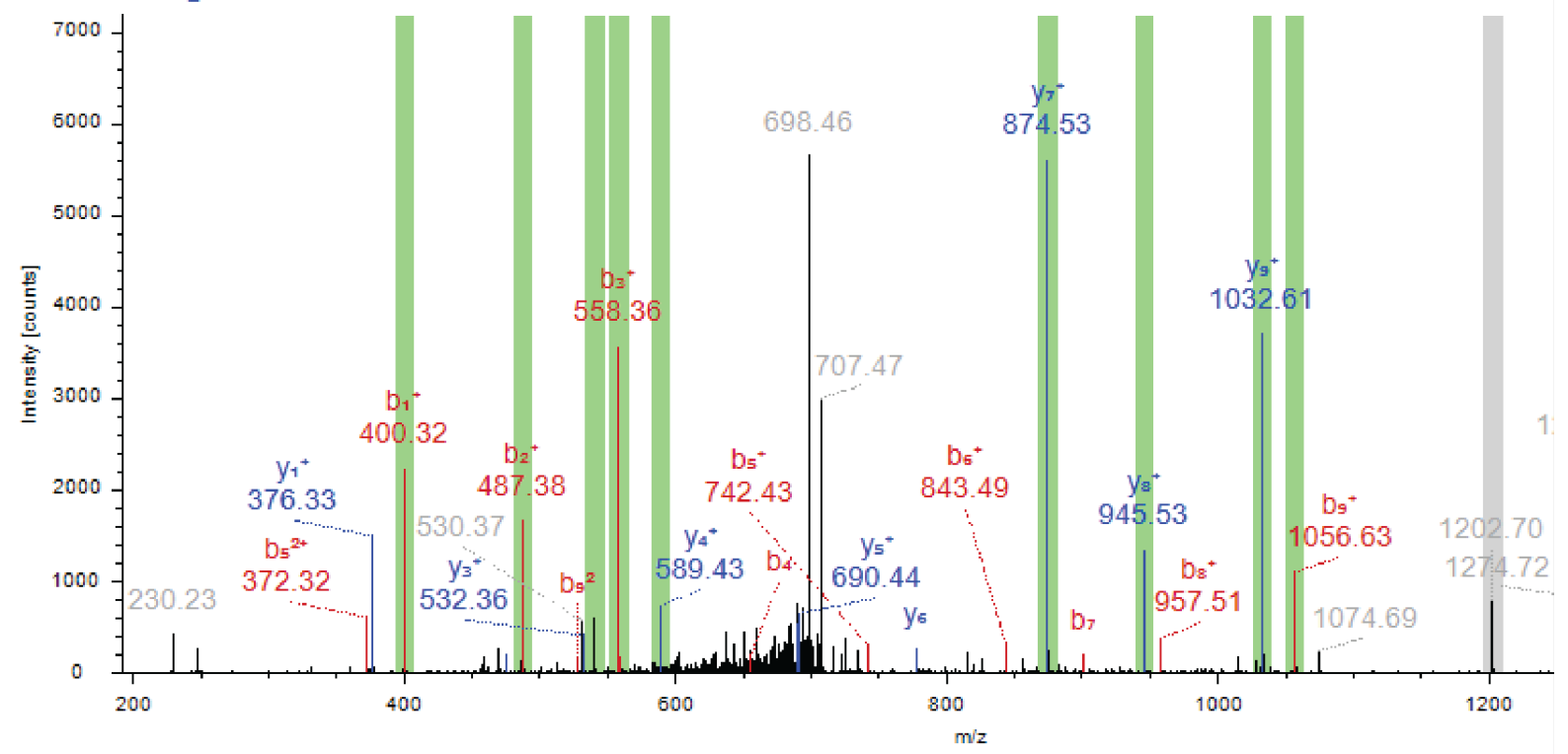


021721_AC102_H3_2.raw \#16995 RT: 49.0244 min

ITMS, 540.3392@cid30.00, $z=+3$, Mono $\mathrm{m} / \mathrm{z}=540.34214 \mathrm{Da}, \mathrm{MH}+=1619.01188 \mathrm{Da}$, Match Tol.=0.8 Da

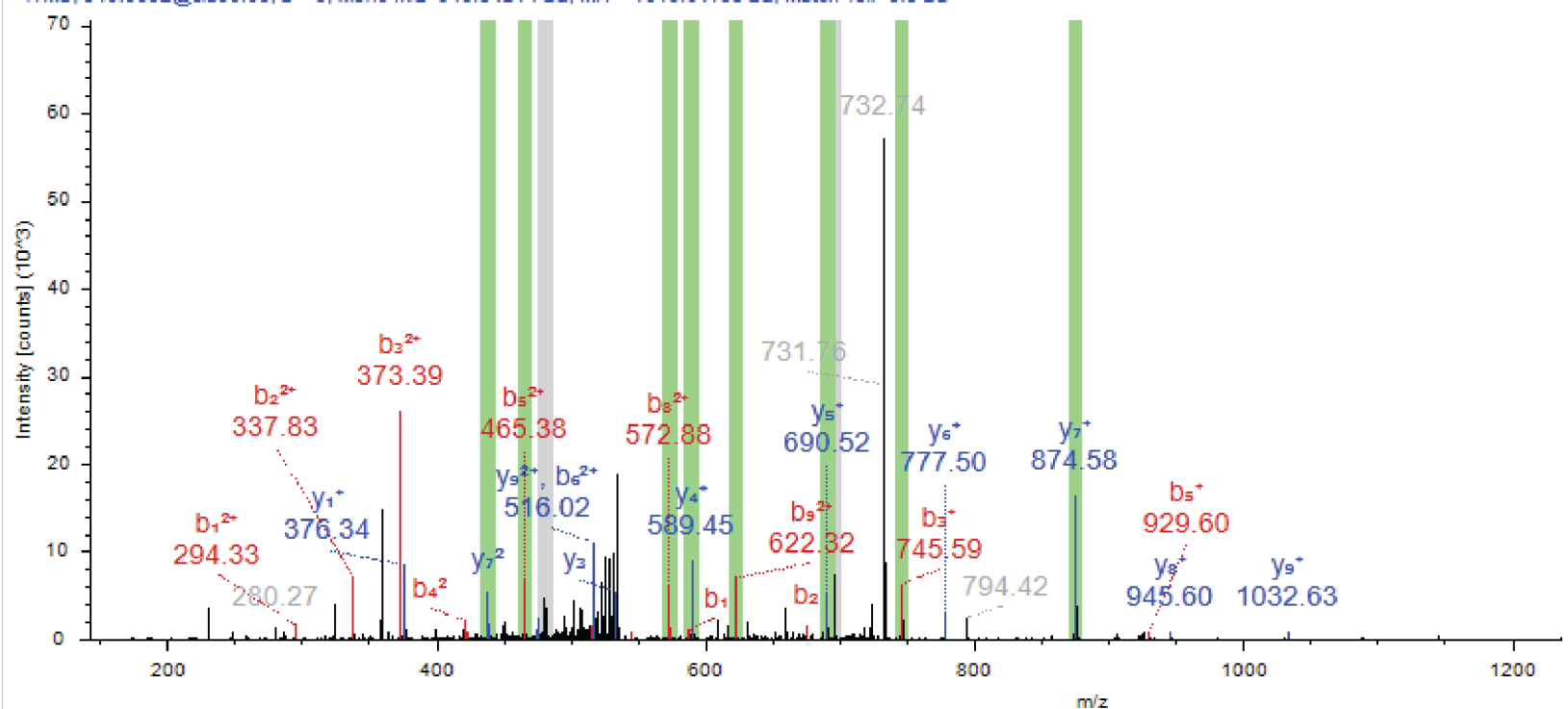

h

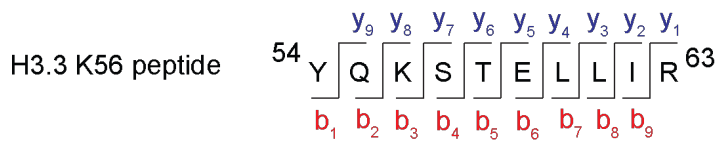

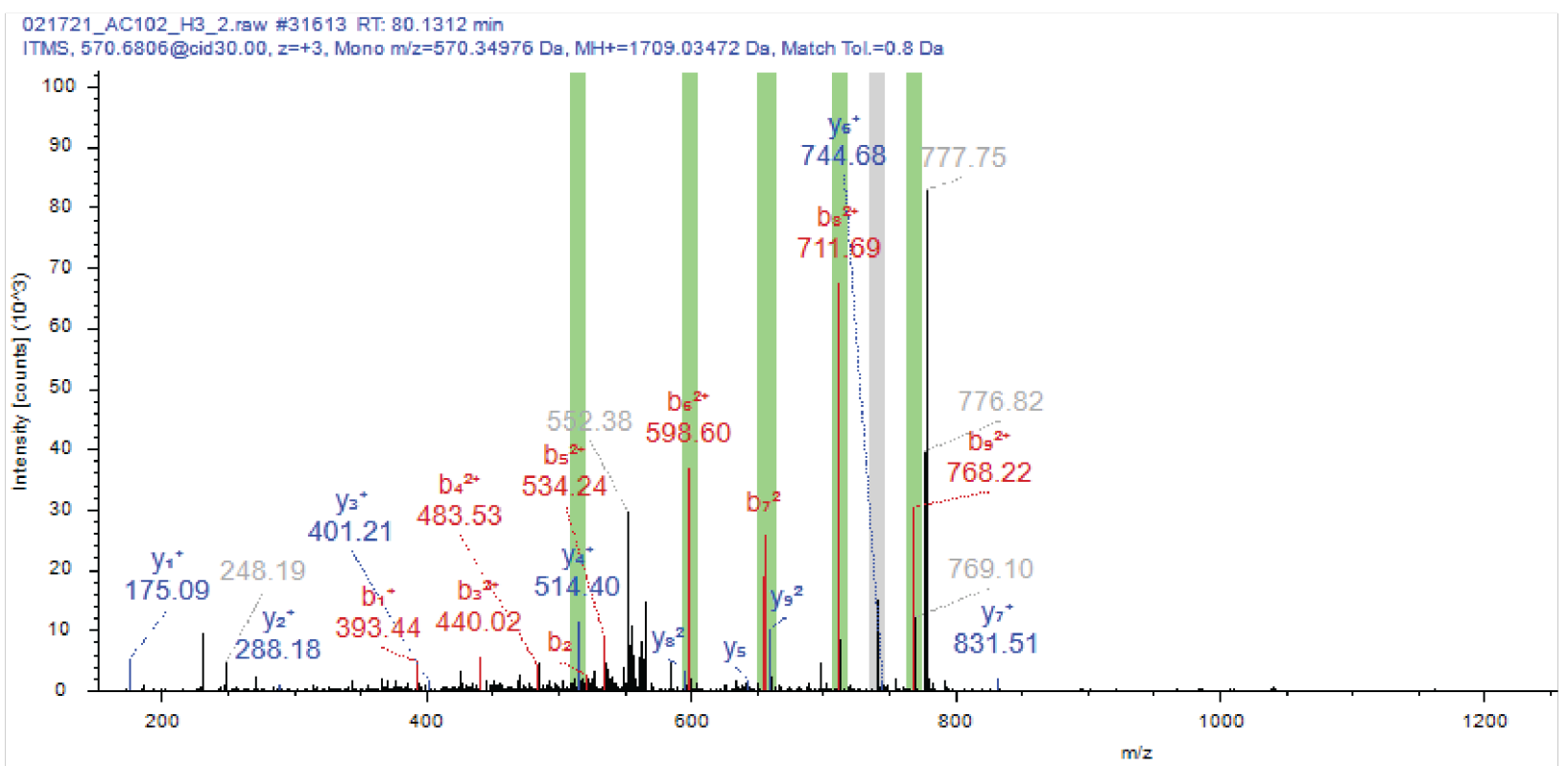


H3.3 K79 peptide

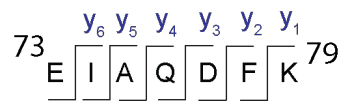

$$
\begin{aligned}
& b_{1} \quad b_{2} b_{3} b_{4} \quad b_{5} \quad b_{6}
\end{aligned}
$$

20210507_AC127_6_1.raw \#29616 RT: $79.3965 \mathrm{~min}$

ITMS, 654.8807@gcid30.00, $z=+2$, Mono $\mathrm{m} / \mathrm{z}=654.88163 \mathrm{Da}, \mathrm{MH}+=1308.75599 \mathrm{Da}$, Match Tol.=0.88

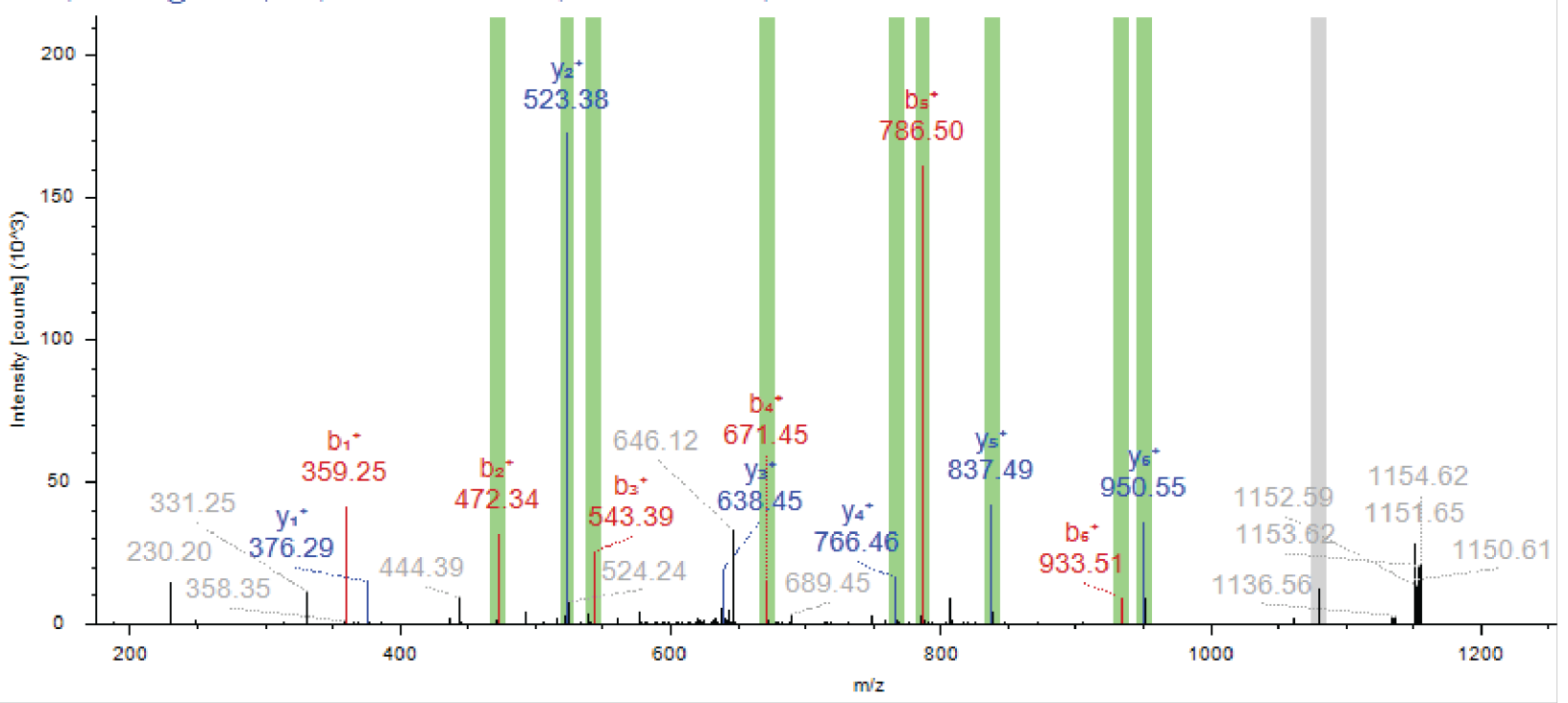

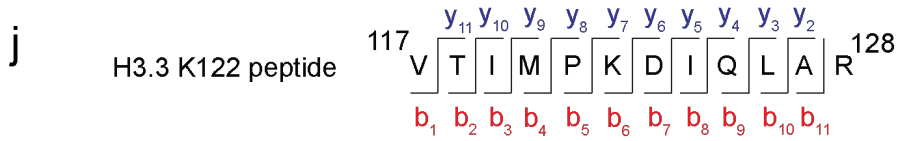

021721_AC102_H3_1.raw \#41569 RT: $98.8867 \mathrm{~min}$

ITMS, 615.3767@cid30.00, $z=+3$, Mono $\mathrm{m} / \mathrm{z}=615.04612 \mathrm{Da}, \mathrm{MH}+=1843.12382 \mathrm{Da}$, Match Tol.=0.8 Da

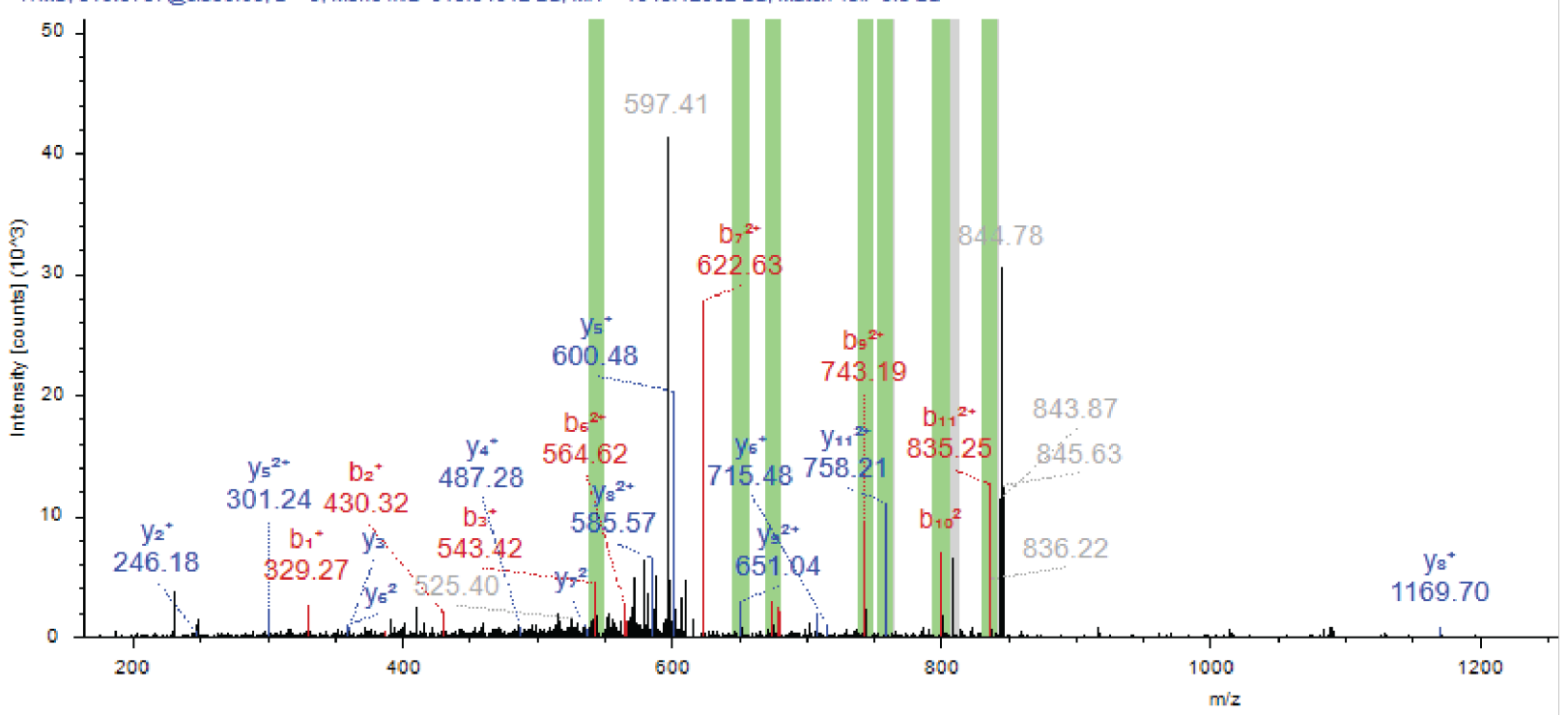

Supplementary Figure 4. Confirmation of $\mathrm{H} 3.3-\mathrm{FKBP} 12^{\mathrm{F} 36 \mathrm{~V}}$ acetylation in cells by quantitative mass spectrometry. a, Schematic depiction of H3.3-FKBP12 $2^{\mathrm{F} 36 \mathrm{~V}}$ acetylation determination using TMT-based quantitative proteomics and immunoblot. H3.3-FKBP12 ${ }^{\mathrm{F} 36 \mathrm{~V}} \mathrm{HeLa}$ cells were treated with DMSO, $625 \mathrm{nM}$ AceTAG-1 and $5 \mu \mathrm{M}$ SAHA for $2 \mathrm{~h}$ or $24 \mathrm{~h}$, respectively. H3.3-FKBP12 $336 \mathrm{~V}$ was enriched by immunoprecipitation with HA antibody conjugated beads. Eluted protein was resolved by immunoblot 
analysis or SDS-PAGE. Gel slices containing H3.3-FKBP12 $2^{\mathrm{F} 36 \mathrm{~V}}$ were subjected for in-gel trypsin digestion. Recovered peptides were labeled with TMT10plex Isobaric Label Reagent and analyzed by LC-MS/MS/MS proteomics. Data were processed and analyzed with Proteome Discoverer 2.4. Figure created with BioRender.com. b, MS2 spectrum of H3.3K9ac/K14ac peptide. c, MS2 spectrum of H3.3K14ac peptide. d, MS2 spectrum of H3.3K18ac/K23ac peptide. e, MS2 spectrum of H3.3K23ac peptide. f, MS2 spectrum of H3.3K27ac peptide. g, MS2 spectrum of H3.3K36 peptide. h, MS2 spectrum of H3.3K56 peptide. i, MS2 spectrum of H3.3K79 peptide. j, MS2 spectrum of H3.3K122 peptide. 
a
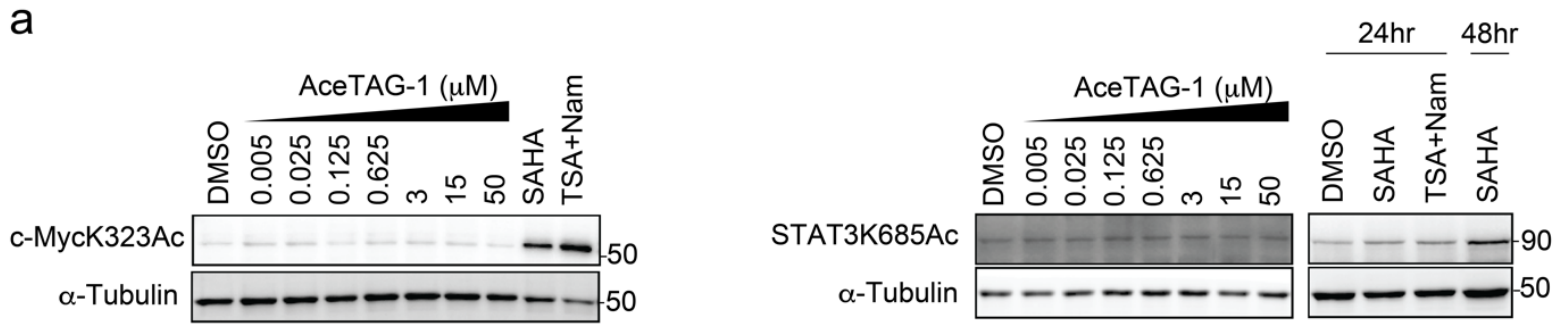

b

H3.3-FKBP12 ${ }^{F^{36 v}}$ stably

transfected HeLa cells

DMSO $(2 \mathrm{hr})$
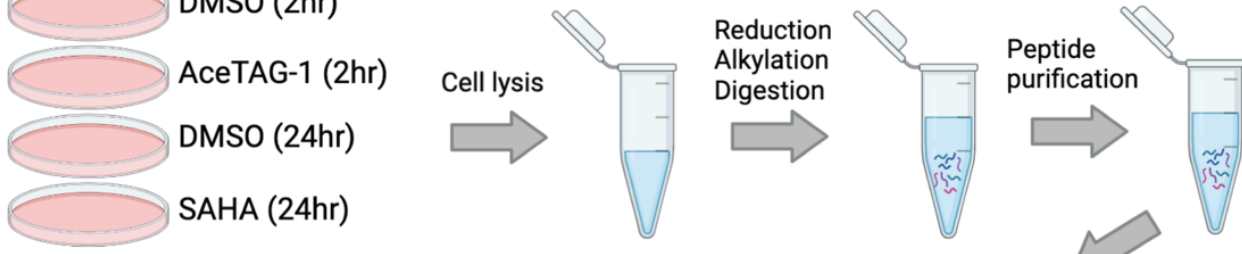

MS2-Identification

TMT

labeling

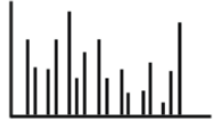

TMT-126 $\sim$ TMT-129N $\sim$
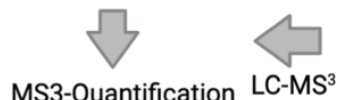

TMT-127N $\sim$ TMT-129C $\sim$

MS3-Quantification analysis

TMT-127C $\sim$ TMT-130N $\sim$

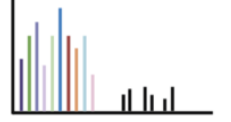

TMT-128N $\sim$ TMT-130C $\sim$ TMT

TMT-128C $\sim$ TMT-131

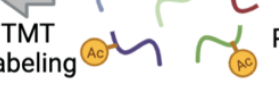

\section{Acetylated}

peptides

C

DMSO vs. SAHA (Experiment 2)

DMSO vs. AceTAG (Experiment 2)
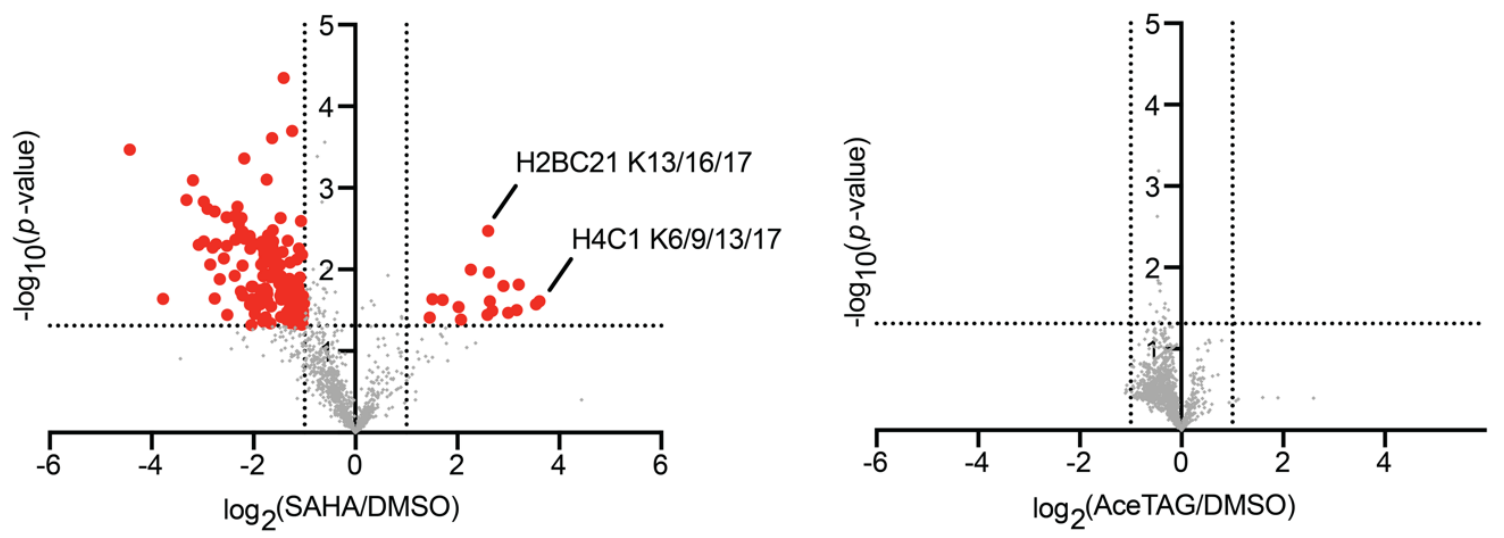
d
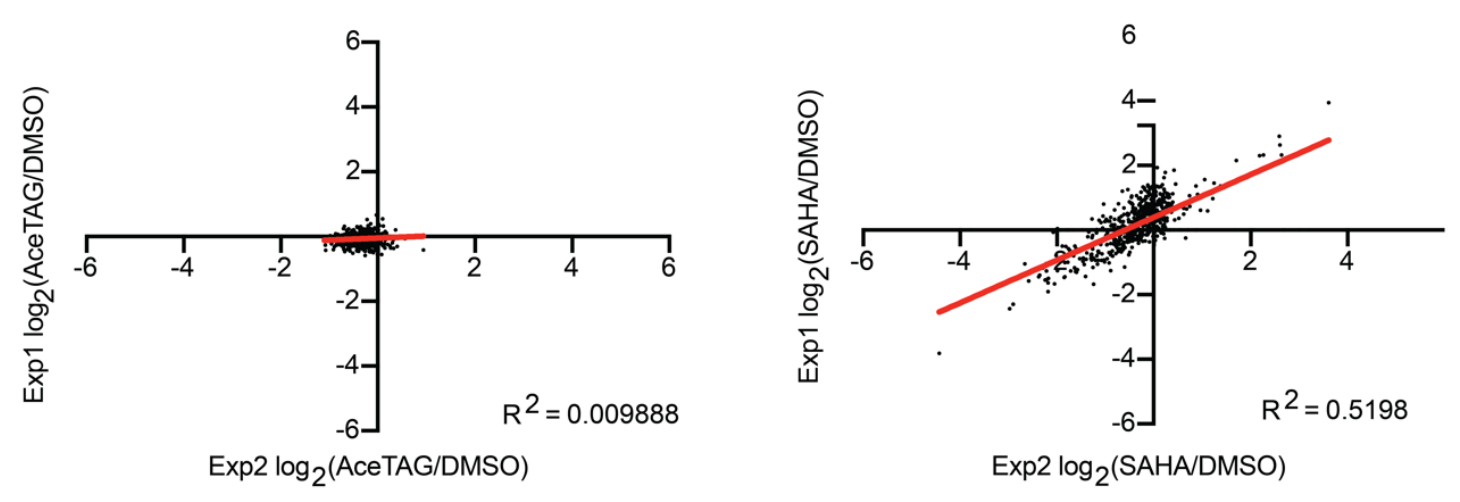

e $\mathrm{H} 4 \mathrm{C} 1 \mathrm{~K} 6 / 9 / 13 / 17$
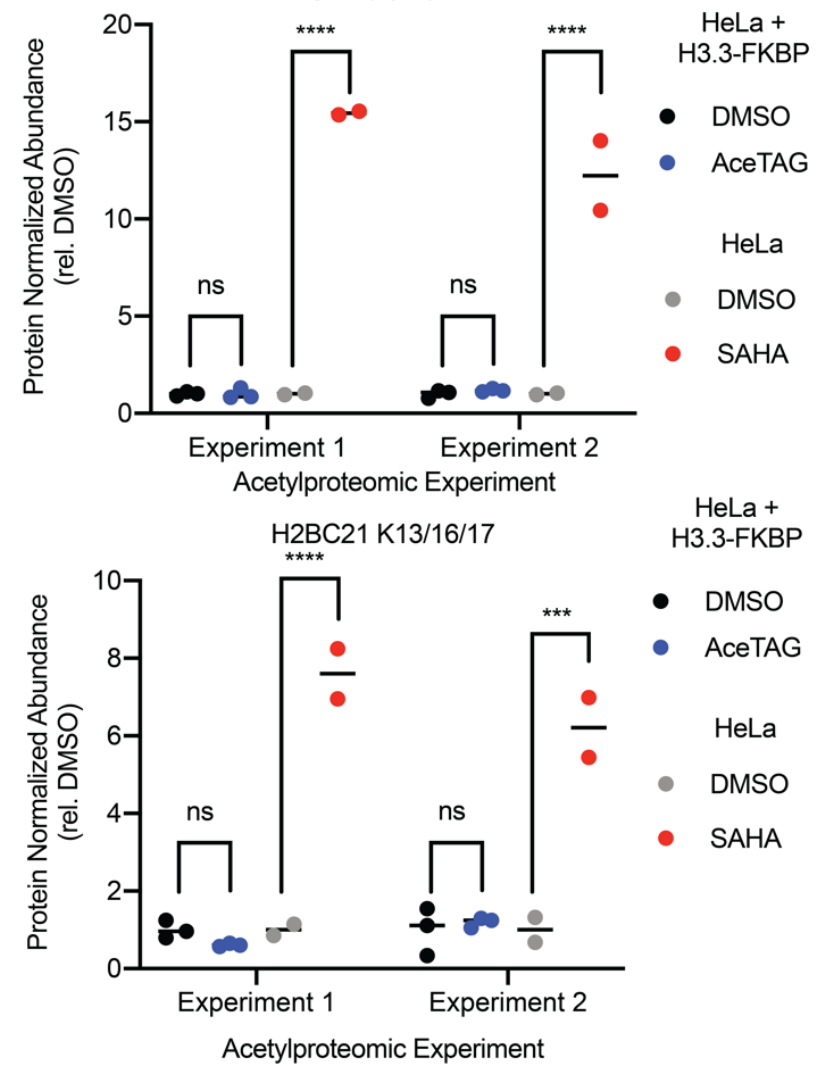

f

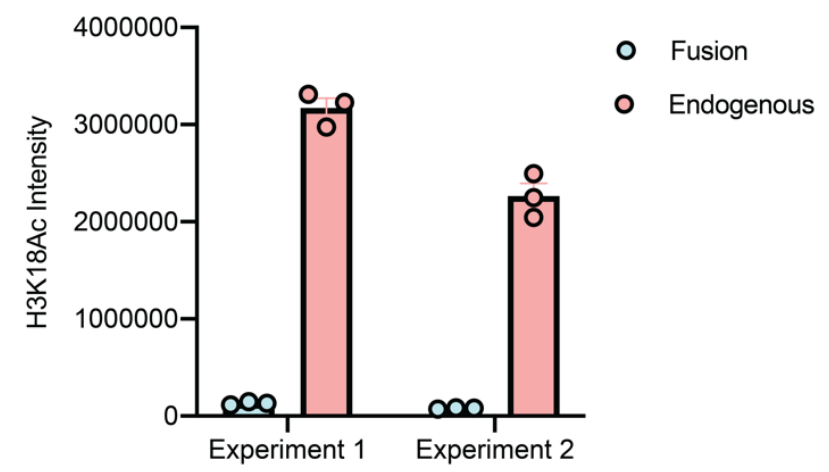


Supplementary Figure 5. Confirmation of proteome-wide selectivity of AceTAG induced acetylation. a, No acetylation increase was observed for established p300/CBP targets including c-Myc and STAT3. H3.3-FKBP12 ${ }^{\text {F36V }}$ HeLa cells were treated with increasing concentrations of AceTAG-1 for $2 \mathrm{~h}$. Acetylation of c-myc K323ac and STAT3 K685ac was monitored by immunoblot analysis. b. Schematic depiction of quantitative proteomics experiments to profile global acetylation changes. H3.3-FKBP12 ${ }^{\mathrm{F} 36 \mathrm{~V}} \mathrm{HeLa}$ cells were treated with (1) DMSO, (2) $600 \mathrm{nM}$ AceTAG-1 for $2 \mathrm{~h}$ or (3) $2 \mu \mathrm{M}$ SAHA for $16 \mathrm{~h}$. Acetyl peptides were enriched from cell lysates using PTMscan acetyl-lysine motif immunoaffnity beads. Both acetyl peptides and unenriched peptides were labeled with TMT10plex isobaric tags and analyzed by LC-MS/MS/MS quantitative proteomics. Data were processed and analyzed with Proteome Discoverer 2.4. Figure created with BioRender.com. c, Volcano plot of independent TMT experiment of AceTAG-1 or SAHA induced acetylproteome changes. H3.3-FKBP12 ${ }^{\mathrm{F} 36 \mathrm{~V}} \mathrm{HeLa}$ cells were treated with DMSO, AceTAG-1 (600 nM) or SAHA $(2 \mu \mathrm{M})$ for 2 or $16 \mathrm{~h}$ respectively, lysed, trypsinized and acetylated peptides enriched and labeled with TMT reagents, then subjected to quantitative MS. The vertical dashed lines correspond to 2-fold change in enrichment relative to DMSO and the horizontal line corresponds to a $P$-value of 0.05 for statistical significance. Red circles correspond to protein targets with $>2$-fold change $(P<0.05)$ relative to DMSO. d, Scatter plot of independent experiments 1 and 2 of AceTAG or SAHA induced acetylproteome changes. e, Selected histone acetylpeptides demonstrating minimal off-target effects of AceTAG. Significance was determined using two-way ANOVA with Šídák's multiple comparisons test (ns - not significant, $\left.{ }^{* * *} p<0.001,{ }^{* * * *} p<0.0001\right)$. f, H3.3-FKBP12 ${ }^{\mathrm{F} 36 \mathrm{~V}}$ acetylation and expression levels are lower relative to endogenous histones. H3.3-FKBP12 ${ }^{\mathrm{F} 36 \mathrm{~V}} \mathrm{HeLa}$ cells or HeLa cells were treated with DMSO, AceTAG $(600 \mathrm{nM})$ or SAHA $(2 \mu \mathrm{M})$ for 2 or $16 \mathrm{~h}$ respectively. Acetylation of H3.3K18ac-FKBP12 ${ }^{\mathrm{F} 36 \mathrm{~V}}$ and endogenous H3K18ac were monitored by immunoblot analysis. Shown in the right panel is quantitation of immunoblot signal of H3.3K18ac-FKBP12 ${ }^{\mathrm{F} 36 \mathrm{~V}}$ and endogenous $\mathrm{H} 3 \mathrm{~K} 18 \mathrm{ac}$ as the mean \pm s.e.m. of $n=3$ biologically independent experiments. See Supplementary Figure 15 for full blot images. 
Fig. $1 f$

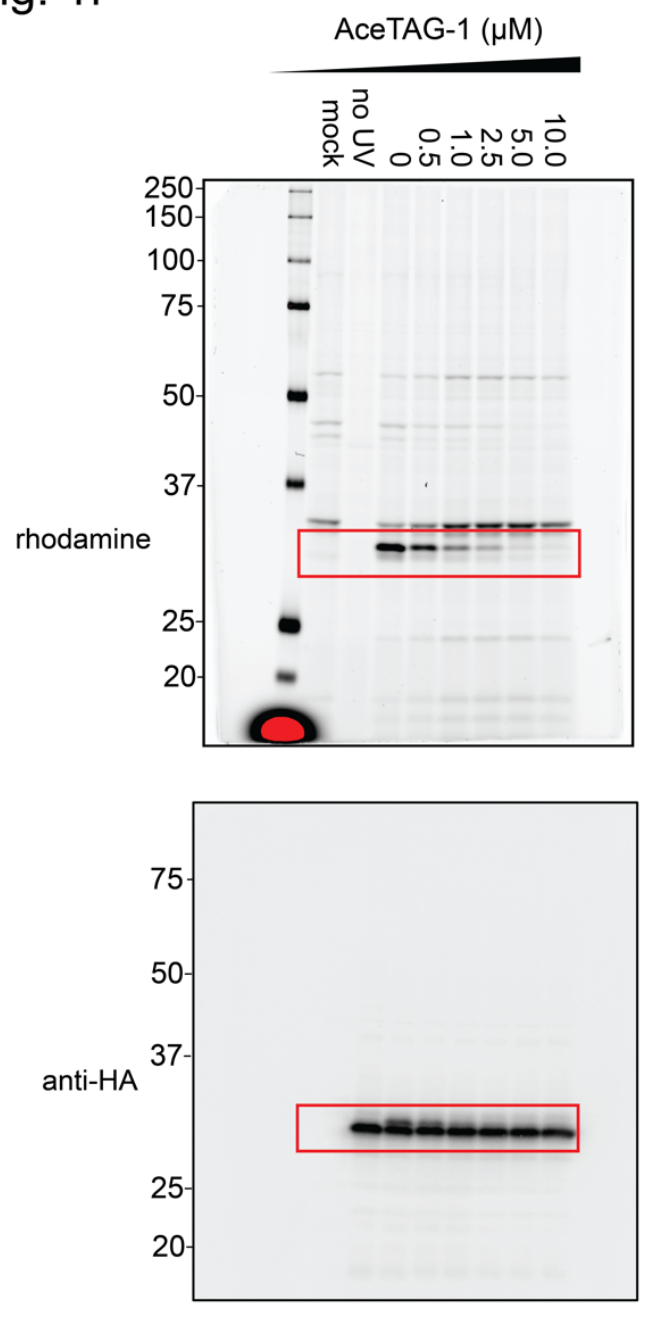

Fig. 1g

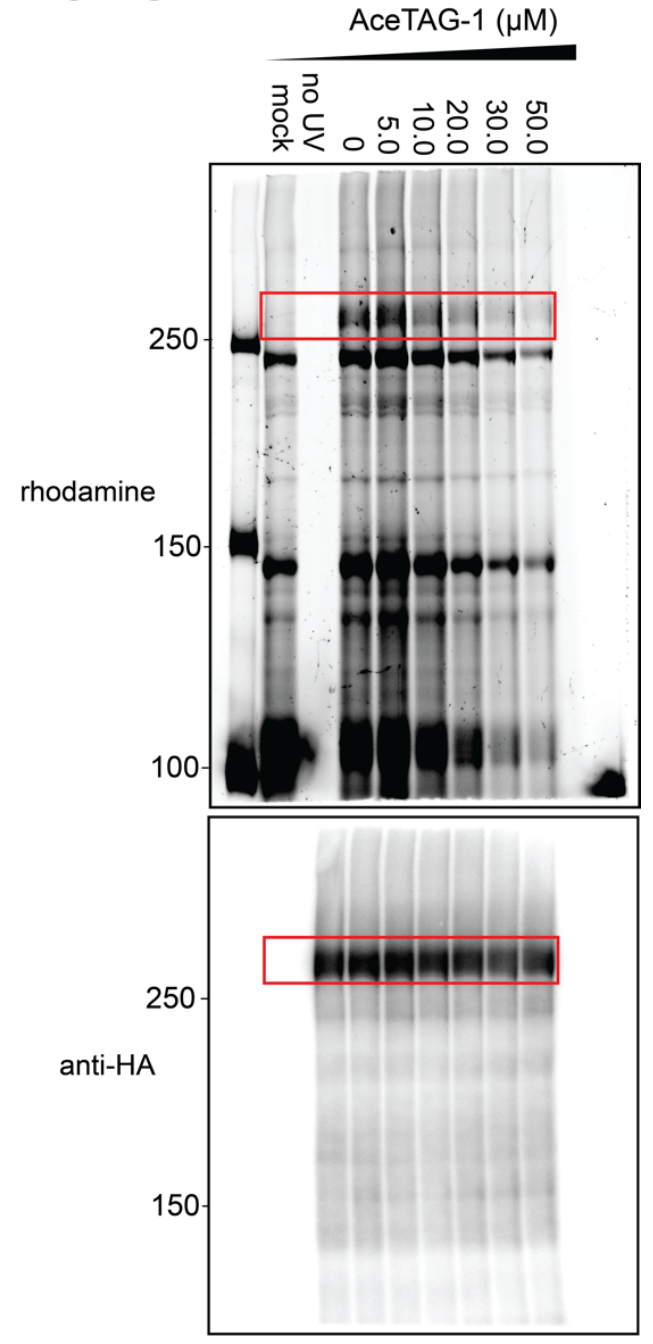

Supplementary Figure 6. Uncropped gels and immunoblots for Figure $1 \mathrm{f}$ and Figure $1 \mathrm{~g}$. 
Fig. 2a AceTAG-1 $(\mu \mathrm{M})$

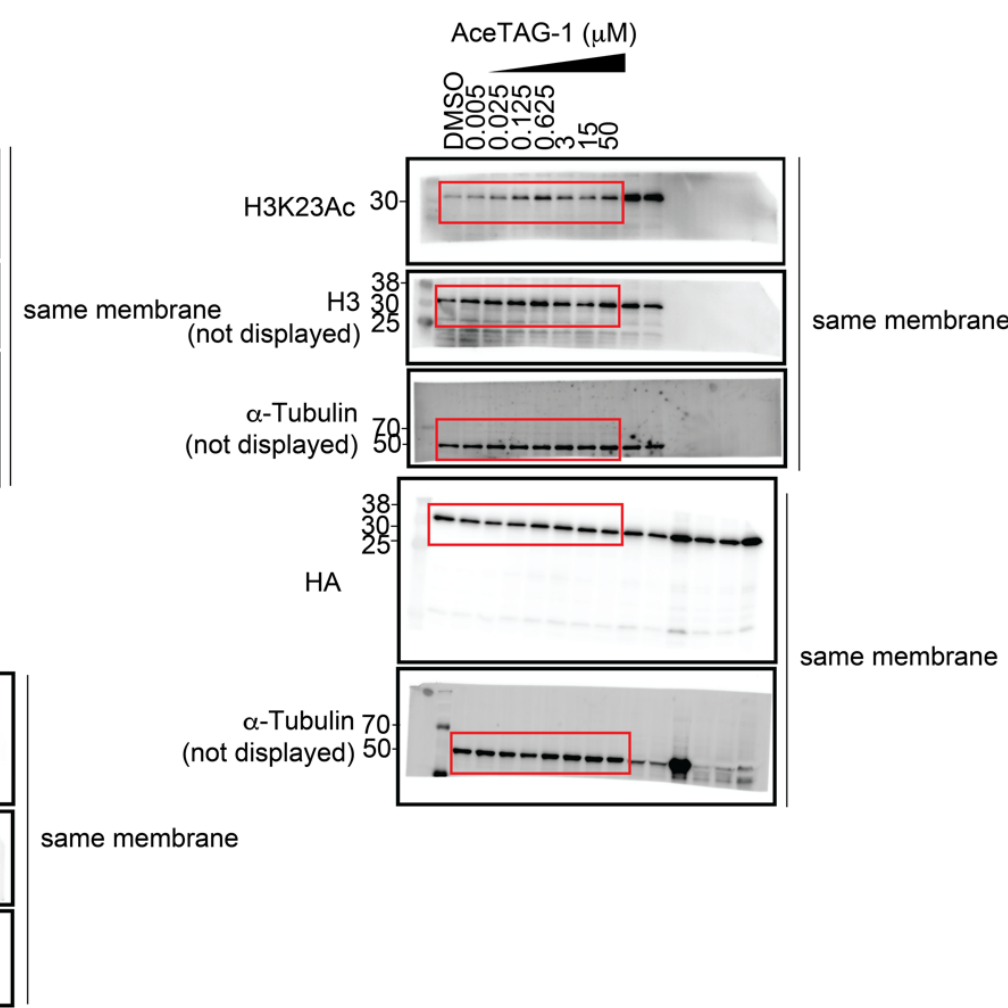

Fig. $2 b$

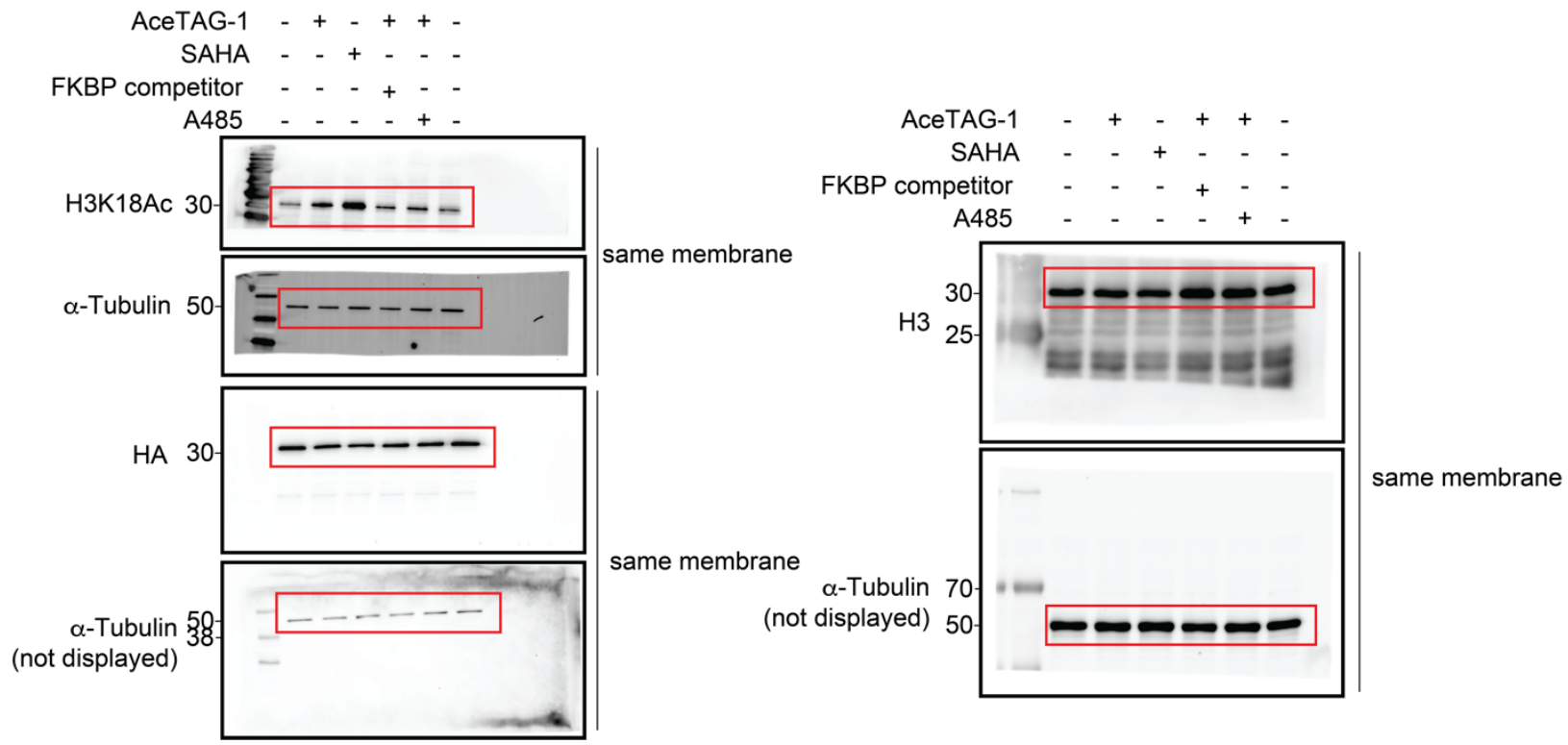

Supplementary Figure 7. Uncropped immunoblots for Figure 2a and Figure 2b. 
Fig. 2c

Time (min)

$5 \quad 1030 \quad 60 \quad 90120$

$-+-+-+-+-+-+$

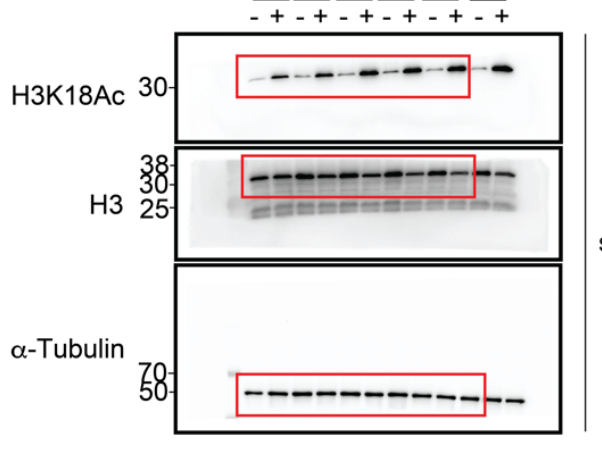

same membrane

H3

30

$\alpha$-Tubulin
Time (hr)

$\frac{2}{-+} \frac{4}{-+} \frac{8}{-+} \frac{12}{-+} \frac{24}{-+}$

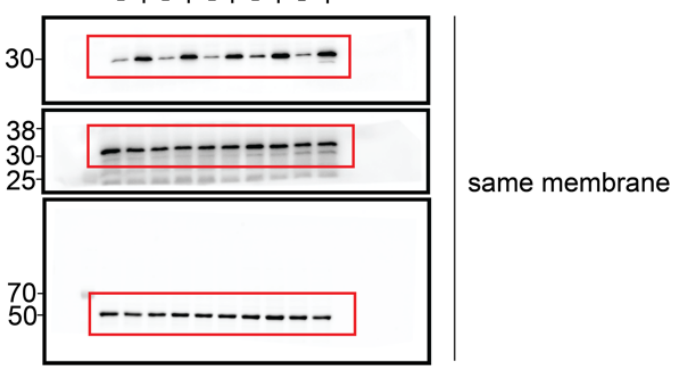

Fig. 2d

Pre-treatment $2.5 \mathrm{~h} 4 \mathrm{hr} 2 \mathrm{hr} 2 \mathrm{hr} 2 \mathrm{hr} 2 \mathrm{hr}$ 1030

Post-washout - - $\min \min 2 \mathrm{hr} 8 \mathrm{hr}$

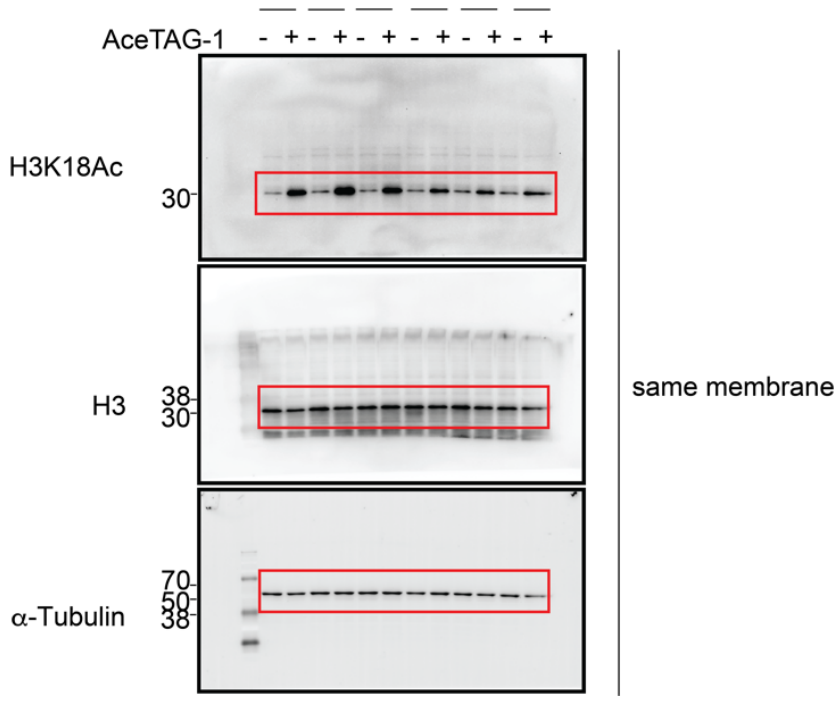

Supplementary Figure 8. Uncropped immunoblots for Figure 2c and Figure 2d. 
Fig. 3a

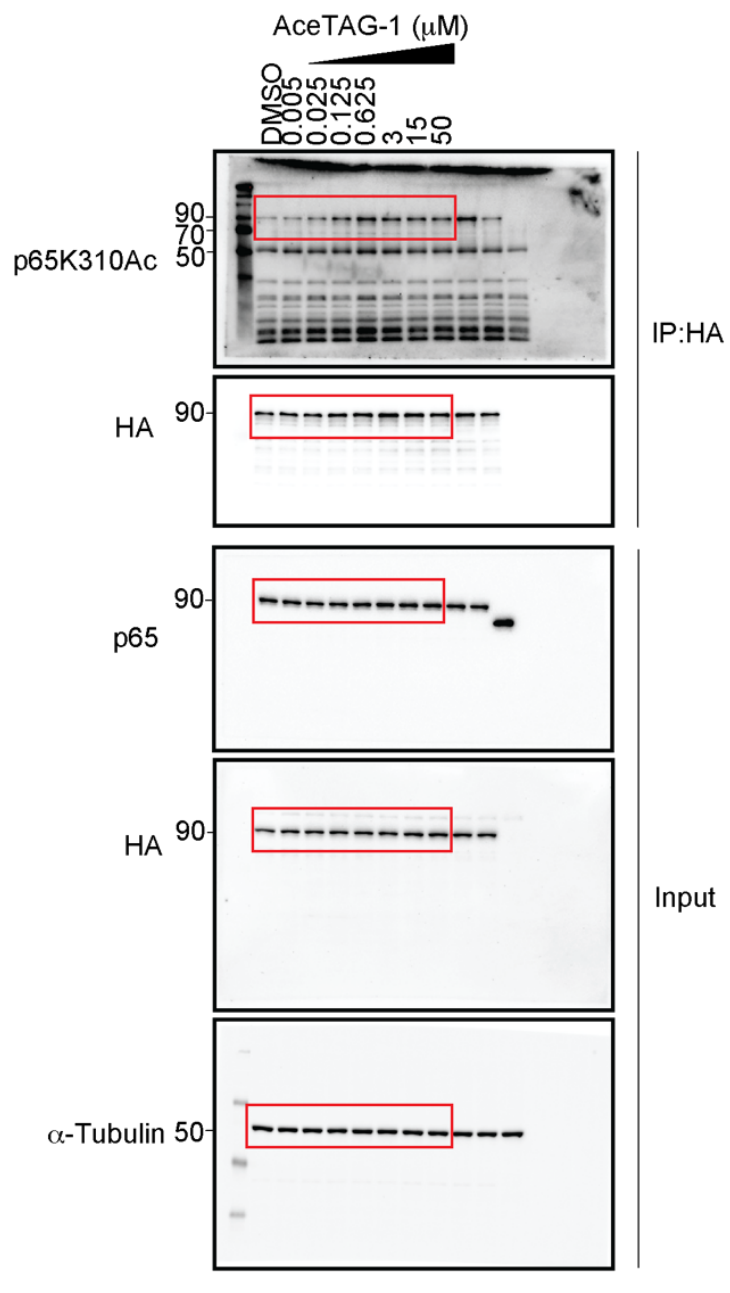

Fig. 3b

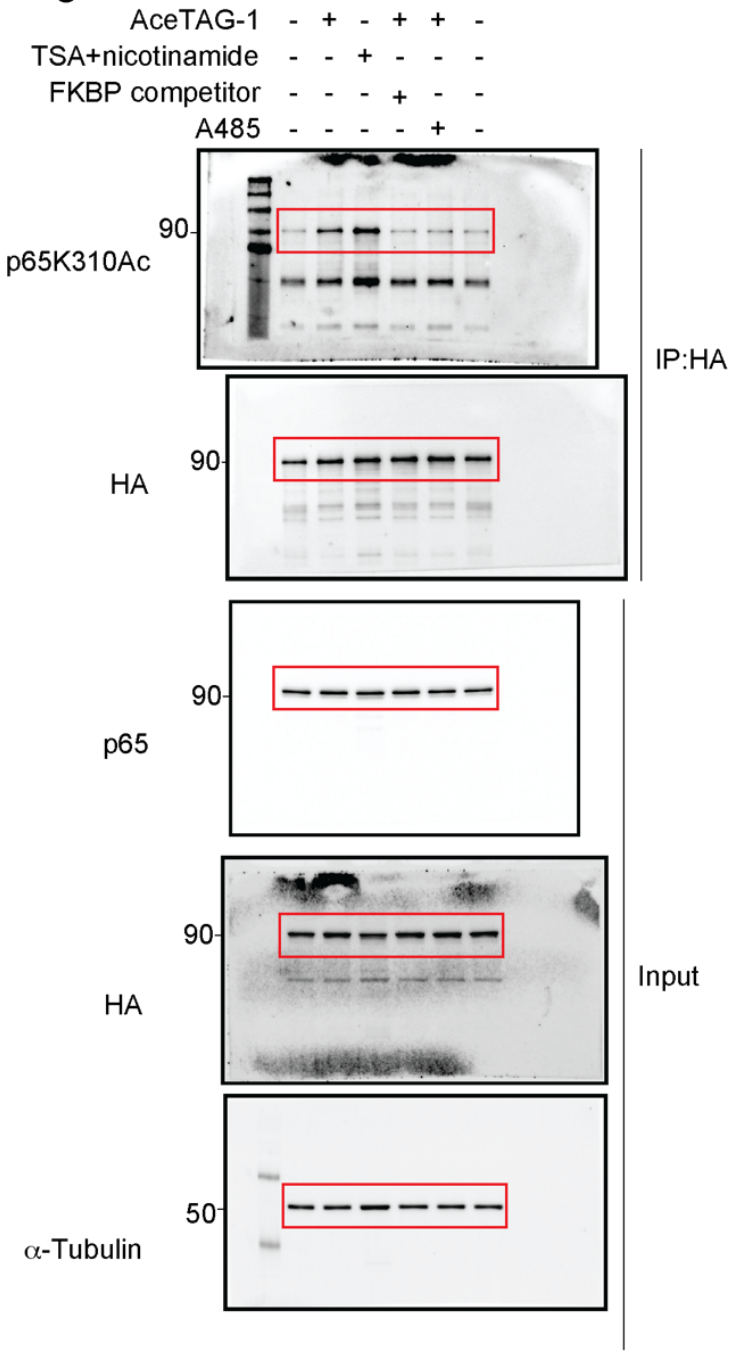

Supplementary Figure 9. Uncropped immunoblots for Figure 3a and Figure 3b. 
Fig. 3c

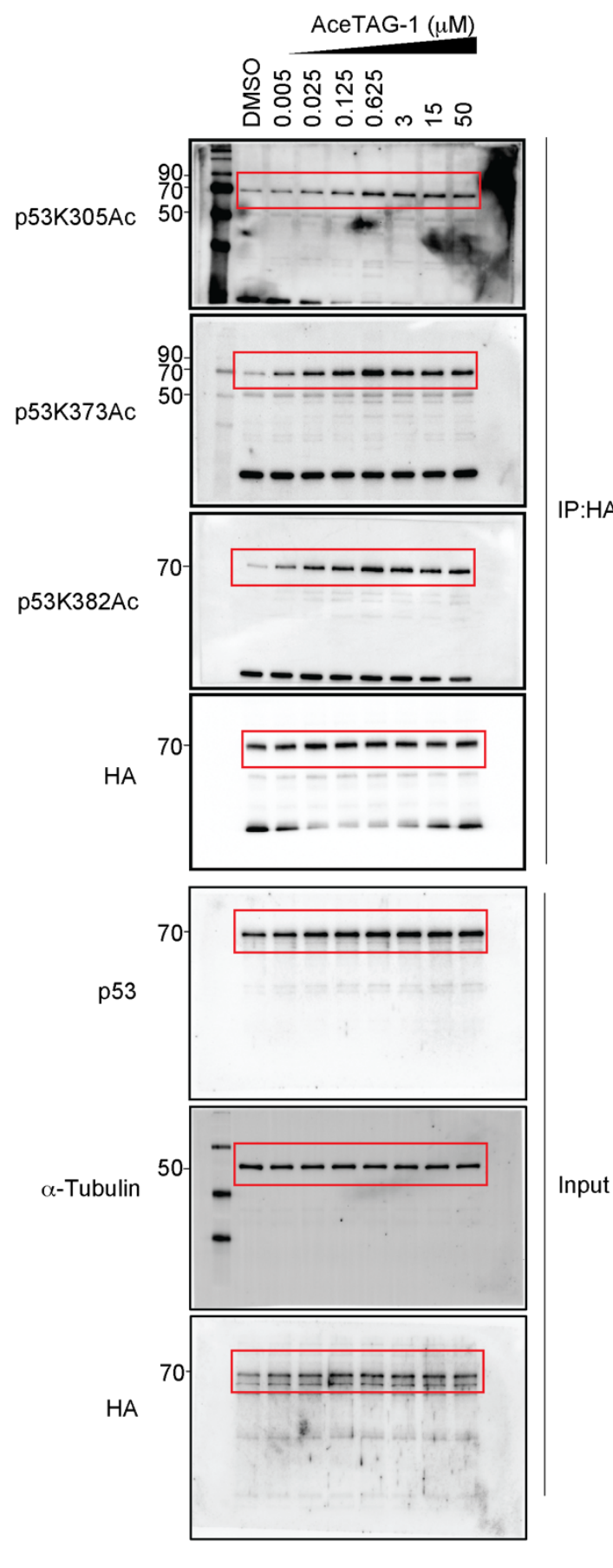

Fig. 3d

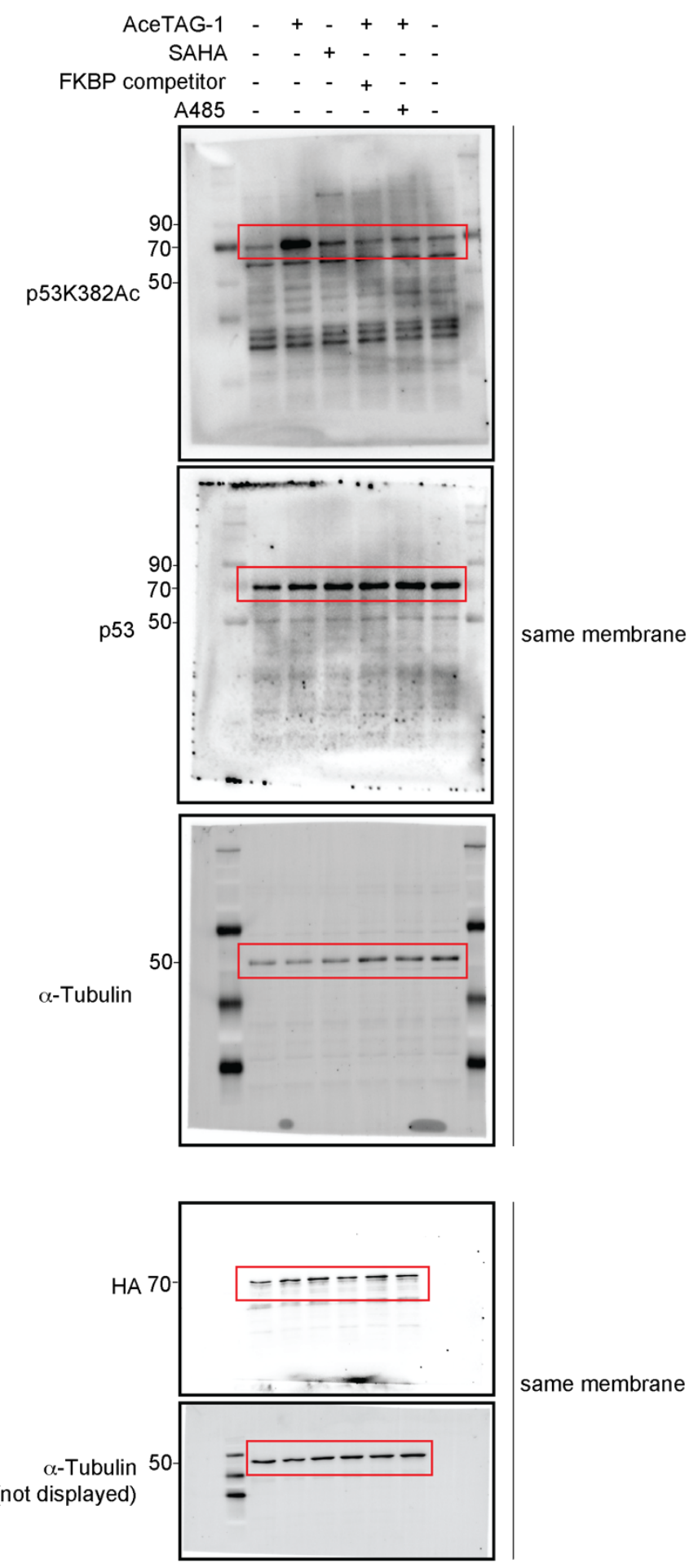

Supplementary Figure 10. Uncropped immunoblots for Figure $3 \mathrm{c}$ and Figure $3 \mathrm{~d}$. 
Fig. $4 b$

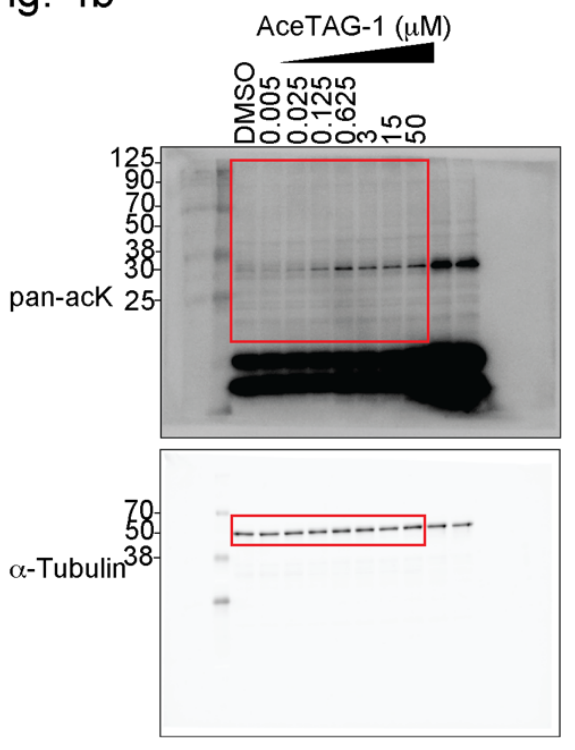

Supplementary Figure 11. Uncropped immunoblots for Figure 4b. 
SI Fig. 2a
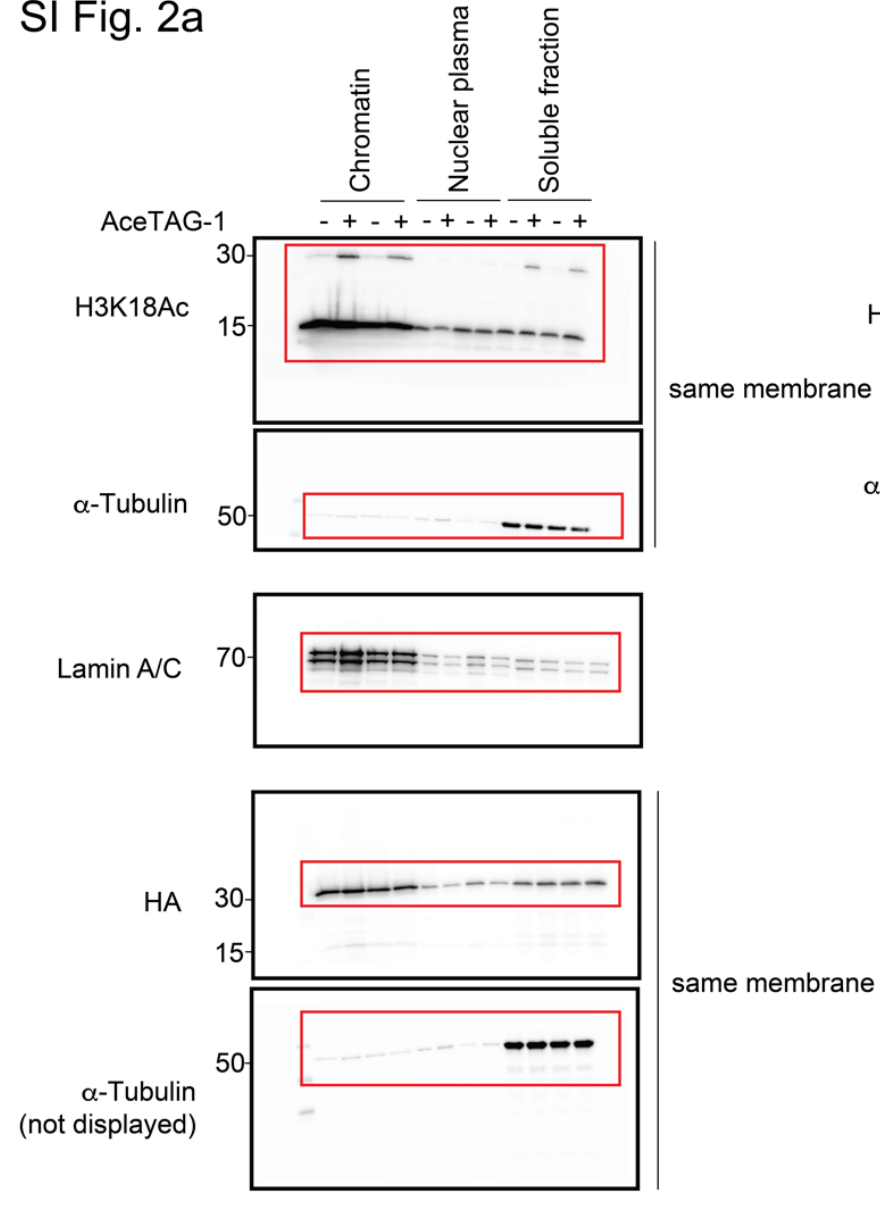

SI Fig. 2b

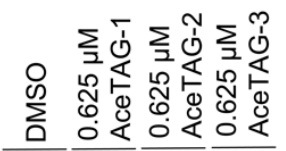
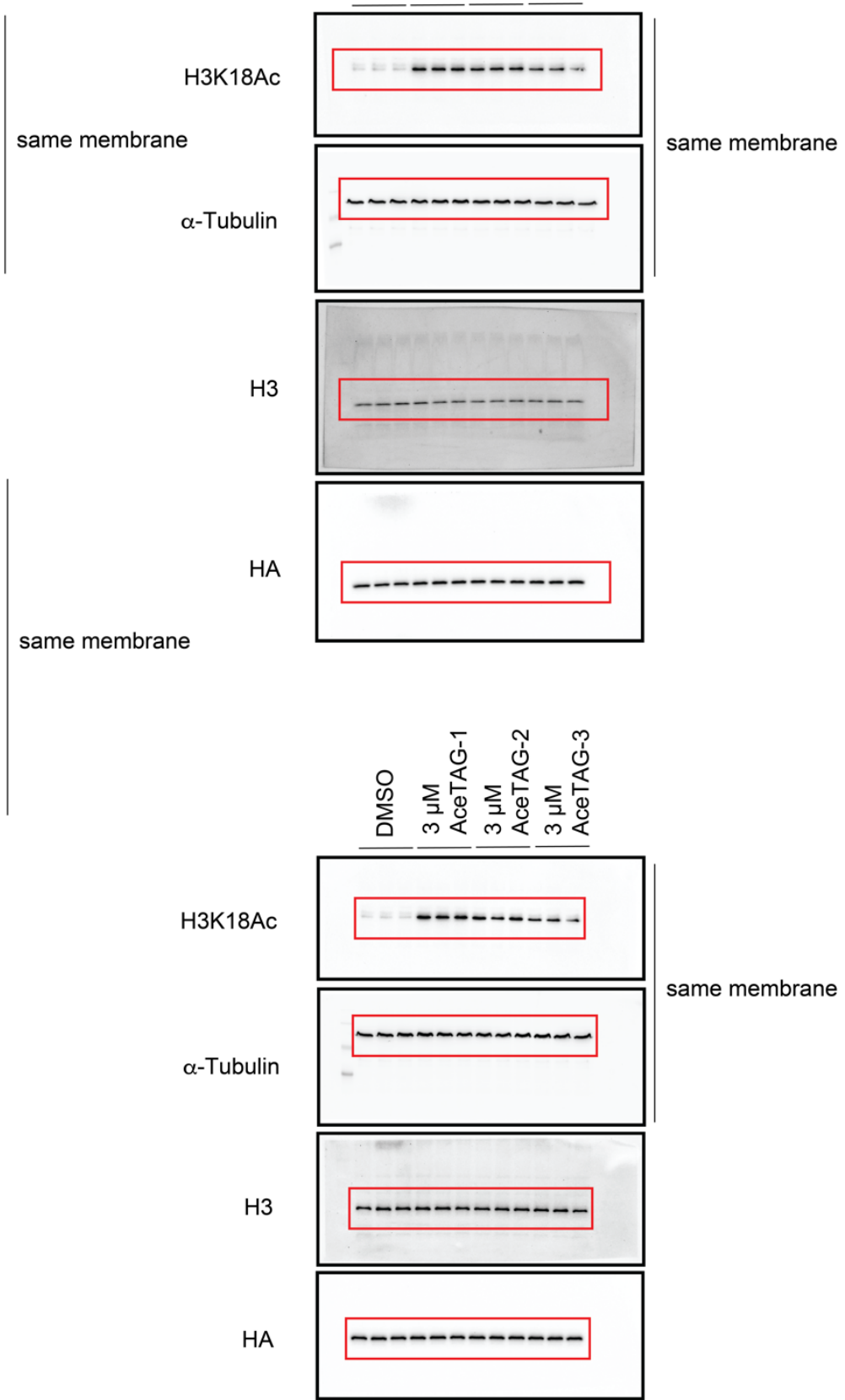

Supplementary Figure 12. Uncropped immunoblots for SI Figure 2a and SI Figure 2b. 
SI Fig. 2c

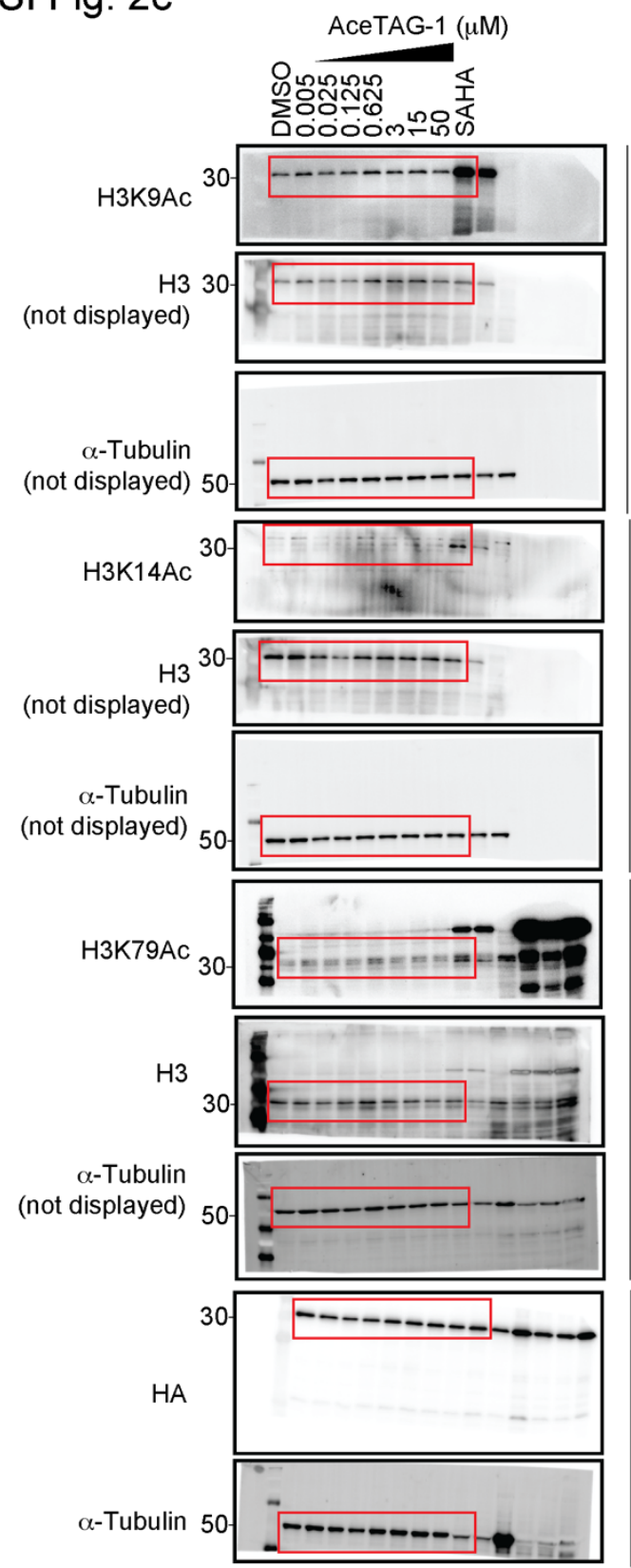

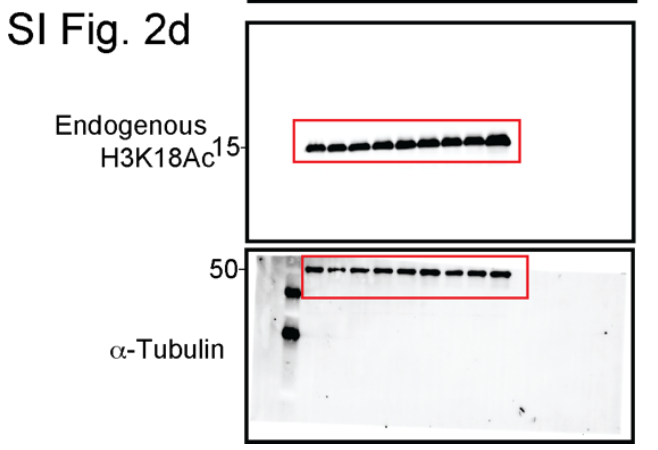

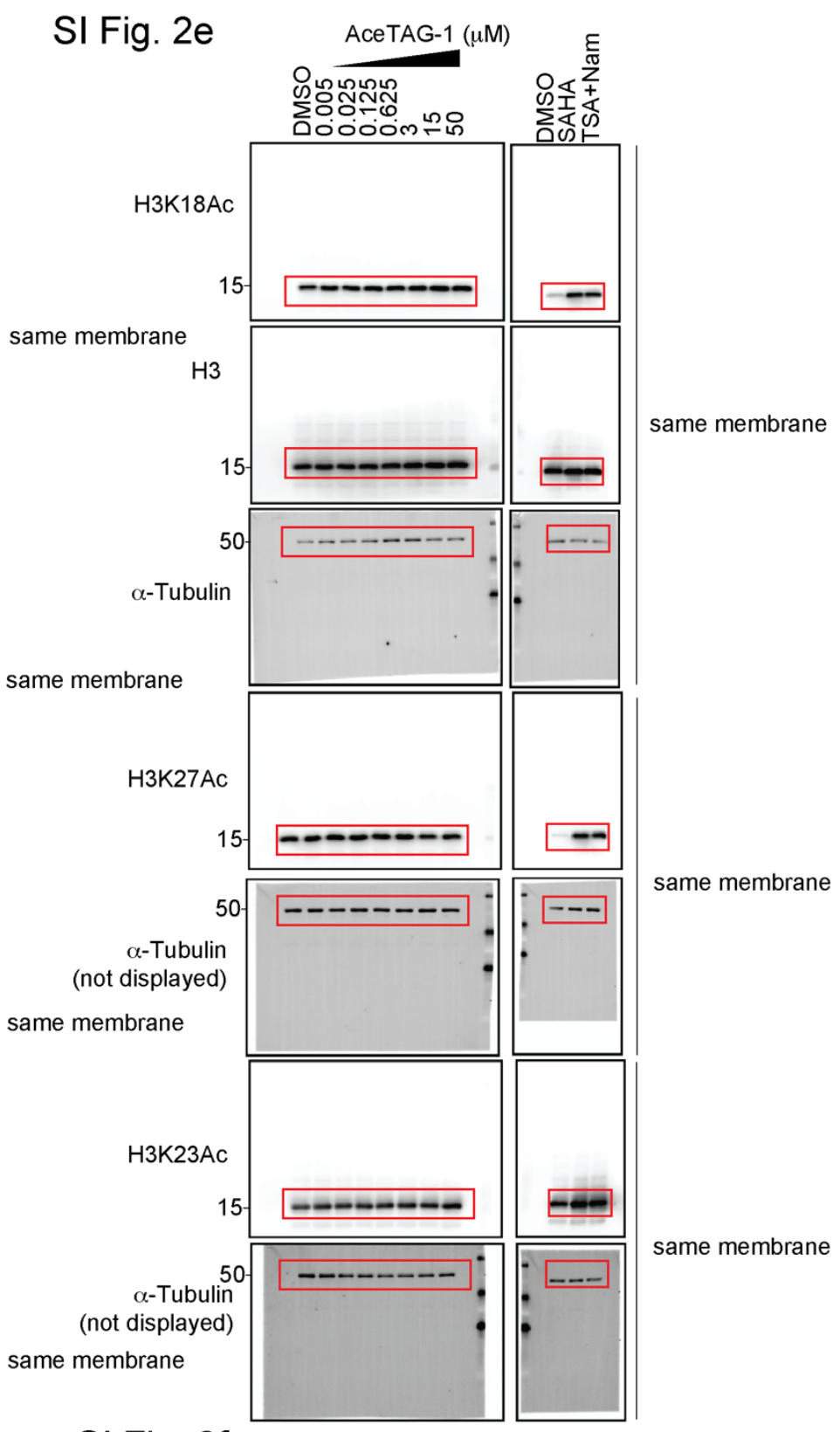

SI Fig. $2 f$

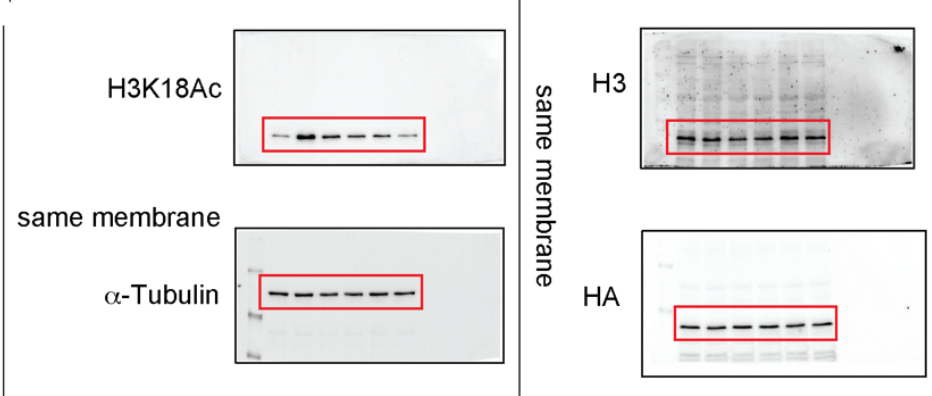

Supplementary Figure 13. Uncropped immunoblots for SI Figure 2c, SI Figure 2d, SI Figure 2e, and SI Figure 2f. 


\section{SI Fig. 3a}

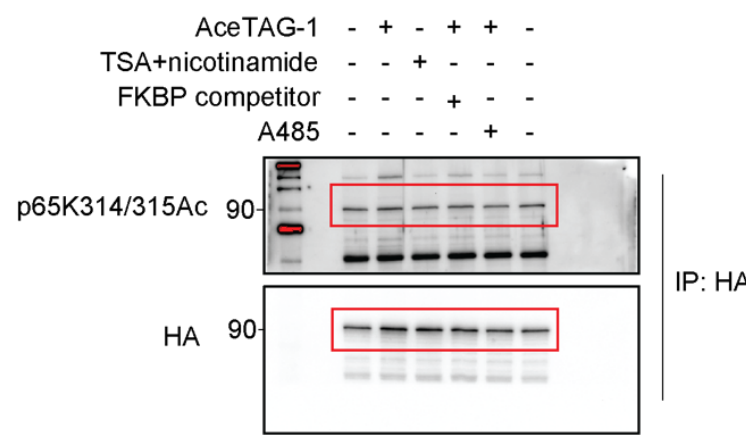

SI Fig. 3c

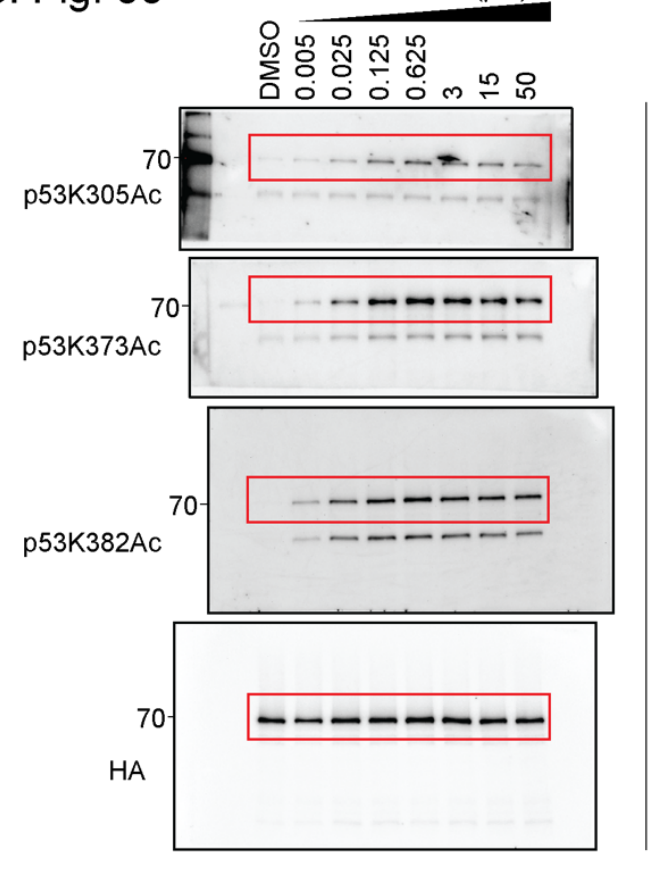

SI Fig. 3b

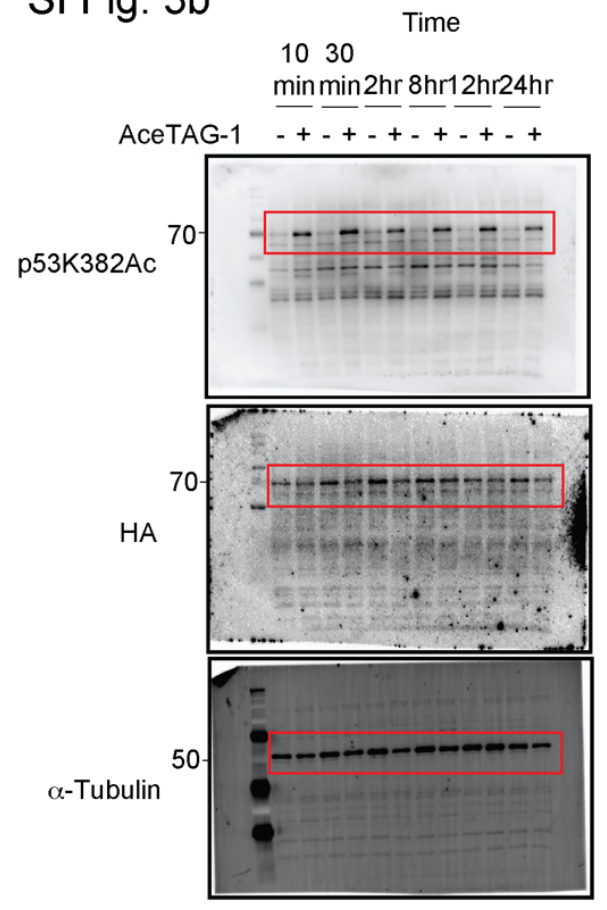

same membrane

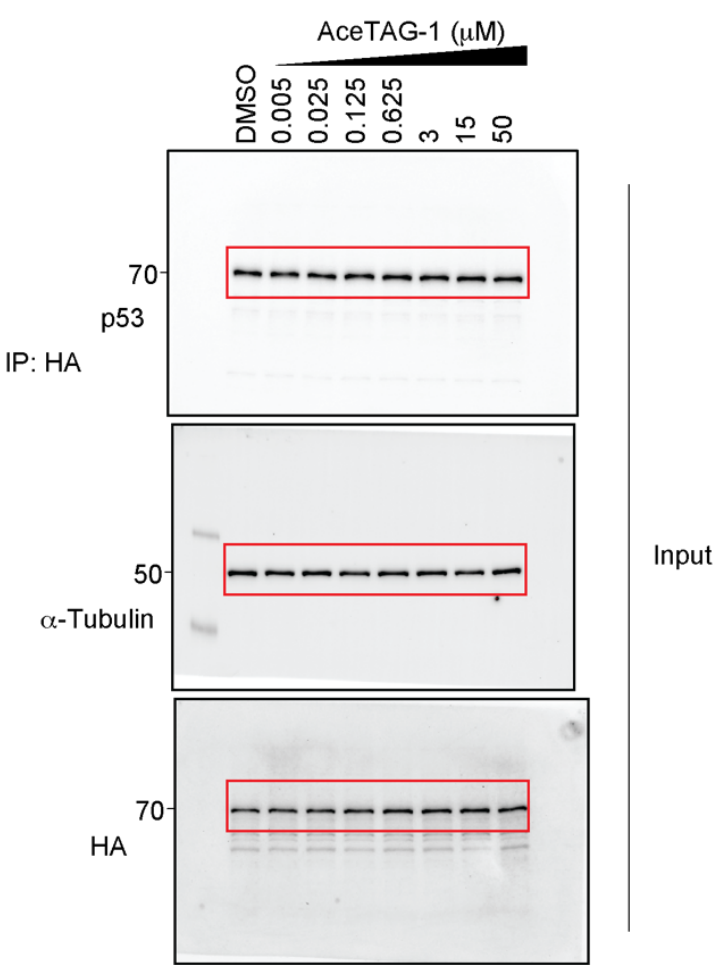

Supplementary Figure 14. Uncropped immunoblots for SI Figure 3a, SI figure 3b, and SI Figure 3c. 


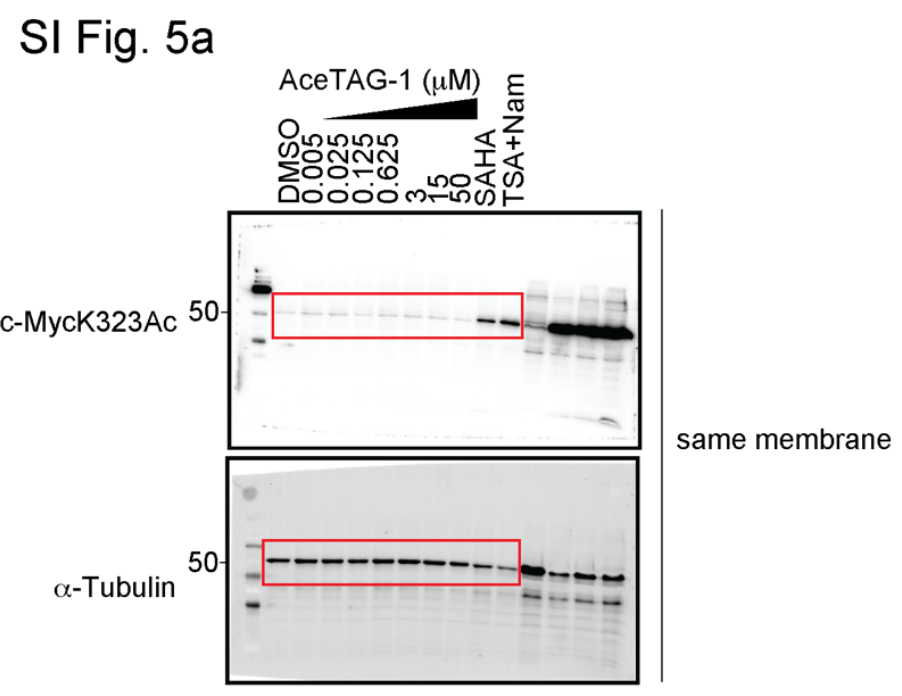

SI Fig. $5 f$
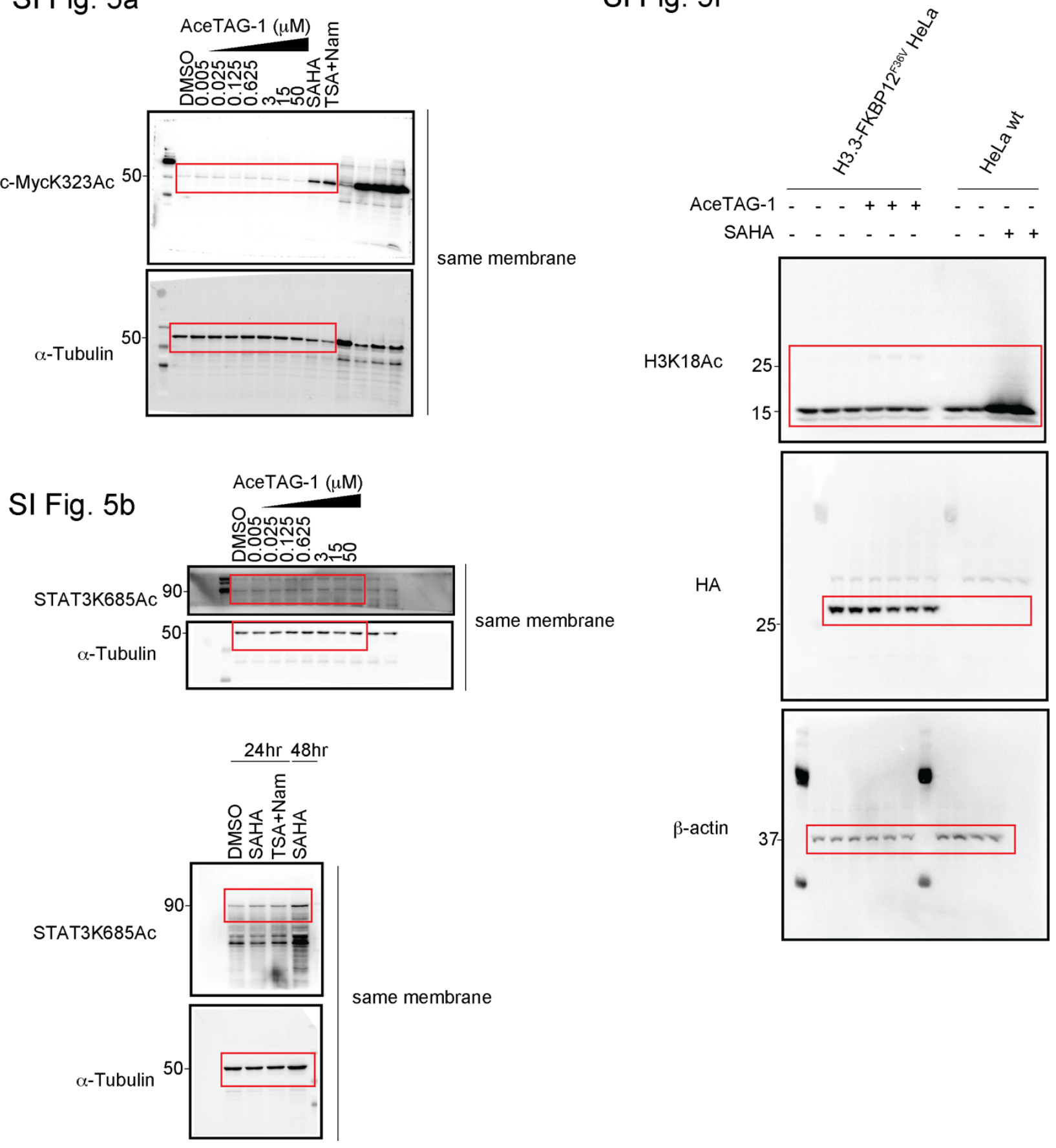

Supplementary Figure 15. Uncropped immunoblots for SI Figure 5a, SI figure 5b, and SI Figure $5 f$. 


\section{MATERIALS AND METHODS}

\section{Materials}

Mouse Anti-HA (2367S, 1:2000 dilution), rabbit anti-HA (3724S, 1:2000 dilution), rabbit antiH3K9ac (9649S, 1:2000 dilution), rabbit anti-H3K14ac (7627S, 1:2000 dilution), rabbit antiH3K18ac (13998S, 1:2000 dilution), rabbit anti-H3K27ac (8173S, 1:2000 dilution), rabbit anti-H3 (4499S, 1:2000 dilution), rabbit anti-acetyl lysine (9814S, 1:1000 dilution), rabbit anti-acetyl-p65 (Lys310) (3045S, 1:1000 dilution), rabbit anti-NFkBp65 (8242S, 1:2000 dilution), rabbit antip53K382ac (2525S, 1:1000 dilution), rabbit anti-Stat3K685ac (2523S, 1:2000 dilution), rabbit Lamin A/C antibody (2032S, 1:1000 dilution), and anti-rabbit IgG HRP conjugate (7074P2, 1:10000 dilution) were from Cell Signaling Technology. Anti-tubulin hFAB Rhodamine (12004166, 1:3000 dilution) was from Bio-rad. Rabbit anti-H3K23ac (07-355, 1:2000 dilution), rabbit antiH3K79 (SAB5600231-100UG, 1:2000 dilution), rabbit anti-c-MycK323ac (ABE26, 1:2000 dilution) were from Millipore Sigma. rabbit anti-p53K373ac (ab62376, 1:1000 dilution), and rabbit antip53K305ac (ab109396, 1:1000 dilution) were from Abcam. Mouse anti-p53 (628202, 1:2000 dilution) was from Biolegend. Rabbit anti-p65K314/315ac (PA5-114696, 1:500 dilution), Antimouse $\lg G(H+L)$ HRP conjugate (PA1-28568, 1:10000 dilution) was from Thermo Fisher Scientific.

\section{Cell Culture}

HEK293T and HeLa cells (ATCC) were cultured in DMEM supplemented with $10 \%$ FBS, 1\% (v/v) penicillin/streptomycin, and $2 \mathrm{mM}$ glutamine. H1299 (ATCC) were cultured in RPMI supplemented with $10 \%$ FBS, $1 \%(\mathrm{v} / \mathrm{v})$ penicillin/streptomycin, $2 \mathrm{mM}$ glutamine, $10 \mathrm{mM}$ HEPES, and $1 \mathrm{mM}$ sodium pyruvate. RelA KO HeLa cells (Abcam) we cultured in DMEM supplemented with 10\% FBS, $1 \%(\mathrm{v} / \mathrm{v})$ penicillin/streptomycin, and $2 \mathrm{mM}$ glutamine. All cells were cultured at $37^{\circ} \mathrm{C}$ and $5 \% \mathrm{CO}_{2}$.

\section{Lentivirus Plasmid Construction}

pLEX_305-N-dTAG and pLEX305-C-dTAG empty vectors were kindly provided by Dr. Erb (The Scripps Research Institute). Gateway recombination cloning technology (Invitrogen) was used to clone targets of interest into pLEX_305-N-dTAG and pLEX_305-C-dTAG. H3.3 cDNA ORF clone in pGEM-T vector was purchased from SinoBiological (Cat\# HG16451-G). p53 cDNA ORF clone in pCMV3-C-HA vector was purchased from SinoBiological (Cat\# HG10182-CY). RelA cDNA ORF clone was purchased from SinoBiological (Cat\# HG12054-G). H3.3, p53, and RelA were cloned into Gateway compatible donor vector pDONR221 using BP clonase after PCR with 
primers containing BP overhangs sequence from the vector described above. $\mathrm{H} 3.3$ and $\mathrm{p} 53$ were cloned into pLEX_305-C-dTAG and p53 as well as RelA were cloned into pLEX_305-N-dTAG using Gateway LR clonase II Enzyme mix kit (Invitrogen). The sequences of the primers are listed below.

Briefly, $100 \mathrm{ng}$ pDONR221 vectors containing genes of interest were mixed with $150 \mathrm{ng}$ of pLEX_305-C-dTAG or pLEX_305-N-dTAG in TE buffer. $1 \mu \mathrm{l}$ of LR clonase II enzyme was added to the plasmid mix and incubated for $1 \mathrm{~h}$ at room temperature, followed by addition of $1 \mu \mathrm{l}$ Proteinase $\mathrm{K}$ and incubated for $10 \mathrm{~min}$ at $37^{\circ} \mathrm{C}$ to terminate the reaction. Samples were transformed using $\mathrm{DH} 10 \mathrm{~B}$ competent cells and plated on Ampicillin selective agar plates. After

\begin{tabular}{|c|c|c|}
\hline $\begin{array}{l}\text { Insert Gene } \\
\text { (Human) }\end{array}$ & Forward (5'-3') & Reverse (5'-3') \\
\hline $\begin{array}{l}\text { Histone H3.3 } \\
\text { (C-terminus) }\end{array}$ & $\begin{array}{l}\text { GGGGACAAGTTTGTACAAAAA } \\
\text { AGCAGGCTTCATGGCTCGTAC } \\
\text { AAAGCAGACTG }\end{array}$ & $\begin{array}{l}\text { GGGGACCACTTTGTACAAGAAA } \\
\text { GCTGGGTCAGCACGTTCTCCAC } \\
\text { GTATGC }\end{array}$ \\
\hline $\begin{array}{l}\text { p53 } \\
\text { (N-terminus) }\end{array}$ & $\begin{array}{l}\text { GGGGACAAGTTTGTACAAAAA } \\
\text { AGCAGGCTTCGAGGAGCCGCA } \\
\text { GTCAGATCC }\end{array}$ & $\begin{array}{l}\text { GGGGACCACTTTGTACAAGAAA } \\
\text { GCTGGGTCTCAGTCTGAGTCAG } \\
\text { GCCCTTC }\end{array}$ \\
\hline $\begin{array}{l}\text { p53 } \\
\text { (C-terminus) }\end{array}$ & $\begin{array}{l}\text { GGGGACAAGTTTGTACAAAAA } \\
\text { AGCAGGCTTCATGGAGGAGC } \\
\text { CGCAGTCAG }\end{array}$ & $\begin{array}{l}\text { GGGGACCACTTTGTACAAGAAA } \\
\text { GCTGGGTCGTCTGAGTCAGGCC } \\
\text { CTTC }\end{array}$ \\
\hline $\begin{array}{l}\text { p65 } \\
\text { (N-terminus) }\end{array}$ & $\begin{array}{l}\text { GGGGACAAGTTTGTACAAAAA } \\
\text { AGCAGGCTTCGACGAACTGTT } \\
\text { CCCCCTCATCTTC }\end{array}$ & $\begin{array}{l}\text { GGGGACCACTTTGTACAAGAAA } \\
\text { GCTGGGTCTTAGGAGCTGATCT } \\
\text { GACTCAGCAGG }\end{array}$ \\
\hline
\end{tabular}

growing at $30^{\circ} \mathrm{C}$ overnight, colonies were picked and grown up in $5 \mathrm{~mL}$ LB media supplemented with Ampicillin at $30^{\circ} \mathrm{C}$ overnight. Plasmid DNA was purified using Zyppy Plasmid Miniprep Kit (Genesee Scientific) and sequenced using primers as followed: pLEX_305-dTAG-seq-F: TGTTCCGCATTCTGCAAGCCTC and pLEX_305-dTAG-seq$\mathrm{R}$ ACAAAGGCATTAAAGCAGCGTATCC. 


\section{Lentivirus Production and Transduction}

Lentiviral production was performed using HEK293T cells, which were co-transfected with pMD2.G (Addgene, \#12259), psPAX2 (Addgene, \#12260), and AceTAG lentiviral plasmids using PEI (Polysciences Inc). Viral particles were collected $72 \mathrm{~h}$ after transfection and filtered through a $0.45 \mu \mathrm{M}$ membrane. A range of dilutions of the lentivirus in DMEM complete and $10 \mu \mathrm{g} / \mathrm{mL}$ polybrene were added to HeLa, H1299, or HeLa RelA KO cell lines. Transduced cells were selected with $1 \mu \mathrm{g} / \mathrm{mL}$ or $2 \mu \mathrm{g} / \mathrm{mL}$ puromycin.

\section{Protein Expression}

A construct containing residues 2-108 of FKBP12 $2^{\mathrm{F} 36 \mathrm{~V}}$ in pGEX4t-1 vector was overexpressed in E. coli BL21(DE3) in LB medium in the presence of $100 \mathrm{mg} / \mathrm{mL}$ carbenicillin. Cells were grown at $37^{\circ} \mathrm{C}$ to an OD of 0.6 , induced with $100 \mu \mathrm{M}$ isopropyl-1-thio-D-galatopyranoside (IPTG), incubated for $4 \mathrm{~h}$ at $37^{\circ} \mathrm{C}$, and collected by centrifugation. Cell pellets were suspended in lysis buffer (50 mM HEPES pH 8.0, $250 \mathrm{mM} \mathrm{NaCl}, 0.1 \%(\mathrm{v} / \mathrm{v})$ Triton X-100, $1 \mathrm{mM}$ TCEP), sonicated and then cleared by centrifugation at $11,000 \mathrm{~g}$ for $40 \mathrm{~min}$ at $4^{\circ} \mathrm{C}$. FKBP $12^{\mathrm{F} 36 \mathrm{~V}}$ was first purified with Pro Affinity Concentration Kit GST (Amicon: ACR5000GS), and further purified on HiPrep 16/60 Sephacryl S-200 HR gel filtration column. Clean fraction was concentrated and buffer exchanged to storage buffer (50 mM HEPES, $250 \mathrm{mM} \mathrm{NaCl}, \mathrm{pH}$ 8.0, 10\% Glycerol), protein concentration was measured with Thermo $660 \mathrm{nM}$ kit, flash freezed and stored at $-80^{\circ} \mathrm{C}$.

\section{GST- FKBP12 ${ }^{\mathrm{F} 36 \mathrm{~V}} / \mathrm{His}-\mathrm{P300}$-BRD AlphaScreen Assay}

GST-FKBP12 ${ }^{\mathrm{F} 36 \mathrm{~V}}$ and 6xHis-p300-BRD (active motif \#31372) were diluted to $250 \mathrm{nM}$ and $500 \mathrm{nM}$, in assay buffer (50 mM HEPES pH 7.4, $200 \mathrm{mM} \mathrm{NaCl}, 1 \mathrm{mM} \mathrm{TCEP}$, and 0.1\% BSA), $20 \mu \mathrm{L}$ of protein mixture was added to each well of a 1/2 area 96-well OptiPlate (PerkinElmer). Compounds were then added from DMSO stock to protein mixture $(0.4 \mu \mathrm{l} /$ well) with $1 \%$ DMSO in final mixture. Plates were then shaken orbitally at room temperature for $1 \mathrm{~h}$. Nickel Chelate AlphaLISA Acceptor and Glutathione AlphaLISA Donor beads (PerkinEImer) diluted to $20 \mathrm{ng} / \mu \mathrm{l}$ in assay buffer and 20 $\mu \mathrm{l}$ beads mixture was added to each well. After a $1 \mathrm{~h}$ orbital shaking at room temperature. luminescence was measured on the Envision 2104 plate reader (PerkinElmer). Data were plotted and analyzed using GraphPad PRISM v8 and fit with 'Bell-shaped' dose response curve.

For ternary complex competition experiments, GST-FKBP $12^{\mathrm{F} 36 \mathrm{~V}}$ and $6 x \mathrm{His}-\mathrm{p} 300-\mathrm{BRD}$ (active motif \#31372) were diluted to $250 \mathrm{nM}$ and $500 \mathrm{nM}$, in assay buffer (50 mM HEPES pH 7.4, $200 \mathrm{mM} \mathrm{NaCl}, 1 \mathrm{mM}$ TCEP, and 0.1\% BSA). AceTAG-1 was added into protein mixture from 600 $\mu \mathrm{M}$ DMSO stock (final concentration $300 \mathrm{nM}$ ). $20 \mu \mathrm{L}$ of protein mixture was added to each well of 
a $1 / 2$ area 96 -well OptiPlate (PerkinElmer). FKBP12 ${ }^{\mathrm{F} 36 \mathrm{~V}}$ competitor or $\mathrm{p} 300-\mathrm{BRD}$ competitor was then added from DMSO stock to protein mixture $(0.4 \mu \mathrm{l} /$ well) with $1 \%$ DMSO in final mixture. Plates were then shaken orbitally at room temperature for $1 \mathrm{~h}$. Nickel Chelate AlphaLISA Acceptor and Glutathione AlphaLISA Donor beads (PerkinElmer) diluted to $20 \mathrm{ng} / \mu \mathrm{l}$ in assay buffer and 20 $\mu \mathrm{l}$ beads mixture was added to each well. After a $1 \mathrm{~h}$ orbital shaking at room temperature. luminescence was measured on the Envision 2104 plate reader (PerkinElmer). Data were plotted using GraphPad PRISM v8 and fit with 'log(inhibitor)-response, four parameters' curve.

\section{AceTAG-1 Target Engagement}

At 50\%-70\% confluency, HEK293t cells in 6-well plates were transfected with pLEX305-C-dTAGH3.3. After 24h, cells were co-treated for 30 min with $0.5 \mu \mathrm{M}$ FKBP-p probe and increasing concentration of AceTAG-1 in serum-free DMEM media. Cells then underwent UVphotocrosslinking $(365 \mathrm{~nm})$ for $20 \mathrm{~min}$ at $4{ }^{\circ} \mathrm{C}$, harvested in cold DPBS by scraping and centrifugation, cell pellets were washed with cold DPBS two times and aspirated. Cells were then lysed in $400 \mu \mathrm{L}$ DPBS buffer supplemented with $0.2 \%$ SDS (w/v) and 1X Halt protease inhibitor cocktail. Lysate was then normalized to $1.5 \mathrm{mg} / \mathrm{mL}$. To each sample $(50 \mu \mathrm{L}), 6 \mu \mathrm{L}$ of a freshly prepared "click" reagent mixture containing $0.1 \mathrm{mM}$ tris(benzyltriazolylmethyl)amine (TBTA) (3 $\mu \mathrm{L} /$ sample, $1.7 \mathrm{mM}$ in 1:4 DMSO:t-ButOH), $1 \mathrm{mM} \mathrm{CuSO}_{4}\left(1 \mu \mathrm{L} /\right.$ sample, $50 \mathrm{mM}$ in $\mathrm{H}_{2} \mathrm{O}$ ), $25 \mu \mathrm{M}$ Rhodamine-azide $(1 \mu \mathrm{L} /$ sample, $1.25 \mathrm{mM}$ in DMSO), and freshly prepared $1 \mathrm{mM}$ tris(2carboxyethyl)phosphine $\mathrm{HCl}$ (TCEP) ( $1 \mu \mathrm{L} /$ sample, $50 \mathrm{mM}$ in $\mathrm{H}_{2} \mathrm{O}$ ) was added to conjugate the fluorophore to probe-labeled proteins. Upon addition of the click mixture, each reaction was immediately mixed by vortexing and then allowed to react at room temperature for $1 \mathrm{~h}$ before quenching the reactions with SDS loading buffer ( $4 \mathrm{X}$ stock, $17 \mu \mathrm{L})$. Proteins $(25 \mu \mathrm{g}$ total protein loaded per gel lane) were resolved using SDS-PAGE (10\% acrylamide) and visualized by in-gel fluorescence on Bio-Rad ChemiDoc MP Imaging System. Gel fluorescence and imaging was processed using Image Lab $(v$ 6.0.1) software. Proteins were then transferred to PVDF membranes using Trans-Blot Turbo RTA Mini 0.45 mM LF PVDF Transfer Kit (Bio-Rad), and blotted with anti-HA antibody. Chemiluminescence was recorded with Bio-Rad ChemiDoc MP Imaging System and processed using Image Lab (v 6.0.1) software.

In-situ photocrosslinking with p300-BRD photocrosslinking probe and competition by AceTAG-1 
At 50\%-70\% confluency, HEK293t cells in 6-well plates were transfected with pSG5-HA-p300. After $24 \mathrm{~h}$, cells were co-treated for 30 min with $5 \mu \mathrm{M}$ p300-p probe and increasing concentration of AceTAG-1 in serum-free media. Cells then underwent UV-photocrosslinking (365 nm) for 20 min at $4^{\circ} \mathrm{C}$ and harvested in cold DPBS by scraping and centrifugation. Cell pellets were washed with cold DPBS two times and aspirated. Cells were then lysed in $200 \mu \mathrm{L}$ DPBS buffer supplemented with 1X Halt protease inhibitor cocktail. Lysate was fractionated by ultracentrifuge (100000 g, $45 \mathrm{~min}, 4^{\circ} \mathrm{C}$ ) to provide soluble fraction (supernatant) and membrane fraction (pellets).

Soluble fraction was normalized to $2 \mathrm{mg} / \mathrm{mL}$, underwent click reaction with Rhodamine-azide as previously described. Proteins ( $25 \mu \mathrm{g}$ total protein loaded per gel lane) were resolved using SDSPAGE (6\% acrylamide). In-gel fluorescence visualization and immunoblot analysis was carried out as previously described.

\section{Immunoblotting}

Cells were harvested in cold DPBS by scraping and washed with cold DPBS twice. Cell pellets were resuspended in DPBS supplemented with $5 \mathrm{mM}$ sodium butyrate, $20 \mathrm{mM}$ Nicotinamide, and 1X Halt Protease Inhibitor Cocktail and lysed by sonication (15 ms on, 40 ms off, 15\% amplitude, 1s total on $x$ 3). Protein concentration was determined using DC Protein Assay (Bio-Rad) and absorbance read using a CLARIOstar plate reader following manufacturer's instructions. Samples with equal protein content were boiled in 4X SDS gel loading buffer for $10 \mathrm{~min}$. Proteins were separated by $10 \%, 12.5 \%$, or $15 \%$ SDS-polyacrylamide gel electrophoresis and transferred to PVDF membranes using Trans-Blot Turbo RTA Mini 0.45 $\mu$ M LF PVDF Transfer Kit (Bio-Rad). Membranes were incubated for $1 \mathrm{~h}$ at room temperature with blocking buffer, followed by incubating overnight at $4^{\circ} \mathrm{C}$ with primary antibodies. After washing in TBST, the secondary antibodies were incubated with the membranes at room temperature for $1 \mathrm{~h}$. The membranes were washed with TBST for three times and visualized on a Bio-Rad ChemiDoc MP Imaging System with Clarity Max Western ECL substrate (Bio-Rad) or SuperSignal West Femto Chemiluminescent substrate proprietary luminol and peroxide solution kit (Thermo Scientific Pierce).

\section{Immunoprecipitation}

Cells were split in $10 \mathrm{~cm}$ dishes in indicated media. The probes were added once the cells grew to $70-80 \%$ confluency and incubated for indicated time. The cells were harvested and washed with cold DPBS twice. The pelleted cells were lysed in $1 \mathrm{~mL}$ lysis buffer, containing $50 \mathrm{mM}$ Tris$\mathrm{HCl} \mathrm{pH} \mathrm{7.5,} 300 \mathrm{mM} \mathrm{NaCl}, 0.5 \%$ (v/v) NP40, $5 \mathrm{mM}$ sodium butyrate, $20 \mathrm{mM}$ Nicotinamide, and 
1X Halt Protease Inhibitor, followed by clarification by centrifugation at $16,000 \mathrm{~g}$ for $20 \mathrm{~min}$ at $4^{\circ} \mathrm{C}$. The protein concentration was normalized by DC Proein Assay (Bio-Rad) and equal amount of protein was subjected to enrichment. For HA tag fusion protein enrichment, Monoclonal Anti-HA Agarose antibody produced in mouse (Sigma-Aldrich) was pre-washed with lysis buffer and added to the clarified lysate. Enrichment was carried out at $4^{\circ} \mathrm{C}$ for $4 \mathrm{~h}$ with rotating. After allowing immune complex binding, the beads were spun down at 2,000 rpm for $3 \mathrm{~min}$ at $4^{\circ} \mathrm{C}$. The beads were washed with lysis buffer and DPBS and incubated with HA peptide elution buffer at $37^{\circ} \mathrm{C}$ for $15 \mathrm{~min}$ twice or $4 \mathrm{X}$ SDS gel loading buffer at $95^{\circ} \mathrm{C}$ for $10 \mathrm{~min}$. Supernatant was collected for immunoblot analysis or mass spectrometry sample preparation.

\section{Chromatin Isolation}

To isolate chromatin, $3 \times 10^{6}$ cells were resuspended in $200 \mu \mathrm{L}$ buffer A (10 mM HEPES, pH 7.9, $10 \mathrm{mM} \mathrm{KCl}, 1.5 \mathrm{mM} \mathrm{MgCl}_{2}$, $0.34 \mathrm{M}$ sucrose, 10\% glycerol, $1 \mathrm{mM}$ DTT, 5 mM sodium butyrate, 20 $\mathrm{mM}$ Nicotinamide, and $1 \mathrm{X}$ Halt Protease Inhibitor). Cells were incubated for $5 \mathrm{~min}$ on ice with $0.1 \%(\mathrm{v} / \mathrm{v})$ Triton $\mathrm{X}-100$. Nuclei and soluble protein were separated by low-speed centrifugation at $1,300 \mathrm{~g}$ for $15 \mathrm{~min}$ at $4^{\circ} \mathrm{C}$. The soluble protein was further clarified by high-speed centrifugation at $20,000 \mathrm{~g}$ for $15 \mathrm{~min}$ at $4^{\circ} \mathrm{C}$. Nuclei was washed with buffer A, following by lysis in buffer $\mathrm{B}$ (3 mM EDTA, 0.2 mM EGTA, 1 mM DTT, 5 mM sodium butyrate, $20 \mathrm{mM}$ Nicotinamide, and $1 \mathrm{X}$ Halt Protease Inhibitor). Insoluble chromatin and nuclear plasma were separated by centrifugation at $1,700 \mathrm{~g}$ for $4 \mathrm{~min}$ at $4^{\circ} \mathrm{C}$. The insoluble chromatin was washed once in buffer $\mathrm{B}$ and resuspended in DPBS with $0.1 \%$ SDS. Protein concentration of chromatin, nuclear plasma, and soluble protein were normalized by DC Protein Assay (Bio-Rad) and equal amount of protein was subjected to immunoblotting analysis as described above.

\section{Quantitative Proteomic Analysis of H3.3 Acetylation}

\section{Sample preparation}

Cells were split in $10 \mathrm{~cm}$ dishes in indicated media. The probes were added once the cells grew to $60 \%-70 \%$ confluency and incubated for indicated time. The cells were harvested and washed with cold DPBS twice. The pelleted cells were lysed in $1 \mathrm{~mL}$ lysis buffer, containing $10 \mathrm{mM}$ Tris $\mathrm{pH} 7.5,300 \mathrm{mM} \mathrm{NaCl}, 0.1 \%$ (v/v) NP40, $5 \mathrm{mM}$ sodium butyrate, $20 \mathrm{mM}$ Nicotinamide, and 1X Halt Protease Inhibitor, followed by centrifuging for $5 \mathrm{~min}$ at $1,000 \mathrm{~g}$ at $4^{\circ} \mathrm{C}$. The pellets were resuspended in benzonase buffer, containing $50 \mathrm{mM}$ Tris $\mathrm{pH} 7.5,300 \mathrm{mM} \mathrm{NaCl}, 0.5 \% \mathrm{NP} 40$, and $2.5 \mathrm{mM} \mathrm{MgCl}_{2}$. Protein concentration was normalized by DC Protein Assay (Bio-Rad) and equal amount of protein was subjected to $50 \mathrm{U} / 100 \mu$ l benzonase nuclease (Millipore Sigma) treatment. 
Samples with benzonase were incubated on ice for $30 \mathrm{~min}$ and centrifuged at $300 \mathrm{~g}$ for $3 \mathrm{~min}$ at $4{ }^{\circ} \mathrm{C}$ to obtain soluble chromatin fraction. Samples were diluted with dilution buffer, containing 50 $\mathrm{mM}$ Tris $\mathrm{pH} 7.5,300 \mathrm{mM} \mathrm{NaCl}, 0.5 \% \mathrm{NP} 40$, and $15 \mathrm{mM}$ EDTA to quench the benzonase activity. Protein concentration was normalized again by DC Protein Assay (Bio-Rad) and equal amount of protein was used for HA-tag protein enrichment as described above. The beads were washed with lysis buffer and DPBS and incubated with $8 \mathrm{M}$ urea and boiled in 4X SDS gel loading buffer at $95^{\circ} \mathrm{C}$ for $15 \mathrm{~min}$. Supernatant was collected for in-gel digestion for mass-spectrometry sample preparation. HA-tag protein enriched samples were run on SDS-PAGE gel, flanked by MW markers, and stained with ProtoBlue. The desire protein bands were excised out and diced into approximately $1 \mathrm{~mm}^{3}$ pieces. The gels were washed with $500 \mu \mathrm{l} 100 \mathrm{mM}$ TEAB for 2 times and reduced in $10 \mathrm{mM}$ TCEP solution at $60^{\circ} \mathrm{C}$ for $30 \mathrm{~min}$. After reaction, TCEP solution was replaced with a solution of freshly prepared iodoacetamide (55 mM in $100 \mathrm{mM} \mathrm{TEAB})$ and incubated for 30 min at room temperature while protected from light. A solution of $1: 1$ acetonitrile and $100 \mathrm{mM}$ TEAB was added to wash the gels bands, followed by $100 \%$ acetonitrile to completely dry the gels. Sequencing-grade modified porcine trypsin $\left(0.2 \mu \mathrm{g}, 25 \mathrm{mM}\right.$ TEAB pH 8.5, $\left.100 \mu \mathrm{M} \mathrm{CaCl}_{2}\right)$ was added to the gel and incubated at $37^{\circ} \mathrm{C}$ for $14 \mathrm{~h}$ with shaking. The digest was collected and the peptides within the gels were extracted with $25 \%$ acetonitrile/5\% formic acid (MS-grade) for one time, $75 \%$ acetonitrile (MS-grade) for two times, and 100\% acetonitrile (MS-grade) for two times. The peptide samples were dried under vacuum centrifugation.

\section{TMT Labeling and Fractionation}

Samples were dissolved in 100 mM TEAB containing $30 \%$ acetonitrile (MS-grade) and labeled with respective TMT 10 plex isotope $(8 \mu \mathrm{L}, 20 \mu \mathrm{g} / \mu \mathrm{L})$ for $1 \mathrm{~h}$ with occasional vortexing at RT. To quench the reaction, hydroxylamine $(6 \mu \mathrm{L}, 5 \% \mathrm{v} / \mathrm{v})$ was added to each sample, vortexed, and incubated for $15 \mathrm{~min}$ at RT. Formic acid $(4 \mu \mathrm{L})$ was added to each tube to acidify and the samples were dried under vacuum centrifugation. Multiplexed samples were fractionated using the Pierce $^{\mathrm{TM}}$ High $\mathrm{pH}$ Reversed-Phase Peptide Fractionation Kit according to manufacturer instructions with the following elution scheme (\% acetonitrile in 0.1\% TEA; F1: 5\%, F2: 7.5\%, F3: 10\%, F4: 12.5\%, F5: 15\%, F6: 17.5\%, F7: 20\%, F8: 22.5\%, F9: 25\%, F10: 30\%, F11: 50\%, F12: 95\%). Fractions were then combined into six fractions by the following scheme: F1+F7, F2+F8, $\mathrm{F} 3+\mathrm{F} 9, \mathrm{~F} 4+\mathrm{F} 10, \mathrm{~F} 5+\mathrm{F} 11, \mathrm{~F} 6+\mathrm{F} 12$. Combined fractions were lyophilized prior to resuspension for MS analysis. 


\section{MS Analysis}

TMT labeled samples were redissolved in MS buffer A (20 $\mu \mathrm{L}, 0.1 \%$ formic acid in water). $3 \mu \mathrm{L}$ of each sample was loaded onto an Acclaim PepMap 100 precolumn ( $75 \mu \mathrm{m} \times 2 \mathrm{~mm})$ and eluted on an Acclaim PepMap RSLC analytical column $(75 \mu \mathrm{m} \times 15 \mathrm{~cm})$ using the UltiMate 3000 RSLCnano system (Thermo Fisher Scientific). Buffer A $(0.1 \%$ formic acid) and buffer B $(0.1 \%$ formic acid in $\mathrm{MeCN}$ ) were used in a $200 \mathrm{~min}$ gradient (flow rate $0.3 \mathrm{~mL} / \mathrm{min}, 35^{\circ} \mathrm{C}$ ) of $2 \%$ buffer $\mathrm{B}$ for $10 \mathrm{~min}$, followed by an incremental increase to $25 \%$ buffer B over $155 \mathrm{~min}, 25 \%-45 \%$ buffer B for $10 \mathrm{~min}$, 45\%-95 \% buffer B for $5 \mathrm{~min}$, hold at $95 \%$ buffer B for $2 \mathrm{~min}$, followed by descent to $2 \%$ buffer B for $1 \mathrm{~min}$ and re-equilibration at $2 \%$ for $6 \mathrm{~min}$. The elutions were analyzed with a Thermo Fisher Scientific Orbitrap Fusion Lumos mass spectrometer with a cycle time of $3 \mathrm{~s}$ and nano-LC electrospray ionization source applied voltage of $2.0 \mathrm{kV} . \mathrm{MS}^{1}$ spectra were recorded at a resolution of 120,000 with an automatic gain control (AGC) value of $1 \times 10^{6}$ ions, maximum injection time of $50 \mathrm{~ms}$ (dynamic exclusion enabled, repeat count 1, duration $20 \mathrm{~s}$ ). The scan range was specified from 375 to $1,500 \mathrm{~m} / \mathrm{z}$. Peptide fragmentation $\mathrm{MS}^{2}$ spectra was recorded via collision-

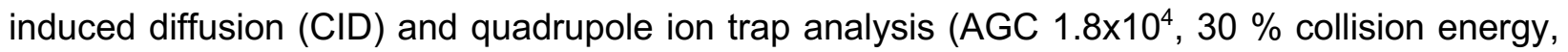
maximum inject time $120 \mathrm{~ms}$, isolation window 0.7). $\mathrm{MS}^{3}$ spectra were generated by high-energy collision-induced dissociation (HCD) with collision energy of $65 \%$. Precursor selection included up to $10 \mathrm{MS}^{2}$ ions for the $\mathrm{MS}^{3}$ spectrum. Proteomic analysis was performed with the processing software Proteome Discoverer 2.4 (Thermo Fisher Scientific). Peptide sequences were identified by matching proteome databases with experimental fragmentation patterns via the SEQUEST HT algorithm. Fragment tolerances were set to $0.6 \mathrm{Da}$, and precursor mass tolerances set to $10 \mathrm{ppm}$ with four missed cleavage sites allowed. Carbamidomethyl $(C,+57.021)$ and TMT-tag (N-terminal, +229.163) were specified in the static modifications. Oxidation ( $M$, +15.995), TMT-tag (K, +229.163), and Acetylation $(K,+42.011)$ were defined as dynamic modifications. Spectra were searched against the Homo Sapiens proteome database (42,358 sequences) using a false discovery rate of $1 \%$ (Percolator). $\mathrm{MS}^{3}$ peptide quantitation was performed with a mass tolerance of 20 ppm. Peptide abundance of TMT ratios obtained by Proteome Discoverer were normalized to total protein abundance.

\section{Quantitative Acetylproteomics}

\section{Sample preparation}

Frozen cell pellets were thawed on ice and lysed in a buffer containing $50 \mathrm{mM}$ Tris- $\mathrm{HCl}(\mathrm{pH} 7.5)$, $150 \mathrm{mM} \mathrm{NaCl}, 1 \mathrm{mM}$ EDTA, 1\% NP-40, 0.1\% sodium deoxycholate, $5 \mathrm{mM}$ sodium butyrate, 10 $\mathrm{mM}$ nicotinamide and $1 \mathrm{X}$ Pierce ${ }^{\mathrm{TM}}$ protease inhibitor cocktail. Cells were sonicated to ensure 
complete lysis, mixed with $5 \mathrm{M} \mathrm{NaCl}$ at a ratio of $1: 10$ with sample volume and incubated on ice for $15 \mathrm{~min}$ to release chromatin-bound proteins. Cell lysates were then sonicated again to shear genomic DNA. Cellular debris was cleared by centrifugation at $16,000 \mathrm{~g}$ for $20 \mathrm{~min}$ at $4^{\circ} \mathrm{C}$, protein concentration was determined using a Pierce ${ }^{\mathrm{TM}}$ BCA assay and $\sim 10 \mathrm{mg}$ of protein was aliquoted for acetyl-proteomic analysis. Proteins were denatured with $8 \mathrm{M}$ urea in $50 \mathrm{mM}$ HEPES, reduced with $5 \mathrm{mM}$ dithiothreitol for $30 \mathrm{~min}$ at $56^{\circ} \mathrm{C}$, then alkylated with $5 \mathrm{mM}$ iodoacetamide for $20 \mathrm{~min}$ in the dark at RT. Following alkylation, proteins were precipitated using chloroform-methanol as previously described, and protein pellets were dried at $56^{\circ} \mathrm{C}$ for $15 \mathrm{~min}$. Proteins pellets were resuspended in $1 \mathrm{M}$ urea in $50 \mathrm{mM}$ HEPES and digested in a two-step process with Lys $\mathrm{C}$ and trypsin as previously described. Digested peptides were desalted using Phenomenex Strata-X polymeric reverse phase extraction cartridges using the following protocol. Cartridges were

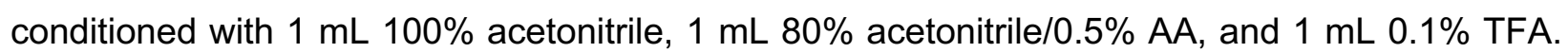
Peptides were then loaded on to the cartridge at a reduced flow rate and desalted with $5 \mathrm{~mL} 0.1 \%$

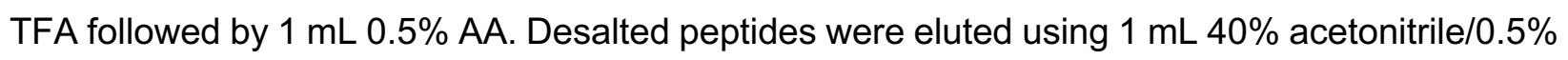
AA followed by $1 \mathrm{~mL} 80 \%$ acetonitrile/0.5\% AA and lyophilized. Digested peptides were quantified using the Pierce ${ }^{\mathrm{TM}}$ Quantitative Colorimetric Peptide Assay and $25 \mu \mathrm{g}$ was aliquoted from each for total protein analysis while the remaining peptide was lyophilized and retained for acetylpeptide enrichment.

\section{Acetyl-peptide Enrichment}

Acetyl-peptides were enriched using the PTMScan® Acetyl-Lysine Motif $[A c-K]$ Kit according to manufacturer instructions. Briefly, lyophilized peptides were resuspended in immuno-affinity purification buffer (IAP) and added to PBS-washed antibody-bead slurry. Acetyl-peptides were enriched on a rotator for $2 \mathrm{~h}$ at $4^{\circ} \mathrm{C}$. Bead-peptide complexes were then washed $2 \mathrm{X}$ with $1 \mathrm{~mL}$ IAP and $3 \mathrm{X}$ with $1 \mathrm{~mL} \mathrm{H} 2 \mathrm{O}$. Acetyl-peptides were eluted from the beads with $2 \mathrm{X}$ treatments of $0.15 \%$ TFA (gently mixing at RT for $10 \mathrm{~min}$ for each elution), desalted with Phenomenex Strata-X polymeric reverse phase extraction cartridge as above and lyophilized prior to TMT labeling.

\section{TMT Labeling and Fractionation}

Peptide aliquots were resuspended in $30 \%$ dry acetonitrile, $200 \mathrm{mM} \mathrm{HEPES}, \mathrm{pH} 8.5$ and $8 \mu \mathrm{l}$ of TMT labeling reagents was added to each sample. Labeling was allowed to proceed for $1 \mathrm{~h}$ at RT after which TMT labels were quenched by the addition of $9 \mu \mathrm{l} \%$ hydroxylamine for 15 min before the samples were acidified with $50 \mu \mathrm{l} 1 \%$ TFA. Samples were then pooled into respective 10plexes, lyophilized and resuspended in $0.1 \%$ TFA. Multiplexed samples were fractionated using 
the Pierce ${ }^{\mathrm{TM}}$ High $\mathrm{pH}$ Reversed-Phase Peptide Fractionation Kit according to manufacturer instructions with the following elution scheme (\% acetonitrile in 0.1\% TEA; F1: 7.5\%, F2: 10\%, F3: 12.5\%, F4: 15\%, F5: 17.5\%, F6: 20\%, F7: 22.5\%, F8: 25\%, F9: 27.5\%, F10: 30\%, F11: 32.5\%, F12: 35\%, F13: 37.5\%, F14: 40\%, F15: 42.5\%, F16: 45\%, F17: 47.5\%, F18: 75\%). Fractions were then combined into nine fractions by the following scheme: F1+F10, F2+F11, F3+F12, F4+F13, $\mathrm{F} 5+\mathrm{F} 14, \mathrm{~F} 6+\mathrm{F} 15, \mathrm{~F} 7+\mathrm{F} 16, \mathrm{~F} 8+\mathrm{F} 17, \mathrm{~F} 9+18$. Combined fractions were lyophilized prior to resuspension for MS analysis.

\section{MS analysis}

Acetylproteomic samples were subject to analysis via $\mathrm{LC}^{-M S^{3}}$ as above with the following alterations. Samples were resuspended in $60 \mu \mathrm{L}$ buffer $\mathrm{A}$ and $10 \mu \mathrm{L}$ was loaded on to the analytical column. Samples were eluted with $5 \%$ buffer B for $10 \mathrm{~min}$, a gradient of $5-20 \%$ buffer B over $160 \mathrm{~min}, 20-45 \%$ buffer B over $20 \mathrm{~min}, 45-95 \%$ buffer B over $5 \mathrm{~min}, 95 \%$ buffer B for 2 min, $5 \%$ buffer $B$ for $2 \mathrm{~min}, 95 \%$ buffer $B$ for $2 \mathrm{~min}$ and $5 \%$ buffer $B$ for 10 min to re-equilibrate the column. Eluted peptides were analyzed with a Thermo Fisher Orbitrap Fusion mass spectrometer as above with the following alterations: $\mathrm{MS}^{1}$ scan range of $400-1700 \mathrm{~m} / \mathrm{z}$, dynamic exclusion of $15 \mathrm{sec}, \mathrm{MS}^{1} \mathrm{AGC}$ target of $2 \times 10^{5}, \mathrm{MS}^{2} \mathrm{CID}$ collision energy $35 \%, \mathrm{MS}^{3} \mathrm{HCD}$ collision energy of $55 \%$.

\section{Data availability}

The mass spectrometry proteomics data have been deposited to the ProteomeXchange Consortium via the PRIDE [1] partner repository with the dataset identifier PXD027617. All other raw data are available upon requests.

[1] Perez-Riverol Y, Csordas A, Bai J, Bernal-Llinares M, Hewapathirana S, Kundu DJ, Inuganti A, Griss J, Mayer G, Eisenacher M, Pérez E, Uszkoreit J, Pfeuffer J, Sachsenberg T, Yilmaz S, Tiwary S, Cox J, Audain E, Walzer M, Jarnuczak AF, Ternent T, Brazma A, Vizcaíno JA (2019). The PRIDE database and related tools and resources in 2019: improving support for quantification data. Nucleic Acids Res 47(D1):D442-D450 (PubMed ID: 30395289).

\section{Chemistry Materials}

Chemicals and reagents were purchased from commercial vendors, including Sigma-Aldrich, Fisher Scientific, Combi-Blocks, MedChemExpress, Alfa Aesar and AstaTech, and were used as received without further purification, unless otherwise noted. Anhydrous solvents were purchased from Sigma-Aldrich in Sure/Seal ${ }^{\mathrm{TM}}$ formulations. All reactions were monitored by thin-layer chromatography (TLC, Merck silica gel 60 F-254 plates). The plates were stained either with $p$ anisaldehyde (2.5\% p-anisaldehyde, $1 \% \mathrm{AcOH}, 3.5 \% \mathrm{H} 2 \mathrm{SO} 4$ (conc.) in 95\% $\mathrm{EtOH}$ ), ninhydrin (0.3\% ninhydrin (w/v), 97:3 EtOH-AcOH), $\mathrm{KMnO} 4(1.5 \mathrm{~g}$ of KMnO4, $10 \mathrm{~g} \mathrm{~K} 2 \mathrm{CO} 3$, and $1.25 \mathrm{~mL}$ 
$10 \% \mathrm{NaOH}$ in $200 \mathrm{~mL}$ water), iodine or directly visualized with UV light. Reaction purification was carried out using Flash chromatography (230 - 400 mesh silica gel), Biotage $®$ or thin layer chromatography (pTLC, Analtech, 500-2000 $\mu \mathrm{m}$ thickness). NMR spectra were recorded on Bruker DPX-400 MHz or Bruker AV-600 MHz spectrometers in the indicated solvent. Multiplicities are reported with the following abbreviations: $s$ singlet; $d$ doublet; $t$ triplet; $q$ quartet; $p$ pentet; $m$ multiplet; br broad; dd doublet of doublets; dt doublet of triplets; td triplet of doublets; Chemical shifts are reported in ppm relative to the residual solvent peak and $\mathrm{J}$ values are reported in $\mathrm{Hz}$. Mass spectrometry data were collected on an Agilent 6120 single-quadrupole LC/MS instrument (ESI, low resolution) or an Agilent ESI-TOF instrument (ESI-TOF, HRMS).

\section{COMPOUND SYNTHESIS AND CHARACTERIZATION}

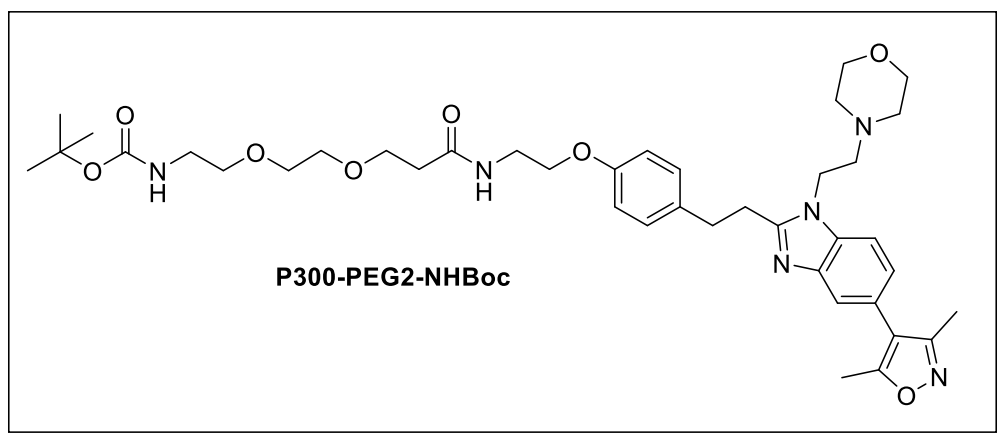

tert-butyl (2-(2-(3-((2-(4-(2-(5-(3,5-dimethylisoxazol-4-yl)-1-(2-morpholinoethyl)-1Hbenzo[d]imidazol-2-yl)ethyl)phenoxy)ethyl)amino)-3-oxopropoxy)ethoxy)ethyl)carbamate (P300-PEG2-NHBoc): To a solution of 2-(4-(2-(5-(3,5-dimethylisoxazol-4-yl)-1-(2morpholinoethyl)-1H-benzo[d]imidazol-2-yl)ethyl)phenoxy)ethan-1-amine (10.0 mg, $0.020 \mathrm{mmol}$, 1.0 eq) (synthesized according to previous method $\left.{ }^{1}\right)$ in DMF $(1 \mathrm{~mL})$, DIPEA (10.6 $\mu \mathrm{L}, 0.061 \mathrm{mmol}$, $3.0 \mathrm{eq}$ ) and t-Boc-N-amido-PEG2-acid $(5.35 \mathrm{mg}, 0.020 \mathrm{mmol}, 1 \mathrm{eq})$ was added followed by HATU $(8.54 \mathrm{mg}, 0.022 \mathrm{mmol}, 1.1 \mathrm{eq})$ were added at $0^{\circ} \mathrm{C}$ and resulting mixture was stirred for 5 minutes the corresponding starting material was fully consumed (indicated by TLC). The crude mixture was diluted with cold water and extracted in ethyl acetate $(20 \mathrm{~mL} \times 3)$ then combined organic 
extract was dried over sodium sulfate, filtered, and concentrated under reduced pressure. The crude material was purified by PTLC (DCM/Methanol, 19:1) to obtain P300-PEG2-NHBoc as a colorless sticky material $(8.4 \mathrm{mg}, 55 \%)$.

'H NMR: (400 MHz, $\left.\mathrm{CDCl}_{3}\right)$ ס $7.62(\mathrm{dd}, \mathrm{J}=1.5,0.6 \mathrm{~Hz}, 1 \mathrm{H}), 7.35$ (dd, J = 8.3, 0.7 Hz, 1H), 7.18 $-7.10(\mathrm{~m}, 3 \mathrm{H}), 6.88-6.80(\mathrm{~m}, 3 \mathrm{H}), 4.13(\mathrm{t}, \mathrm{J}=6.9 \mathrm{~Hz}, 2 \mathrm{H}), 4.02(\mathrm{t}, \mathrm{J}=5.3 \mathrm{~Hz}, 2 \mathrm{H}), 3.75-3.63$ (m, 10H), $3.62-3.56(\mathrm{~m}, 4 \mathrm{H}), 3.27-3.20(\mathrm{~m}, 2 \mathrm{H}), 3.19-3.13(\mathrm{~m}, 2 \mathrm{H}), 2.62(\mathrm{t}, \mathrm{J}=6.8 \mathrm{~Hz}, 2 \mathrm{H})$, $2.52-2.44(\mathrm{~m}, 8 \mathrm{H}), 2.42(\mathrm{~s}, 3 \mathrm{H}), 2.29(\mathrm{~s}, 3 \mathrm{H}), 1.43(\mathrm{~s}, 9 \mathrm{H})$.

${ }^{13} \mathrm{C}$ NMR: $\left(101 \mathrm{MHz}, \mathrm{CDCl}_{3}\right) \delta 171.87,170.88,165.04,159.02,157.32,155.38,143.00,134.27$, 133.34, 129.41, 124.27, 123.46, 119.92, 117.10, 114.71, 109.44, 80.67, 70.24, 70.11, 67.19, $66.89,66.84,57.64,54.06,41.52,38.88,36.94,36.22,32.98,29.88,28.11,11.60,10.90$.

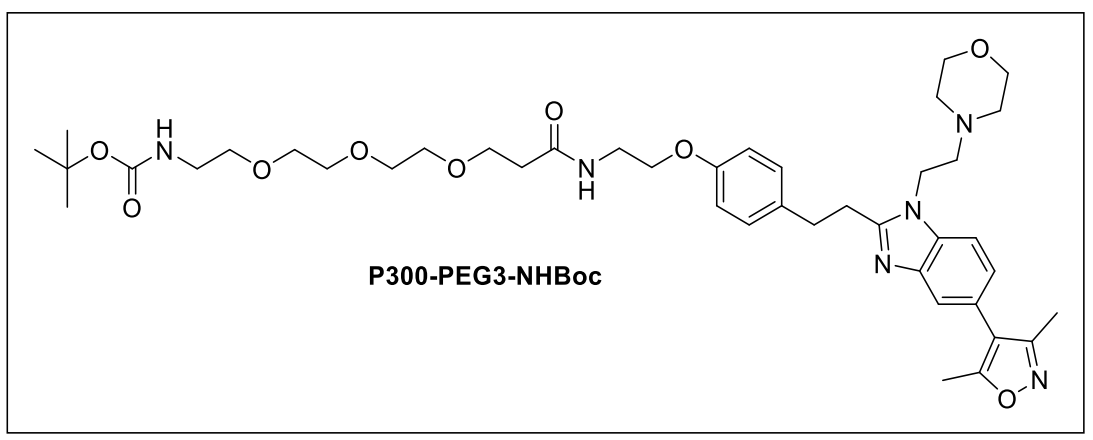

tert-butyl

(15-(4-(2-(5-(3,5-dimethylisoxazol-4-yl)-1-(2-morpholinoethyl)-1Hbenzo[d]imidazol-2-yl)ethyl)phenoxy)-12-oxo-3,6,9-trioxa-13-azapentadecyl)carbamate (P300-PEG3-NHBoc): To a solution of 2-(4-(2-(5-(3,5-dimethylisoxazol-4-yl)-1-(2morpholinoethyl)-1H-benzo[d]imidazol-2-yl)ethyl)phenoxy)ethan-1-amine (10.0 mg, $0.020 \mathrm{mmol}$, 1.0 eq) (synthesized according to previous method $\left.{ }^{1}\right)$ in DMF $(1 \mathrm{~mL})$, DIPEA $(10.6 \mu \mathrm{L}, 0.061 \mathrm{mmol}$, $3.0 \mathrm{eq})$ and t-Boc-N-amido-PEG3-acid $(6.56 \mathrm{mg}, 0.020 \mathrm{mmol}, 1 \mathrm{eq})$ was added followed by HATU $(8.54 \mathrm{mg}, 0.022 \mathrm{mmol}, 1.1 \mathrm{eq})$ were added at $0^{\circ} \mathrm{C}$ and resulting mixture was stirred for 5 minutes the corresponding starting material was fully consumed (indicated by TLC). The reaction mixture was diluted with cold water and extracted in ethyl acetate $(20 \mathrm{~mL} \times 3)$ then combined organic extract was dried over sodium sulfate, filtered, and concentrated under reduced pressure. The crude material was purified by PTLC (DCM/Methanol, 19:1) to obtain P300-PEG2-NHBoc as a colorless sticky material (8.5 mg, $52 \%)$. 
${ }^{1} \mathrm{H}$ NMR: $\left(600 \mathrm{MHz}, \mathrm{CDCl}_{3}\right) \delta 7.62(\mathrm{~d}, \mathrm{~J}=1.5 \mathrm{~Hz}, 1 \mathrm{H}), 7.35(\mathrm{~d}, \mathrm{~J}=8.3 \mathrm{~Hz}, 1 \mathrm{H}), 7.16-7.13(\mathrm{~m}$, 2H), $7.12(\mathrm{dd}, \mathrm{J}=8.2,1.5 \mathrm{~Hz}, 1 \mathrm{H}), 6.84(\mathrm{~d}, \mathrm{~J}=8.6 \mathrm{~Hz}, 2 \mathrm{H}), 6.76(\mathrm{~s}, 1 \mathrm{H}), 5.07(\mathrm{~s}, 1 \mathrm{H}), 4.13(\mathrm{t}, \mathrm{J}=$ $6.9 \mathrm{~Hz}, 2 \mathrm{H}), 4.02(\mathrm{t}, \mathrm{J}=5.3 \mathrm{~Hz}, 2 \mathrm{H}), 3.74(\mathrm{t}, \mathrm{J}=5.8 \mathrm{~Hz}, 2 \mathrm{H}), 3.68-3.61(\mathrm{~m}, 10 \mathrm{H}), 3.60(\mathrm{~s}, 4 \mathrm{H})$, $3.52(\mathrm{t}, \mathrm{J}=5.1 \mathrm{~Hz}, 2 \mathrm{H}), 3.33-3.27(\mathrm{~m}, 2 \mathrm{H}), 3.22-3.13(\mathrm{ddd}, \mathrm{J}=9.7,5.1,2.1 \mathrm{~Hz}, 2 \mathrm{H}), 3.17$ (ddd, $\mathrm{J}=8.5,7.0,2.2 \mathrm{~Hz}, 2 \mathrm{H}), 2.62(\mathrm{t}, \mathrm{J}=6.9 \mathrm{~Hz}, 2 \mathrm{H}), 2.51(\mathrm{t}, \mathrm{J}=5.8 \mathrm{~Hz}, 2 \mathrm{H}), 2.46(\mathrm{t}, \mathrm{J}=4.6 \mathrm{~Hz}, 4 \mathrm{H})$, $2.42(\mathrm{~s}, 3 \mathrm{H}), 2.29(\mathrm{~s}, 3 \mathrm{H}), 1.42(\mathrm{~s}, 9 \mathrm{H})$.

${ }^{13} \mathrm{C}$ NMR: $\left(151 \mathrm{MHz}, \mathrm{CDCl}_{3}\right) \delta$ 171.92, 165.06, 159.03, 157.26, 155.39, 142.97, 134.27, 133.36, 129.42, 124.25, 123.47, 119.89, 117.11, 114.71, 109.47, 70.56, 70.35, 70.20, 70.16, 70.04, 67.24, $66.84,66.76,57.63,54.05,41.51,40.34,38.92,32.97,29.86,28.42,11.61,10.92$.

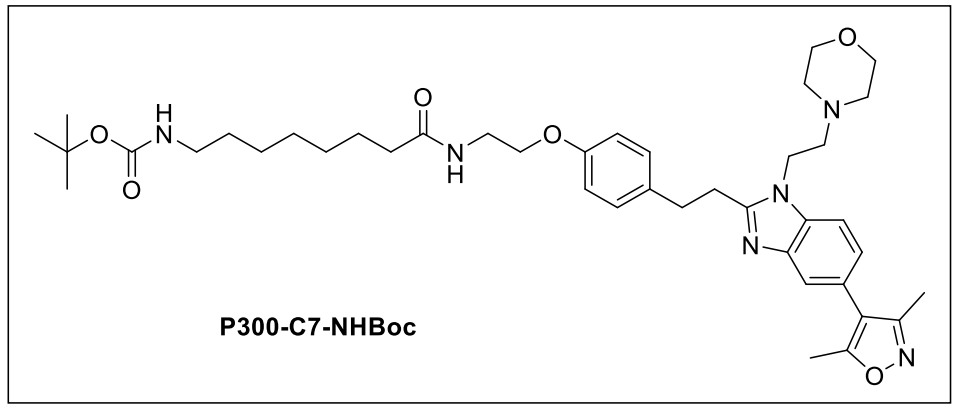

tert-butyl (8-((2-(4-(2-(5-(3,5-dimethylisoxazol-4-yl)-1-(2-morpholinoethyl)-1Hbenzo[d]imidazol-2-yl)ethyl)phenoxy)ethyl)amino)-8-oxooctyl)carbamate (P300-C7NHBoc)

To a solution of 2-(4-(2-(5-(3,5-dimethylisoxazol-4-yl)-1-(2-morpholinoethyl)-1Hbenzo[d]imidazol-2-yl)ethyl)phenoxy)ethan-1-amine $(30.0 \mathrm{mg}, 0.061 \mathrm{mmol}, 1.0 \mathrm{eq})$ (synthesized according to previous method ${ }^{1}$ ) and Boc-8-Aoc-OH (17.5 mg, $\left.0.067 \mathrm{mmol}, 1.1 \mathrm{eq}\right)$ in DCM (4 mL), EDC (18.0 mg, $0.092 \mathrm{mmol}, 1.5 \mathrm{eq}) \mathrm{HOBt}(13.0 \mathrm{mg}, 0.092 \mathrm{mmol}, 1.5 \mathrm{eq})$ and DIPEA (32 $\mu \mathrm{L}, 0.183$ mmol, $3.0 \mathrm{eq}$ ) was added. The mixture was stirred at room temperature for 14 hours. After completion the reaction mixture was diluted with water $(10 \mathrm{~mL})$ and extracted in $\mathrm{DCM}(2 \times 20 \mathrm{~mL})$, the organic layer was washed with saturated sodium bicarbonate (aq), and brine, the combined organic layer was dried over sodium sulfate, filtered, and concentrated under reduced pressure. The crude material was purified by Biotage ${ }^{\circledR}$ Sfär Silica D $10 \mathrm{~g}$ column with a 0-5 \% linear gradient of Methanol in Dichloromethane over 20 column volumes (CV), to obtain P300-C7-NHBoc as a colorless oil (29 mg, $65 \%$ ).

${ }^{1} \mathrm{H}$ NMR $\left(600 \mathrm{MHz}, \mathrm{CDCl}_{3}\right) \delta 7.62(\mathrm{~d}, \mathrm{~J}=1.5 \mathrm{~Hz}, 1 \mathrm{H}), 7.36(\mathrm{~s}, 1 \mathrm{H}), 7.18-7.15(\mathrm{~m}, 2 \mathrm{H}), 7.12$ (dd, $\mathrm{J}=8.2,1.5 \mathrm{~Hz}, 1 \mathrm{H}), 6.86-6.82(\mathrm{~m}, 2 \mathrm{H}), 5.93(\mathrm{t}, \mathrm{J}=5.9 \mathrm{~Hz}, 1 \mathrm{H}), 4.51(\mathrm{~s}, 1 \mathrm{H}), 4.13(\mathrm{t}, \mathrm{J}=6.9 \mathrm{~Hz}$, $2 \mathrm{H}), 4.01(\mathrm{t}, \mathrm{J}=5.1 \mathrm{~Hz}, 2 \mathrm{H}), 3.66(\mathrm{td}, \mathrm{J}=4.9,2.8 \mathrm{~Hz}, 6 \mathrm{H}), 3.27-3.21(\mathrm{~m}, 2 \mathrm{H}), 3.20-3.14(\mathrm{~m}$, 
2H), $3.08(\mathrm{q}, \mathrm{J}=6.7 \mathrm{~Hz}, 2 \mathrm{H}), 2.62(\mathrm{t}, \mathrm{J}=6.9 \mathrm{~Hz}, 2 \mathrm{H}), 2.46(\mathrm{t}, \mathrm{J}=4.6 \mathrm{~Hz}, 4 \mathrm{H}), 2.42(\mathrm{~s}, 3 \mathrm{H}), 2.29$ $(\mathrm{s}, 3 \mathrm{H}), 2.21-2.16(\mathrm{~m}, 2 \mathrm{H}), 1.63(\mathrm{t}, \mathrm{J}=7.3 \mathrm{~Hz}, 3 \mathrm{H}), 1.43(\mathrm{~s}, 9 \mathrm{H}), 1.33-1.28(\mathrm{~m}, 6 \mathrm{H})$.

${ }^{13} \mathrm{C}$ NMR $\left(151 \mathrm{MHz}, \mathrm{CDCl}_{3}\right) \delta 173.26,165.06,159.03,157.18,156.01,155.35,143.03,134.28$, $133.51,129.47,124.26,123.46,119.95,117.10,114.66,109.42$, 66.94, 66.84, 57.64, 54.06, $41.50,40.52,38.89,36.65,32.94,29.98,29.87,29.72,29.11,28.91,28.44,26.56,25.52,11.61$, 10.92.

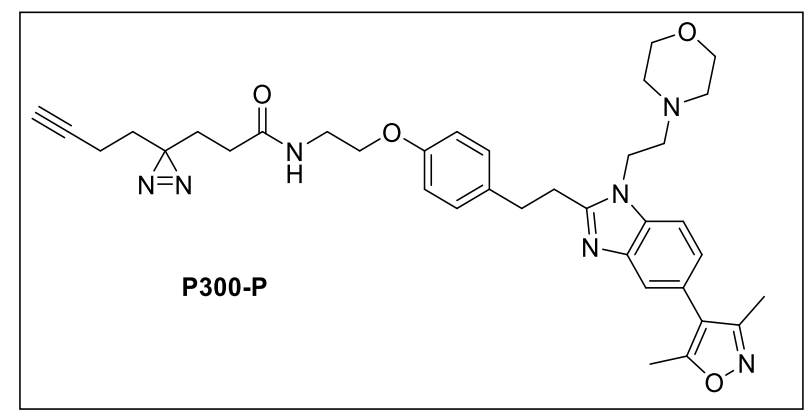

3-(3-(but-3-yn-1-yl)-3H-diazirin-3-yl)-N-(2-(4-(2-(5-(3,5-dimethylisoxazol-4-yl)-1-(2morpholinoethyl)-1H-benzo[d]imidazol-2-yl)ethyl)phenoxy)ethyl)propenamide (P300-P) To a solution of 2-(4-(2-(5-(3,5-dimethylisoxazol-4-yl)-1-(2-morpholinoethyl)-1Hbenzo[d]imidazol-2-yl)ethyl)phenoxy)ethan-1-amine $(15.0 \mathrm{mg}, 0.030 \mathrm{mmol}, 1.0 \mathrm{eq})$ (synthesized according to previous method ${ }^{1}$ ) and 3-(3-(but-3-yn-1-yl)-3H-diazirin-3-yl)propanoic acid (6.0 mg, $0.033 \mathrm{mmol}, 1.1 \mathrm{eq})$ in DCM (2 mL), EDC $(9.0 \mathrm{mg}, 0.046 \mathrm{mmol}, 1.5 \mathrm{eq}) \mathrm{HOBt}(7.0 \mathrm{mg}, 0.046$ $\mathrm{mmol}, 1.5 \mathrm{eq})$ and DIPEA (16 $\mu \mathrm{L}, 0.092 \mathrm{mmol}, 3.0 \mathrm{eq})$ was added. The mixture was stirred at room temperature for 12 hours, then diluted with DCM. The organic layer was washed with saturated sodium bicarbonate (aq), water and brine. The combined organic layer was then dried over sodium sulfate, filtered, and concentrated under reduced pressure. The crude material was purified by Biotage ${ }^{\circledR}$ Sfär Silica D $10 \mathrm{~g}$ with a $0-5 \%$ linear gradient of Methanol in Dichloromethane over 20 column volumes (CV), to obtain P300-diazirine tag as a colorless oil (12.7 mg, $65 \%$ ).

${ }^{1} \mathrm{H}$ NMR $\left(400 \mathrm{MHz}, \mathrm{CDCl}_{3}\right) \delta 7.62(\mathrm{~d}, \mathrm{~J}=1.6 \mathrm{~Hz}, 1 \mathrm{H}), 7.35(\mathrm{~d}, \mathrm{~J}=8.3 \mathrm{~Hz}, 1 \mathrm{H}), 7.19-7.09(\mathrm{~m}$, $3 \mathrm{H}), 6.86-6.79(\mathrm{~m}, 2 \mathrm{H}), 6.10-5.91(\mathrm{~m}, 1 \mathrm{H}), 4.13(\mathrm{t}, \mathrm{J}=6.8 \mathrm{~Hz}, 2 \mathrm{H}), 4.01(\mathrm{t}, \mathrm{J}=5.1 \mathrm{~Hz}, 2 \mathrm{H})$, $3.70-3.61(\mathrm{~m}, 6 \mathrm{H}), 3.23(\mathrm{dd}, \mathrm{J}=8.9,5.8 \mathrm{~Hz}, 2 \mathrm{H}), 3.20-3.12(\mathrm{~m}, 2 \mathrm{H}), 2.61(\mathrm{t}, \mathrm{J}=6.8 \mathrm{~Hz}, 2 \mathrm{H})$, $2.45(\mathrm{t}, \mathrm{J}=4.6 \mathrm{~Hz}, 4 \mathrm{H}), 2.42(\mathrm{~s}, 3 \mathrm{H}), 2.29(\mathrm{~s}, 3 \mathrm{H}), 2.03-1.93(\mathrm{~m}, 5 \mathrm{H}), 1.84(\mathrm{dd}, \mathrm{J}=8.9,6.6 \mathrm{~Hz}$, $2 \mathrm{H}), 1.63(\mathrm{t}, \mathrm{J}=7.3 \mathrm{~Hz}, 2 \mathrm{H})$. 
${ }^{13} \mathrm{C}$ NMR $\left(101 \mathrm{MHz}, \mathrm{CDCl}_{3}\right) \delta 171.30,165.04,159.02,157.09,155.34,143.03,134.28,133.56$, $129.47,124.22,123.45,119.92,117.10,114.63,109.43,82.71,69.26,66.83,66.73,57.64,54.05$, $41.50,39.04,32.92,32.35,30.31,29.85,28.35,27.85,13.28,11.60,10.92$.

HRMS (ESI-TOF) calcd for $\mathrm{C}_{36} \mathrm{H}_{44} \mathrm{~N}_{7} \mathrm{O}_{4}, 638.3449\left(\mathrm{M}+\mathrm{H}^{+}\right)$, found 638.3451.

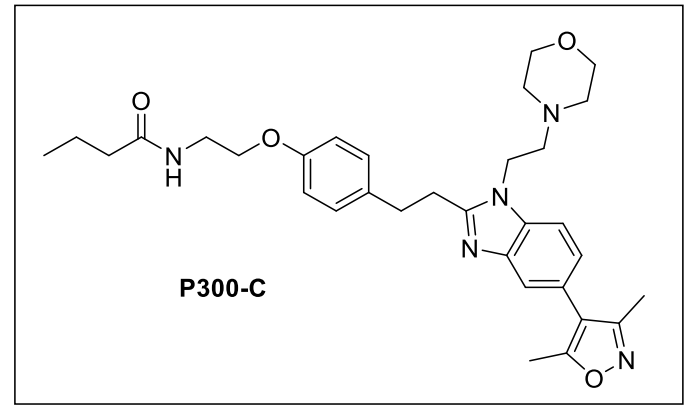

N-(2-(4-(2-(5-(3,5-dimethylisoxazol-4-yl)-1-(2-morpholinoethyl)-1H-benzo[d]imidazol-2yl)ethyl)phenoxy)ethyl)pentanamide (P300-C)

To a solution of 2-(4-(2-(5-(3,5-dimethylisoxazol-4-yl)-1-(2-morpholinoethyl)-1Hbenzo[d]imidazol-2-yl)ethyl)phenoxy)ethan-1-amine (synthesized according to previous method ${ }^{1}$ ) (15.0 mg, $0.030 \mathrm{mmol}, 1.0 \mathrm{eq})$ and butyric acid (3.0 mg, $0.034 \mathrm{mmol}, 1.1 \mathrm{eq})$ in DCM (2 mL), EDC (9.0 mg, $0.046 \mathrm{mmol}, 1.5 \mathrm{eq}) \mathrm{HOBt}(7.0 \mathrm{mg}, 0.046 \mathrm{mmol}, 1.5 \mathrm{eq})$ and DIPEA (16 $\mu \mathrm{L}, 0.092 \mathrm{mmol}$, 3.0 eq) was added. The mixture was stirred at room temperature for 12 hours, then diluted with DCM. The organic layer was washed with saturated sodium bicarbonate (aq), water and brine. The combined organic layer was then dried over sodium sulfate, filtered, and concentrated under reduced pressure. The crude material was purified by PTLC (DCM/Methanol, 19:1) to afford P300-C as a colorless oil (10.0 mg, 58\%).

${ }^{1} \mathrm{H}$ NMR: $(400 \mathrm{MHz}, \mathrm{MeOD}) \delta 7.61-7.54(\mathrm{~m}, 2 \mathrm{H}), 7.24(\mathrm{dd}, \mathrm{J}=8.3,1.6 \mathrm{~Hz}, 1 \mathrm{H}), 7.17-7.09(\mathrm{~m}$, 2H), $6.86(\mathrm{~d}, \mathrm{~J}=8.6 \mathrm{~Hz}, 2 \mathrm{H}), 4.20(\mathrm{t}, \mathrm{J}=6.7 \mathrm{~Hz}, 2 \mathrm{H}), 4.01(\mathrm{t}, \mathrm{J}=5.5 \mathrm{~Hz}, 2 \mathrm{H}), 3.64(\mathrm{t}, \mathrm{J}=4.7 \mathrm{~Hz}$, $4 \mathrm{H}), 3.55(\mathrm{t}, \mathrm{J}=5.5 \mathrm{~Hz}, 2 \mathrm{H}), 3.27-3.24(\mathrm{~m}, 2 \mathrm{H}), 3.23-3.14(\mathrm{~m}, 2 \mathrm{H}), 2.54(\mathrm{t}, \mathrm{J}=6.7 \mathrm{~Hz}, 2 \mathrm{H})$, $2.49-2.41(\mathrm{~m}, 7 \mathrm{H}), 2.29(\mathrm{~s}, 3 \mathrm{H}), 2.20(\mathrm{dd}, \mathrm{J}=7.9,6.9 \mathrm{~Hz}, 2 \mathrm{H}), 1.69-1.60(\mathrm{~m}, 2 \mathrm{H}), 0.94(\mathrm{t}, \mathrm{J}=$ $7.4 \mathrm{~Hz}, 3 \mathrm{H})$.

${ }^{13}$ C NMR: (151 MHz, MeOD) $\delta 175.06,165.34,158.83,157.56,156.11,142.02,134.11,132.96$, $129.19,124.07,123.51,118.43,116.96,114.36,110.25,66.45,66.15,57.06,53.63,40.86,38.67$, $37.49,32.95,29.16,18.96,12.53,10.00,9.33$. 
HRMS (ESI-TOF) calculated for $\mathrm{C}_{32} \mathrm{H}_{41} \mathrm{~N}_{5} \mathrm{O}_{4}, 560.3231\left(\mathrm{M}+\mathrm{H}^{+}\right)$, found 560.3247 .

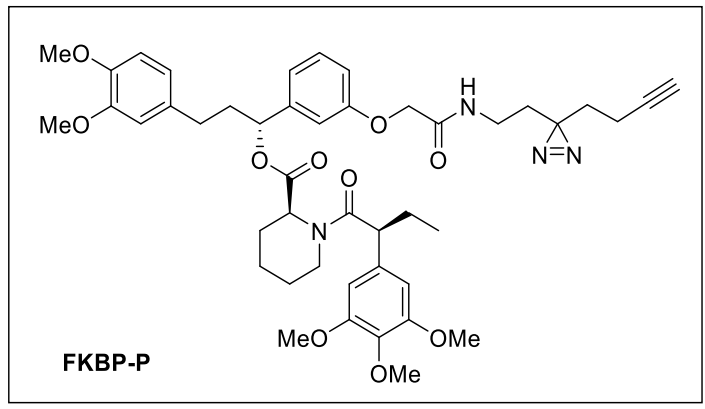

3) (R)-1-(3-(2-((2-(3-(but-3-yn-1-yl)-3H-diazirin-3-yl)ethyl)amino)-2-oxoethoxy)phenyl)-3(3,4-dimethoxyphenyl)propyl (S)-1-((S)-2-(3,4,5-trimethoxyphenyl)butanoyl)piperidine-2carboxylate (FKBP-P)

To a solution of 2-(3-((R)-3-(3,4-dimethoxyphenyl)-1-(((S)-1-((S)-2-(3,4,5trimethoxyphenyl)butanoyl)piperidine-2-carbonyl)oxy)propyl)phenoxy)acetic acid (synthesized according to previous method $\left.^{2}\right)(10.0 \mathrm{mg}, 0.014 \mathrm{mmol}, 1.0 \mathrm{eq})$ and 2-(3-(but-3-yn-1-yl)-3Hdiazirin-3-yl)ethan-1-amine (2.20 mg, $0.016 \mathrm{mmol}, 1.1 \mathrm{eq})$ in DCM (2 mL), EDC (4.15 mg, 0.022 mmol, $1.5 \mathrm{eq}$ ), HOBt (2.94 mg, $0.022 \mathrm{mmol}, 1.5 \mathrm{eq})$ and DIPEA (8.0 $\mu \mathrm{L}, 0.043 \mathrm{mmol}, 3.0 \mathrm{eq})$ was added. The mixture was stirred at room temperature for 12 hours, after completion the reaction mixture was diluted with DCM $(15 \mathrm{~mL})$. The organic layer was washed with saturated sodium bicarbonate (aq), water and brine, the combined organic layer was dried over sodium sulfate, filtered, and concentrated under reduced pressure. The crude material was purified by PTLC (DCM/Methanol, 19:1) to afford FKBP-P as a colorless oil $(8.0 \mathrm{mg}, 58 \%)$.

${ }^{1} \mathrm{H}$ NMR $\left(600 \mathrm{MHz}, \mathrm{CDCl}_{3}\right) \delta 7.33(\mathrm{t}, \mathrm{J}=7.9 \mathrm{~Hz}, 0.25 \mathrm{H}), 7.19(\mathrm{t}, \mathrm{J}=7.9 \mathrm{~Hz}, 1 \mathrm{H}), 7.01-6.99(\mathrm{~m}$, $0.25 \mathrm{H}), .6 .93-6.92(\mathrm{~m}, 0.25 \mathrm{H}), 6.88-6.86(\mathrm{~m}, 0.46 \mathrm{H}), 6.82-6.80(\mathrm{~m}, 1.60 \mathrm{H}), 6.79-6.76(\mathrm{~m}$, $0.25 \mathrm{H}), 6.69-6.66(\mathrm{~m}, 1.37 \mathrm{H}), 6.66-6.62(\mathrm{~m}, 1.20 \mathrm{H}), 6.42(\mathrm{~s}, 0.5 \mathrm{H}), 6.40(\mathrm{~s}, 2 \mathrm{H}), 5.81(\mathrm{dd}, \mathrm{J}=$ $7.8,6.0 \mathrm{~Hz}, 0.23 \mathrm{H}), 5.63(\mathrm{dd}, \mathrm{J}=8.3,5.4 \mathrm{~Hz}, 1 \mathrm{H}), 5.47-5.44(\mathrm{~m}, 1 \mathrm{H}), 4.66(\mathrm{~d}, \mathrm{~J}=5.4 \mathrm{~Hz}, 0.22 \mathrm{H})$, $4.61-4.58(\mathrm{~m}, 0.26 \mathrm{H}), 4.50(\mathrm{~s}, 0.5 \mathrm{H}), 4.48(\mathrm{~s}, 2 \mathrm{H}), 3.87-3.83(\mathrm{~m}, 10 \mathrm{H}), 3.82-3.78(\mathrm{~m}, 1 \mathrm{H})$, $3.78(\mathrm{~s}, 3 \mathrm{H}), 3.67(\mathrm{~s}, 6 \mathrm{H}), 3.59-3.57(\mathrm{~m}, 1 \mathrm{H}), 3.39-3.37(\mathrm{~m}, 0.26 \mathrm{H}), 3.28-3.21(\mathrm{~m}, 2.5 \mathrm{H}), 2.79$ (td, J = 13.4, 3.1 Hz, 1H), $2.63-2.53(\mathrm{~m}, 1.5 \mathrm{H}), 2.50-2.44(\mathrm{~m}, 1 \mathrm{H}), 2.42-2.40(\mathrm{~m}, 0.23 \mathrm{H}), 2.30$ $(\mathrm{dd}, \mathrm{J}=12.0,2.6 \mathrm{~Hz}, 1 \mathrm{H}), 2.13-2.04(\mathrm{~m}, 2.61 \mathrm{H}), 2.02-1.98(\mathrm{~m}, 4 \mathrm{H}), 1.96-1.91(\mathrm{~m}, 1 \mathrm{H}), 2.04$ $1.77-1.67(\mathrm{~m}, 6 \mathrm{H}), 1.66-1.61(\mathrm{~m}, 3 \mathrm{H}), 1.47-1.39(\mathrm{~m}, 1 \mathrm{H}), 1.31-1.25(\mathrm{~m}, 3 \mathrm{H}), 0.90(\mathrm{t}, \mathrm{J}=$ $7.3 \mathrm{~Hz}, 3 \mathrm{H}), 0.86(\mathrm{t}, \mathrm{J}=7.3 \mathrm{~Hz}, 1 \mathrm{H})$. Note: rotomeric isomers observed.

${ }^{13} \mathrm{C}$ NMR $\left(101 \mathrm{MHz}, \mathrm{CDCl}_{3}\right) \delta 172.67,170.65,168.26,157.31,153.51,153.20,148.89,147.37$, $142.41,136.64,135.32,133.34,130.14,129.85,120.21,120.11,120.07,119.92,113.79,113.72$, 
$113.55,113.08,111.69,111.59,111.34,111.27,104.98,104.58,82.60,75.60,69.45,67.37$, $67.31,60.92,60.80,56.33,55.97,55.94,55.88,55.86,55.69,52.06,51.25,50.81,43.49,39.69$, $38.24,38.01,34.05,34.02,32.66,32.63,32.05,31.46,31.30,29.72,28.40,28.37,26.79,26.74$, $26.36,25.34,24.54,20.91,20.68,13.22,12.79,12.58$. Note: rotomeric isomers observed.

HRMS (ESI-TOF) calculated for $\mathrm{C}_{45} \mathrm{H}_{57} \mathrm{~N}_{4} \mathrm{O}_{10}, 813.4069\left(\mathrm{M}+\mathrm{H}^{+}\right)$, found 813.4072.

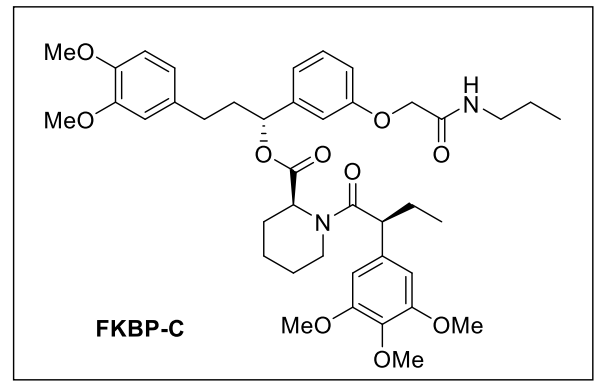

(R)-3-(3,4-dimethoxyphenyl)-1-(3-(2-oxo-2-(propylamino)ethoxy)phenyl)propyl (S)-1-((S)-2(3,4,5-trimethoxyphenyl)butanoyl)piperidine-2-carboxylate (FKBP-C)

To a solution of 2-(3-((R)-3-(3,4-dimethoxyphenyl)-1-(((S)-1-((S)-2-(3,4,5trimethoxyphenyl)butanoyl)piperidine-2-carbonyl)oxy)propyl)phenoxy)acetic acid (synthesized according to previous method ${ }^{2}$ ) $(15.0 \mathrm{mg}, 0.030 \mathrm{mmol}, 1.0 \mathrm{eq})$ and Propylamine $(1.3 \mu \mathrm{L}, 0.034$ mmol, $1.1 \mathrm{eq})$ in DCM (2 mL), EDC (9.0 mg, $0.046 \mathrm{mmol}, 1.5 \mathrm{eq})$, HOBt $(7.0 \mathrm{mg}, 0.046 \mathrm{mmol}, 1.5$ eq) and DIPEA (16 $\mu \mathrm{L}, 0.092 \mathrm{mmol}, 3.0 \mathrm{eq})$ was added. The mixture was stirred at room temperature for 12 hours. After completion the reaction mixture was diluted with DCM $(15 \mathrm{~mL})$, the organic layer was washed with saturated sodium bicarbonate (aq), water and brine. The combined organic layer was dried over sodium sulfate, filtered, and concentrated under reduced pressure. The crude material was purified by PTLC (DCM/Methanol, 19:1) to obtain P300-C as a colorless oil (5.8 mg, $54 \%$ ).

${ }^{1} \mathrm{H}$ NMR $(400 \mathrm{MHz}, \mathrm{MeOD}) \delta 7.34(\mathrm{t}, \mathrm{J}=7.8 \mathrm{~Hz}, 0.21 \mathrm{H}), 7.20(\mathrm{t}, \mathrm{J}=7.9 \mathrm{~Hz}, 1 \mathrm{H}), 7.07-6.94(\mathrm{~m}$, $1 \mathrm{H}), 6.95-6.84(\mathrm{~m}, 2.24 \mathrm{H}), 6.81-6.79(\mathrm{~m}, 1.28 \mathrm{H}), 6.77-6.72(\mathrm{~m}, 1.36 \mathrm{H}), 6.69(\mathrm{dd}, \mathrm{J}=8.2,2.0$ $\mathrm{Hz}, 1 \mathrm{H}), 6.63-6.55(\mathrm{~m}, 3.30 \mathrm{H}), 5.84(\mathrm{dd}, \mathrm{J}=7.9,5.7 \mathrm{~Hz}, 0.2 \mathrm{H}), 5.61(\mathrm{dd}, \mathrm{J}=8.3,5.4 \mathrm{~Hz}, 1 \mathrm{H})$, $5.45-5.35(\mathrm{~m}, 1 \mathrm{H}), 4.98-4.90(\mathrm{~m}, 1 \mathrm{H}), 4.54(\mathrm{~s}, 0.5 \mathrm{H}), 4.51(\mathrm{~s}, 2 \mathrm{H}), 4.14-4.05(\mathrm{~m}, 1.25 \mathrm{H})$, $3.93-3.85(\mathrm{~m}, 2 \mathrm{H}), 3.84(\mathrm{~s}, 1.38 \mathrm{H}), 3.82(\mathrm{~s}, 3 \mathrm{H}), 3.81(\mathrm{~s}, 3 \mathrm{H}), 3.77(\mathrm{~s}, 1 \mathrm{H}), 3.71(\mathrm{~s}, 3 \mathrm{H}), 3.70-$ $3.65(\mathrm{~m}, 6 \mathrm{H}), 3.61-3.58(\mathrm{~m}, 0.5 \mathrm{H}), 3.30-3.22(\mathrm{~m}, 2.5 \mathrm{H}), 2.78-2.70(\mathrm{~m}, 1.22 \mathrm{H}), 2.67-2.53$ $(\mathrm{m}, 2 \mathrm{H}), 2.49-2.41(\mathrm{~m}, 1.5 \mathrm{H}), 2.33-2.29(\mathrm{~m}, 1.3 \mathrm{H}), 2.20-2.11(\mathrm{~m}, 0.6 \mathrm{H}), 2.10-1.98(\mathrm{~m}, 3 \mathrm{H})$, $1.97-1.85(\mathrm{~m}, 1.5 \mathrm{H}), 1.79-1.85(\mathrm{~m}, 5 \mathrm{H}), 1.56-1.48(\mathrm{~m}, 4 \mathrm{H}), 1.37-1.24(\mathrm{~m}, 4 \mathrm{H}), 0.94-0.89$ $(\mathrm{m}, 6 \mathrm{H}), 0.85(\mathrm{t}, \mathrm{J}=7.3 \mathrm{~Hz}, 1 \mathrm{H})$. Note: rotomeric isomers observed. 
${ }^{13} \mathrm{C}$ NMR (101 MHz, MeOD) $\delta 173.76,173.60,170.48,170.02,169.51,158.00,157.79,153.48$, 153.19, 149.05, 147.48, 142.21, 136.55, 136.13, 135.52, 133.81, 133.75, 129.60, 129.44, 120.39, 120.31, 119.69, 119.30, 114.13, 113.68, 113.16, 112.89, 112.27, 111.88, 105.19, 104.61, 76.72, $75.74,66.89,59.68,55.96,55.15,55.06,52.23,50.24,49.87,43.57,37.84,31.20,30.86$, 28.00, $26.21,24.91,20.44,19.63,12.70,11.58,11.27$. Note: rotomeric isomers observed.

HRMS calculated for $\mathrm{C}_{41} \mathrm{H}_{55} \mathrm{~N}_{2} \mathrm{O}_{10}, 749.4008\left(\mathrm{M}+\mathrm{H}^{+}\right)$, found 749.4010 .

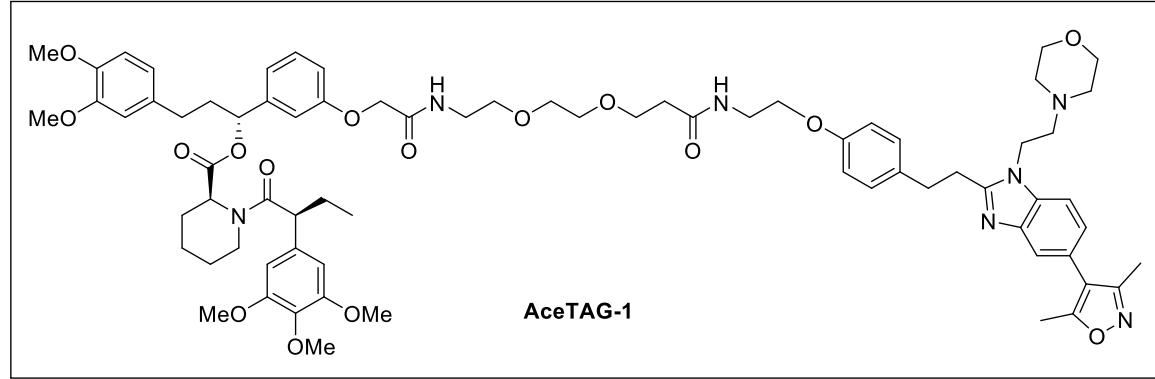

(R)-3-(3,4-dimethoxyphenyl)-1-(3-((15-(4-(2-(5-(3,5-dimethylisoxazol-4-yl)-1-(2morpholinoethyl)-1H-benzo[d]imidazol-2-yl)ethyl)phenoxy)-2,12-dioxo-6,9-dioxa-3,13diazapentadecyl)oxy)phenyl)propyl (S)-1-((S)-2-(3,4,5trimethoxyphenyl)butanoyl)piperidine-2-carboxylate (AceTAG-1):

To a solution of tert-butyl (2-(2-(3-((2-(4-(2-(5-(3,5-dimethylisoxazol-4-yl)-1-(2-morpholinoethyl)1H-benzo[d]imidazol-2-yl)ethyl)phenoxy)ethyl)amino)-3-oxopropoxy)ethoxy)ethyl)carbamate (P300-PEG $2-\mathrm{NHBoc}$ ) (20 mg, $0.027 \mathrm{mmol})$ in DCM (1 mL), a solution of $20 \%$ TFA in DCM (1 mL) was added at $0^{\circ} \mathrm{C}$ and resulting mixture was stirred at room temperature for $2 \mathrm{~h}$. After completion (monitored by TLC), the reaction mixture was evaporated under reduced pressure to obtained the corresponding TFA salt of 3-(2-(2-aminoethoxy)ethoxy)-N-(2-(4-(2-(5-(3,5-dimethylisoxazol-4-yl)1-(2-morpholinoethyl)-1H-benzo[d]imidazol-2-yl)ethyl)phenoxy)ethyl)propenamide (P300-PEG ${ }_{2}$ $\mathrm{NH}_{2}$.TFA), was obtained were used in next step without further purification. To a solution of corresponding TFA salt of 3-(2-(2-aminoethoxy)ethoxy)-N-(2-(4-(2-(5-(3,5-dimethylisoxazol-4-yl)1-(2-morpholinoethyl)-1H-benzo[d]imidazol-2-yl)ethyl)phenoxy)ethyl)propenamide $\quad(5.0 \quad \mathrm{mg}$, $0.0077 \mathrm{mmol}, 1.0 \mathrm{eq})$ in DMF (1 mL), DIPEA (6.70 $\mu \mathrm{L}, 0.038 \mathrm{mmol}, 5.0$ eq.) and 2-(3-((R)-3-(3,4dimethoxyphenyl)-1-(((S)-1-((S)-2-(3,4,5-trimethoxyphenyl)butanoyl)piperidine-2carbonyl)oxy)propyl)phenoxy)acetic acid (synthesized as previously described ${ }^{2}$ ) (5.34 mg, 0.0077 mmol, 1 eq) was added followed by HATU $(3.22 \mathrm{mg}, 0.0085 \mathrm{mmol}, 1.1 \mathrm{eq})$ were added at $0^{\circ} \mathrm{C}$ and resulting mixture was stirred for 5 minutes the corresponding starting material was fully consumed (indicated by TLC). The crude mixture was diluted with cold water and extracted in 
ethyl acetate ( $20 \mathrm{mlL} \times 3$ ) then combined organic extract was dried over sodium sulfate, filtered, and concentrated under reduced pressure. The crude material was purified by PTLC (DCM/Methanol, 19:1) to obtain AceTAG-1 as a colorless sticky material (5.4 mg, $53 \%$ ).

${ }^{1} \mathrm{H}$ NMR $\left(600 \mathrm{MHz}, \mathrm{CDCl}_{3}\right): \delta 7.55(\mathrm{~d}, \mathrm{~J}=1.5 \mathrm{~Hz}, 1 \mathrm{H}), 7.29(\mathrm{~d}, \mathrm{~J}=8.2 \mathrm{~Hz}, 1 \mathrm{H}), 7.25(\mathrm{t}, \mathrm{J}=8.0$ $\mathrm{Hz}, 0.25 \mathrm{H}), 7.14-7.05(\mathrm{~m}, 4 \mathrm{H}), 7.03-6.98(\mathrm{~m}, 1 \mathrm{H}), 6.94(\mathrm{dt}, \mathrm{J}=7.6,1.2 \mathrm{~Hz}, 0.23 \mathrm{H}), 6.83(\mathrm{dd}$, $\mathrm{J}=2.6,1.5 \mathrm{~Hz}, 0.22 \mathrm{H}), 6.80-6.77(\mathrm{~m}, 0.27 \mathrm{H}), 6.77-6.74(\mathrm{~m}, 2 \mathrm{H}), 6.73-6.71(\mathrm{~m}, 0.36 \mathrm{H}), 6.70$ $-6.68(\mathrm{~m}, 2.6 \mathrm{H}), 6.67-6.63(\mathrm{~m}, 1 \mathrm{H}), 6.62-6.57(\mathrm{~m}, 3.3 \mathrm{H}), 6.35(\mathrm{~s}, 0.4 \mathrm{H}), 6.34(\mathrm{~s}, 2 \mathrm{H}), 5.72(\mathrm{dd}$, $\mathrm{J}=7.8,6.0 \mathrm{~Hz}, 0.2 \mathrm{H}), 5.55(\mathrm{dd}, \mathrm{J}=8.3,5.4 \mathrm{~Hz}, 1 \mathrm{H}), 5.41-5.33(\mathrm{~m}, 1 \mathrm{H}), 4.59(\mathrm{~d}, \mathrm{~J}=5.6 \mathrm{~Hz}$, $0.2 \mathrm{H}), 4.44-4.38(\mathrm{~m}, 2 \mathrm{H}), 4.09-4.04(\mathrm{~m}, 2 \mathrm{H}), 3.96-3.91(\mathrm{~m}, 2 \mathrm{H}), 3.84-3.74(\mathrm{~m}, 8 \mathrm{H}), 3.74-$ $3.71(\mathrm{~m}, 0.5 \mathrm{H}), 3.71(\mathrm{~s}, 11 \mathrm{H}), 3.67-3.63(\mathrm{~m}, 2.3 \mathrm{H}), 3.62-3.60(\mathrm{~m}, 5 \mathrm{H}), 3.60-3.58(\mathrm{~m}, 4.4 \mathrm{H})$, $3.53-3.49(\mathrm{~m}, 10 \mathrm{H}), 3.30-3.23(\mathrm{~m}, 0.3 \mathrm{H}), 3.17-3.14(\mathrm{~m}, 2 \mathrm{H}), 3.12-3.06(\mathrm{~m}, 2 \mathrm{H}), 2.73(\mathrm{td}, \mathrm{J}$ = 13.4, $3.0 \mathrm{~Hz}, 1 \mathrm{H}), 2.63-2.53(\mathrm{~m}, 2.2 \mathrm{H}), 2.52-2.45(\mathrm{~m}, 1.4 \mathrm{H}), 2.44-2.38(\mathrm{~m}, 7 \mathrm{H}), 2.36(\mathrm{~s}$, $3.3 \mathrm{H}), 2.26-2.20(\mathrm{~s}, 4.3 \mathrm{H}), 2.05-1.95(\mathrm{~m}, 2.6 \mathrm{H}), 1.88-1.82(\mathrm{~m}, 2 \mathrm{H}), 1.69-1.58(\mathrm{~m}, 4 \mathrm{H}), 1.56$ $-1.51(\mathrm{~m}, 1.6 \mathrm{H}), 1.42-1.34(\mathrm{~m}, 3 \mathrm{H}), 1.31(\mathrm{t}, \mathrm{J}=7.4 \mathrm{~Hz}, 1 \mathrm{H}), 0.83(\mathrm{t}, \mathrm{J}=7.3 \mathrm{~Hz}, 3 \mathrm{H}), 0.78(\mathrm{t}, \mathrm{J}$ $=7.3 \mathrm{~Hz}, 1.3 \mathrm{H})$. Note: rotomeric isomers observed.

${ }^{13} \mathrm{C}$ NMR $\left(151 \mathrm{MHz}, \mathrm{CDCl}_{3}\right): \delta 172.70,172.38,171.66,171.59,170.62,168.34,168.10,165.06$, $159.03,157.41,157.30,157.24,157.21,155.38,155.35,153.50,153.20,148.97,148.89,147.52$, $147.38,142.99,142.37,141.89,136.96,136.62,135.98,135.34,134.28,133.43,133.33,133.28$ 130.16, 129.88, 129.44, 124.25, 123.46, 120.20, 120.12, 119.97, 119.91, 119.81, 117.11, 114.68, $114.14,113.82,113.70,112.98,111.71,111.48,111.28,109.46,104.97,104.58,75.66,70.27$, $70.13,69.80,67.39,67.17,66.84,65.91,60.91,60.79,57.64,56.31,55.97,55.93,55.88,55.86$, $55.76,54.88,54.06,52.08,51.24,50.79,43.49,41.52,39.70,38.92,38.85,38.82,38.27,37.99$, $36.89,36.86,32.94,31.94,31.50,31.30,29.84,29.72,29.34,28.37,26.81,26.50,25.33,24.52$, $22.71,20.94,20.76,17.58,17.06,14.15,12.74,12.59,11.61,10.92,10.24$. Note: rotomeric isomers observed.

HRMS calculated for $\mathrm{C}_{73} \mathrm{H}_{94} \mathrm{~N}_{7} \mathrm{O}_{16}, 1324.6752\left(\mathrm{M}+\mathrm{H}^{+}\right)$, found 1324.6749 . 


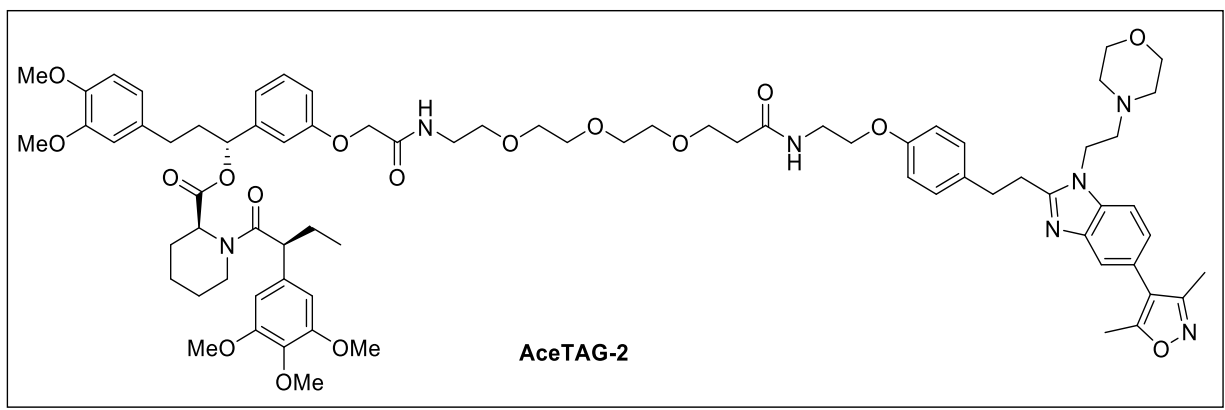

(R)-3-(3,4-dimethoxyphenyl)-1-(3-((18-(4-(2-(5-(3,5-dimethylisoxazol-4-yl)-1-(2morpholinoethyl)-1H-benzo[d]imidazol-2-yl)ethyl)phenoxy)-2,15-dioxo-6,9,12-trioxa-3,16diazaoctadecyl)oxy)phenyl)propyl (S)-1-((S)-2-(3,4,5-

trimethoxyphenyl)butanoyl)piperidine-2-carboxylate (AceTAG-2):

To a solution of tert-butyl (15-(4-(2-(5-(3,5-dimethylisoxazol-4-yl)-1-(2-morpholinoethyl)-1Hbenzo[d]imidazol-2-yl)ethyl)phenoxy)-12-oxo-3,6,9-trioxa-13-azapentadecyl)carbamate (P300$\left.\mathrm{PEG}_{3}-\mathrm{NHBoc}\right)(10 \mathrm{mg}, 0.013 \mathrm{mmol})$ in DCM $(1 \mathrm{~mL})$, a solution of $20 \%$ TFA in DCM (1 mL) was added at $0{ }^{\circ} \mathrm{C}$ and resulting mixture was stirred at room temperature for $2 \mathrm{~h}$. After completion (monitored by TLC), the reaction mixture was evaporated under reduced pressure to obtained the corresponding TFA salt of 3-(2-(2-(2-aminoethoxy)ethoxy)ethoxy)-N-(2-(4-(2-(5-(3,5dimethylisoxazol-4-yl)-1-(2-morpholinoethyl)-1H-benzo[d]imidazol-2-

yl)ethyl)phenoxy)ethyl)propenamide, was obtained were used in next step without further purification. To a solution of corresponding TFA salt of 3-(2-(2-(2-aminoethoxy)ethoxy)ethoxy)-N(2-(4-(2-(5-(3,5-dimethylisoxazol-4-yl)-1-(2-morpholinoethyl)-1H-benzo[d]imidazol-2-

yl)ethyl)phenoxy)ethyl)propanamide $(6.0 \mathrm{mg}, 0.0087 \mathrm{mmol}, 1$ eq.) in DMF (1 mL), DIPEA (7.52 $\mu \mathrm{L}, \quad 0.043 \mathrm{mmol}, \quad 5 \quad$ eq. $)$ and 2-(3-((R)-3-(3,4-dimethoxyphenyl)-1-(((S)-1-((S)-2-(3,4,5trimethoxyphenyl)butanoyl)piperidine-2-carbonyl)oxy)propyl)phenoxy)acetic acid (synthesized as previously described $\left.{ }^{2}\right)(6.0 \mathrm{mg}, 0.0087 \mathrm{mmol}, 1 \mathrm{eq})$ was added followed by HATU (3.16 mg, $0.0083 \mathrm{mmol}, 1.1 \mathrm{eq}$ ) were added at $0^{\circ} \mathrm{C}$ and resulting mixture was stirred for 5 minutes, the corresponding starting material was fully consumed (indicated by TLC). The crude mixture was diluted with cold water and extracted in ethyl acetate $(20 \mathrm{~mL} \times 3)$ then combined organic extract was dried over sodium sulfate, filtered, and concentrated under reduced pressure. The crude material was purified by PTLC (DCM/Methanol, 19:1) to obtain AceTAG-2 as a colorless sticky material (5.6 mg, $48 \%)$.

${ }^{1} \mathrm{H}$ NMR $\left(600 \mathrm{MHz}, \mathrm{CDCl}_{3}\right): \delta 7.62(\mathrm{~d}, \mathrm{~J}=1.4 \mathrm{~Hz}, 1 \mathrm{H}), 7.35(\mathrm{~d}, \mathrm{~J}=8.2 \mathrm{~Hz}, 1 \mathrm{H}), 7.32(\mathrm{t}, \mathrm{J}=7.9$ $\mathrm{Hz}, 0.3 \mathrm{H}), 7.22-7.11(\mathrm{~m}, 4 \mathrm{H}), 7.08(\mathrm{~d}, \mathrm{~J}=5.9 \mathrm{~Hz}, 1 \mathrm{H}), 7.00(\mathrm{dt}, \mathrm{J}=7.6,1.2 \mathrm{~Hz}, 0.3 \mathrm{H}), 6.90(\mathrm{~d}$, $\mathrm{J}=2.4 \mathrm{~Hz}, 0.3 \mathrm{H}), 6.86(\mathrm{dd}, \mathrm{J}=8.4,2.7, \mathrm{~Hz}, 0.5 \mathrm{H}), 6.85-6.80(\mathrm{~m}, 3 \mathrm{H}), 6.80-6.74(\mathrm{~m}, 3 \mathrm{H}), 6.71$ 
- $6.63(\mathrm{~m}, 3 \mathrm{H}), 6.41(\mathrm{~s}, 0.4 \mathrm{H}), 6.40(\mathrm{~s}, 2 \mathrm{H}), 5.81-5.76(\mathrm{~m}, 0.23 \mathrm{H}), 5.62(\mathrm{dd}, \mathrm{J}=8.3,5.4 \mathrm{~Hz}, 1 \mathrm{H})$, $5.46-5.42(\mathrm{~m}, 1 \mathrm{H}), 4.66-4.60(\mathrm{~m}, 0.5 \mathrm{H}), 4.50-4.45(\mathrm{~m}, 2.2 \mathrm{H}), 4.13(\mathrm{t}, \mathrm{J}=6.8 \mathrm{~Hz}, 2 \mathrm{H}), 4.01(\mathrm{t}$, $\mathrm{J}=5.4 \mathrm{~Hz}, 2 \mathrm{H}), 3.87-3.82(\mathrm{~m}, 8.5 \mathrm{H}), 3.80-3.76(\mathrm{~m}, 3.2 \mathrm{H}), 3.72-3.69(\mathrm{~m}, 2.5 \mathrm{H}), 3.69-3.67$ $(\mathrm{m}, 5 \mathrm{H}), 3.67-3.64(\mathrm{~m}, 4.3 \mathrm{H}), 3.63-3.61(\mathrm{~m}, 3 \mathrm{H}), 3.61-3.56(\mathrm{~m}, 11.4 \mathrm{H}), 3.55-3.51(\mathrm{~m}, 2.2 \mathrm{H})$, $3.35-3.32(\mathrm{~m}, 0.4 \mathrm{H}), 3.25-3.20(\mathrm{~m}, 2 \mathrm{H}), 3.19-3.14(\mathrm{~m}, 2.2 \mathrm{H}), 2.81-2.76(\mathrm{~m}, 1 \mathrm{H}), 2.62(\mathrm{t}, \mathrm{J}$ $=6.9 \mathrm{~Hz}, 2 \mathrm{H}), 2.58-2.51(\mathrm{~m}, 1.3 \mathrm{H}), 2.49-2.43(\mathrm{~m}, 7 \mathrm{H}), 2.43-2.40(\mathrm{~m}, 3.4 \mathrm{H}), 2.33-2.26(\mathrm{~m}$, $4 \mathrm{H}), 2.17(\mathrm{~s}, 0.25 \mathrm{H}), 2.13-2.04(\mathrm{~m}, 2 \mathrm{H}), 2.02-1.98(\mathrm{~m}, 1 \mathrm{H}), 1.95-1.88(\mathrm{~m}, 1 \mathrm{H}), 1.83-1.79$ $(\mathrm{m}, 0.3 \mathrm{H}), 1.61-1.59(\mathrm{~m}, 1.3 \mathrm{H}), 1.45-1.40(\mathrm{~m}, 1 \mathrm{H}), 0.89(\mathrm{t}, \mathrm{J}=7.3 \mathrm{~Hz}, 3 \mathrm{H}), 0.84(\mathrm{t}, \mathrm{J}=7.3 \mathrm{~Hz}$, 1H). Note: rotomeric isomers observed.

${ }^{13} \mathrm{C}$ NMR $\left(151 \mathrm{MHz}, \mathrm{CDCl}_{3}\right) \delta 172.67,172.36,171.74,171.69,170.61,170.49,168.21,168.00$, 165.05, 159.03, 157.44, 157.31, 157.26, 155.38, 153.49, 153.20, 148.97, 148.89, 147.52, 147.37, 143.06, 142.34, 141.86, 136.95, 136.62, 135.99, 135.34, 134.30, 133.39, 133.34, 133.08, 130.14, $129.86,129.42,124.23,123.44,120.19,120.12,119.94,119.77,117.11,114.68,114.28,113.94$, $113.61,112.88,111.70,111.60,111.35,111.28,109.44,104.97,104.57,75.66,70.51,70.37$, $70.31,70.27,69.74,67.42,67.38,67.20,66.84,66.80,60.91,60.79,57.65,56.31,55.97,55.93$, $55.88,55.86,55.77,54.07,52.07,51.24,50.80,43.48,41.52,39.69,38.88,38.83,38.29,38.00$, $36.90,32.94,31.50,31.29,30.96,29.87,29.72$, 28.38, 26.82, 25.34, 24.52, 22.71, 22.63, 20.95, $20.77,12.74,12.59,11.61,10.92$. Note: rotomeric isomers observed.

HRMS calculated for $\mathrm{C}_{75} \mathrm{H}_{98} \mathrm{~N}_{7} \mathrm{O}_{17}, 1368.7014\left(\mathrm{M}+\mathrm{H}^{+}\right)$, found 1368.7018 .

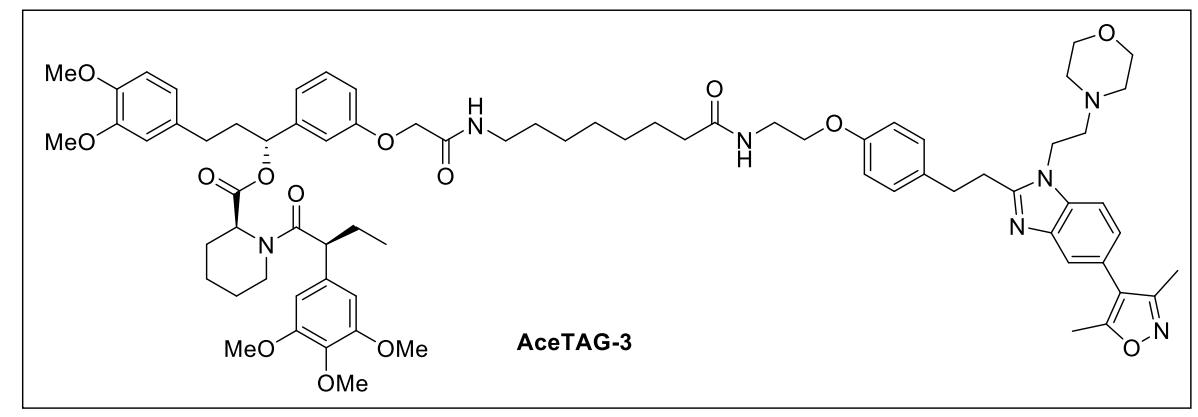

(R)-3-(3,4-dimethoxyphenyl)-1-(3-(2-((8-)(2-(4-(2-(5-(3,5-dimethylisoxazol-4-yl)-1-(2morpholinoethyl)-1H-benzo[d]imidazol-2-yl)ethyl)phenoxy)ethyl)amino)-8oxooctyl)amino)-2-oxoethoxy)phenyl)propyl (S)-1-((S)-2-(3,4,5trimethoxyphenyl)butanoyl)piperidine-2-carboxylate (AceTAG-3):

To a solution of tert-butyl (8-((2-(4-(2-(5-(3,5-dimethylisoxazol-4-yl)-1-(2-morpholinoethyl)-1Hbenzo[d]imidazol-2-yl)ethyl)phenoxy)ethyl)amino)-8-oxooctyl)carbamate (P300-C7-NHBoc) (15 
$\mathrm{mg}, 0.020 \mathrm{mmol})$ in DCM $(1 \mathrm{~mL})$, a solution of $20 \%$ TFA in DCM $(1 \mathrm{~mL})$ was added at $0{ }^{\circ} \mathrm{C}$ and resulting mixture was stirred at room temperature for $2 \mathrm{~h}$. After completion (monitored by TLC), the reaction mixture was evaporated under reduced pressure to obtained the corresponding TFA salt of 8-amino-N-(2-(4-(2-(5-(3,5-dimethylisoxazol-4-yl)-1-(2-morpholinoethyl)-1Hbenzo[d]imidazol-2-yl)ethyl)phenoxy)ethyl)octanamide was obtained, were used in next step without further purification. To a solution of corresponding TFA salt of 8-amino-N-(2-(4-(2-)(5-(3,5dimethylisoxazol-4-yl)-1-(2-morpholinoethyl)-1H-benzo[d]imidazol-2-

yl)ethyl)phenoxy)ethyl)octanamide (8.0 mg, $0.013 \mathrm{mmol}, 1$ eq.) in DCM (1 mL), DIPEA (7.52 $\mu \mathrm{L}$, $0.043 \mathrm{mmol}, \quad 5$ eq.) and 2-(3-((R)-3-(3,4-dimethoxyphenyl)-1-(((S)-1-((S)-2-(3,4,5trimethoxyphenyl)butanoyl)piperidine-2-carbonyl)oxy)propyl)phenoxy)acetic acid (synthesized as previously described $\left.{ }^{2}\right)(8.8 \mathrm{mg}, 0.013 \mathrm{mmol}, 1$ eq.) was added followed by EDC (3.65 mg, 0.019 mmol, 1.5 eq.) and $\mathrm{HOBt}\left(2.60 \mathrm{mg}, 0.019 \mathrm{mmol}, 1.5\right.$ eq.) were added at $0^{\circ} \mathrm{C}$ and resulting mixture was stirred for 10 hours, the corresponding starting material was fully consumed (indicated by TLC). The crude mixture was diluted with cold water and extracted in DCM (20 mL X 3) then combined organic extract was dried over sodium sulfate, filtered, and concentrated under reduced pressure. The crude material was purified by PTLC (DCM/Methanol, 19:1) to obtain AceTAG-3 as a colorless sticky material $(7.8 \mathrm{mg}, 47 \%)$.

${ }^{1} \mathrm{H}$ NMR $\left(600 \mathrm{MHz}, \mathrm{CDCl}_{3}\right): \delta 7.64(\mathrm{~s}, 1 \mathrm{H}), 7.36(\mathrm{~s}, 1 \mathrm{H}), 7.34-7.31(\mathrm{~m}, 0.4 \mathrm{H}), 7.23-7.11(\mathrm{~m}$, $4 \mathrm{H}), 7.00(\mathrm{~d}, \mathrm{~J}=7.6 \mathrm{~Hz}, 0.25 \mathrm{H}), 6.91(\mathrm{~s}, 0.25 \mathrm{H}), 6.87-6.82(\mathrm{~m}, 2.3 \mathrm{H}), 6.81-6.77(\mathrm{~m}, 0.3 \mathrm{H})$, $6.78-7.74(\mathrm{~m}, 3 \mathrm{H}), 6.71-6.60(\mathrm{~m}, 4 \mathrm{H}), 6.41(\mathrm{~s}, 0.4 \mathrm{H}), 6.40(\mathrm{~s}, 2 \mathrm{H}), 6.01-5.99(\mathrm{~m}, 1 \mathrm{H}), 5.81-$ $5.79(\mathrm{~m}, 0.2 \mathrm{H}), 5.62(\mathrm{dd}, \mathrm{J}=8.3,5.4 \mathrm{~Hz}, 1 \mathrm{H}), 5.48-5.43(\mathrm{~m}, 1 \mathrm{H}), 4.70-4.64(\mathrm{~m}, 0.25 \mathrm{H}), 4.66$ $-4.58(\mathrm{~m}, 0.6 \mathrm{H}), 4.50-4.44(\mathrm{~m}, 2 \mathrm{H}), 4.17-4.09(\mathrm{~m}, 2 \mathrm{H}), 4.01(\mathrm{t}, \mathrm{J}=5.1 \mathrm{~Hz}, 2 \mathrm{H}), 3.86-3.81$ $(\mathrm{m}, 9 \mathrm{H}), 3.80-3.76(\mathrm{~s}, 3.5 \mathrm{H}), 3.67-3.63(\mathrm{~m}, 11 \mathrm{H}), 3.60-3.56(\mathrm{~m}, 1 \mathrm{H}), 3.36-3.28(\mathrm{~m}, 2.5 \mathrm{H})$, $3.26-3.21(\mathrm{~m}, 2.5 \mathrm{H}), 3.20-3.15(\mathrm{~m}, 2.3 \mathrm{H}), 2.82-2.76(\mathrm{~m}, 1 \mathrm{H}), 2.65-2.60(\mathrm{~m}, \mathrm{~J}=6.9 \mathrm{~Hz}$, $2.4 \mathrm{H}), 2.58-2.52(\mathrm{~m}, 1.6 \mathrm{H}), 2.49-2.44(\mathrm{~m}, 4.5 \mathrm{H}), 2.43-2.39(\mathrm{~m}, 4.2 \mathrm{H}), 2.33-2.25(\mathrm{~m}, 4.5 \mathrm{H})$, $2.20-2.14(\mathrm{~m}, 2.4 \mathrm{H}), 2.13-2.03(\mathrm{~m}, 2.4 \mathrm{H}), 1.95-1.89(\mathrm{~m}, 1 \mathrm{H}), 1.74-1.66(\mathrm{~m}, 4 \mathrm{H}), 1.63-1.59$ $(\mathrm{m}, 6 \mathrm{H}), 1.55-1.49(\mathrm{~m}, 3 \mathrm{H}), 1.47-1.41(\mathrm{~m}, 1.3 \mathrm{H}), 1.33-1.23(\mathrm{~m}, 12 \mathrm{H}), 0.90(\mathrm{t}, \mathrm{J}=7.3 \mathrm{~Hz}, 3 \mathrm{H})$, $0.85(\mathrm{t}, \mathrm{J}=7.3 \mathrm{~Hz}, 1.3 \mathrm{H})$. Note: rotomeric isomers observed.

${ }^{13} \mathrm{C}$ NMR $\left(151 \mathrm{MHz}, \mathrm{CDCl}_{3}\right) \delta 173.30,172.70,172.39,170.66,170.47,168.03,167.78,165.06$, $159.03,157.43,157.21,155.39,153.52,153.22,148.98,148.91,147.55,147.40,143.06,142.39$, 141.92 , 137.00, 136.64, 136.01, 135.35, 134.31, 133.50, 133.37, 133.11, 130.17, 129.86, 129.47, $124.25,123.46,120.23,120.15,120.03,119.95,119.82,117.12,114.68,113.83,113.53,113.09$, 
$111.74,111.65,111.32,109.45,104.99,104.61,76.57,67.39,66.93,66.85,60.92,60.80,57.66$, $56.33,55.96,55.88,55.74,54.08,52.09,51.26,50.82,43.49,41.53,39.69,39.00,38.92,38.25$, $37.97,36.58,32.96,31.95,31.31,29.88,29.73,29.54,29.09,28.85,28.40,26.82,26.63,26.48$, $25.53,25.35,24.54,22.72,20.93,20.74,14.16,12.76,12.61,11.62,10.93$. Note: rotomeric isomers observed.

HRMS calculated for $\mathrm{C}_{74} \mathrm{H}_{96} \mathrm{~N}_{7} \mathrm{O}_{14}, 1306.7010\left(\mathrm{M}+\mathrm{H}^{+}\right)$, found 1306.7008 .

\section{References}

1. Hay et al. J. Am. Chem. Soc. 2014, 136, 26, 9308-9319

2. B. Nabet et al. Nature Chemical Biology, 2018, 14, $431-441$. 


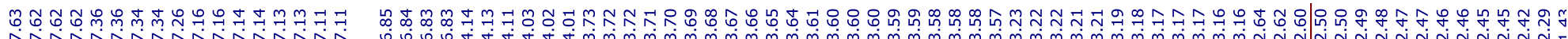
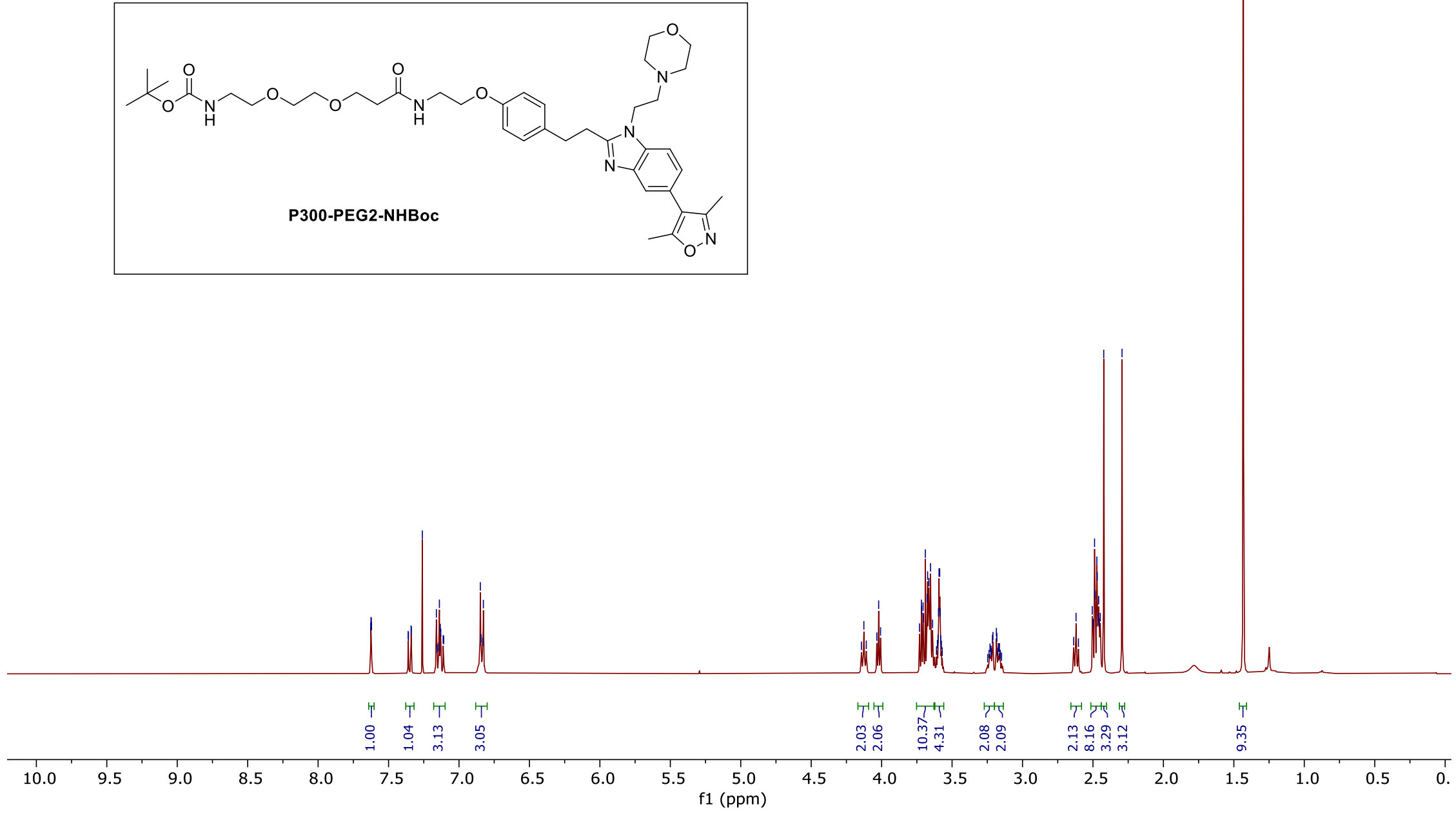

${ }^{1} \mathrm{H}$ NMR (P300-PEG2-NHBoc)

$-S 49-$ 


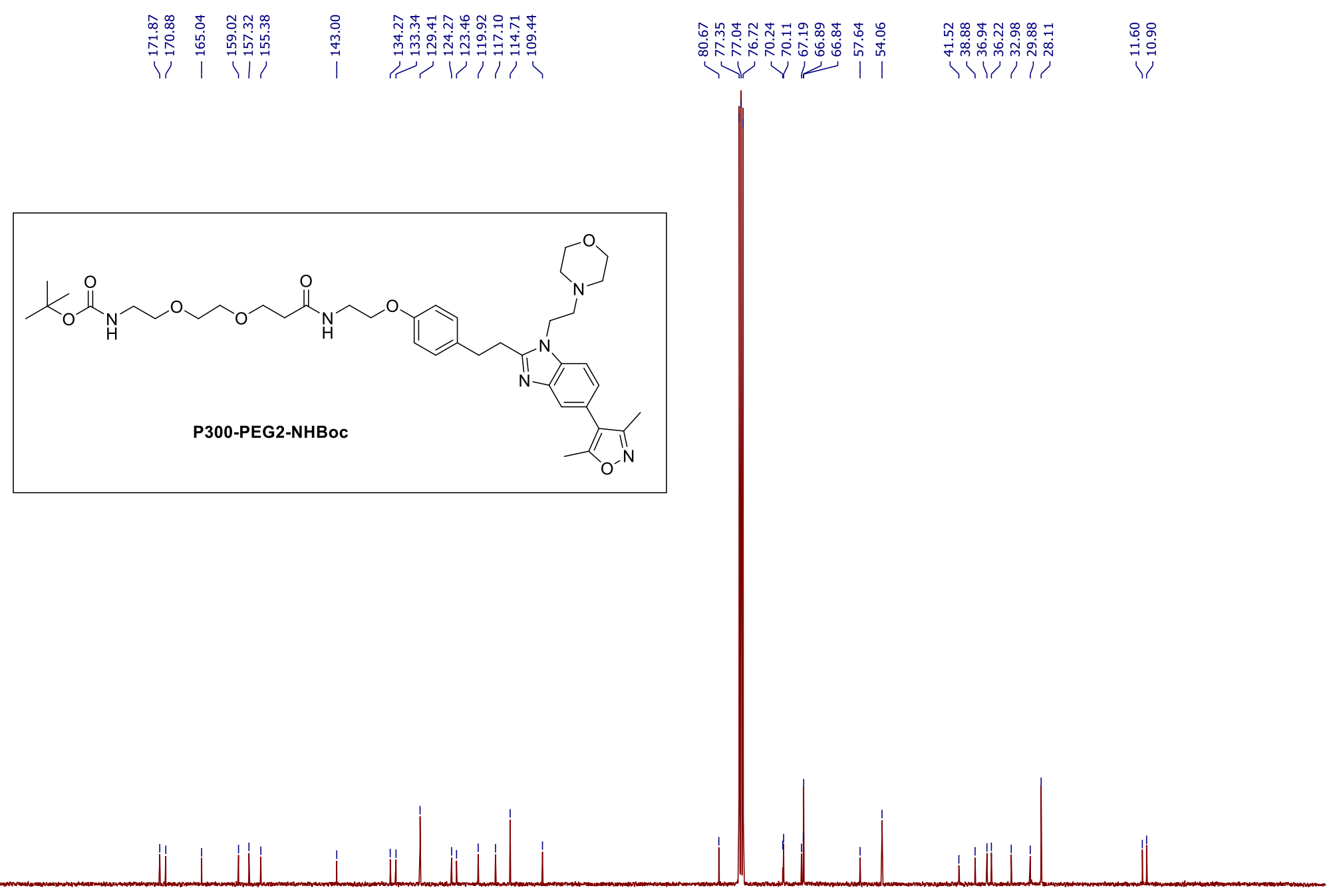

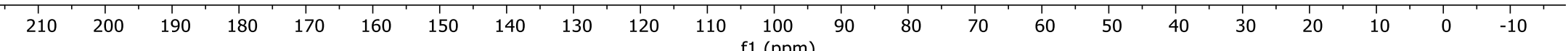

${ }^{13} \mathrm{C}$ NMR (P300-PEG2-NHBoc)

-S50- 


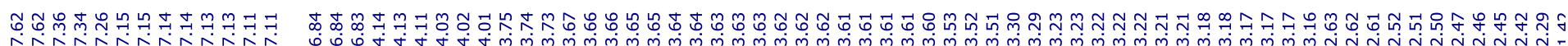
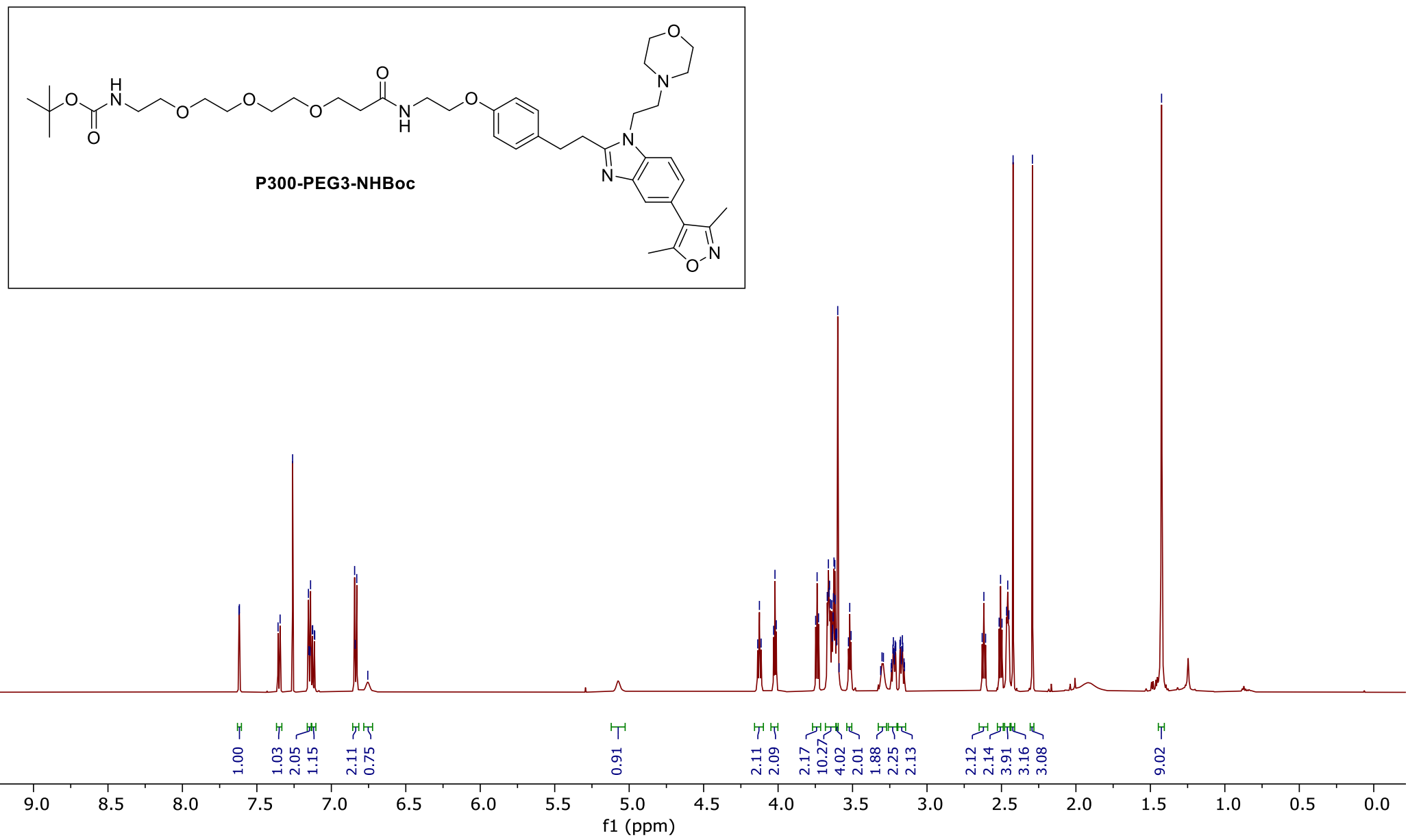

${ }^{1} \mathrm{H}$ NMR (P300-PEG3-NHBoc)

-S51- 


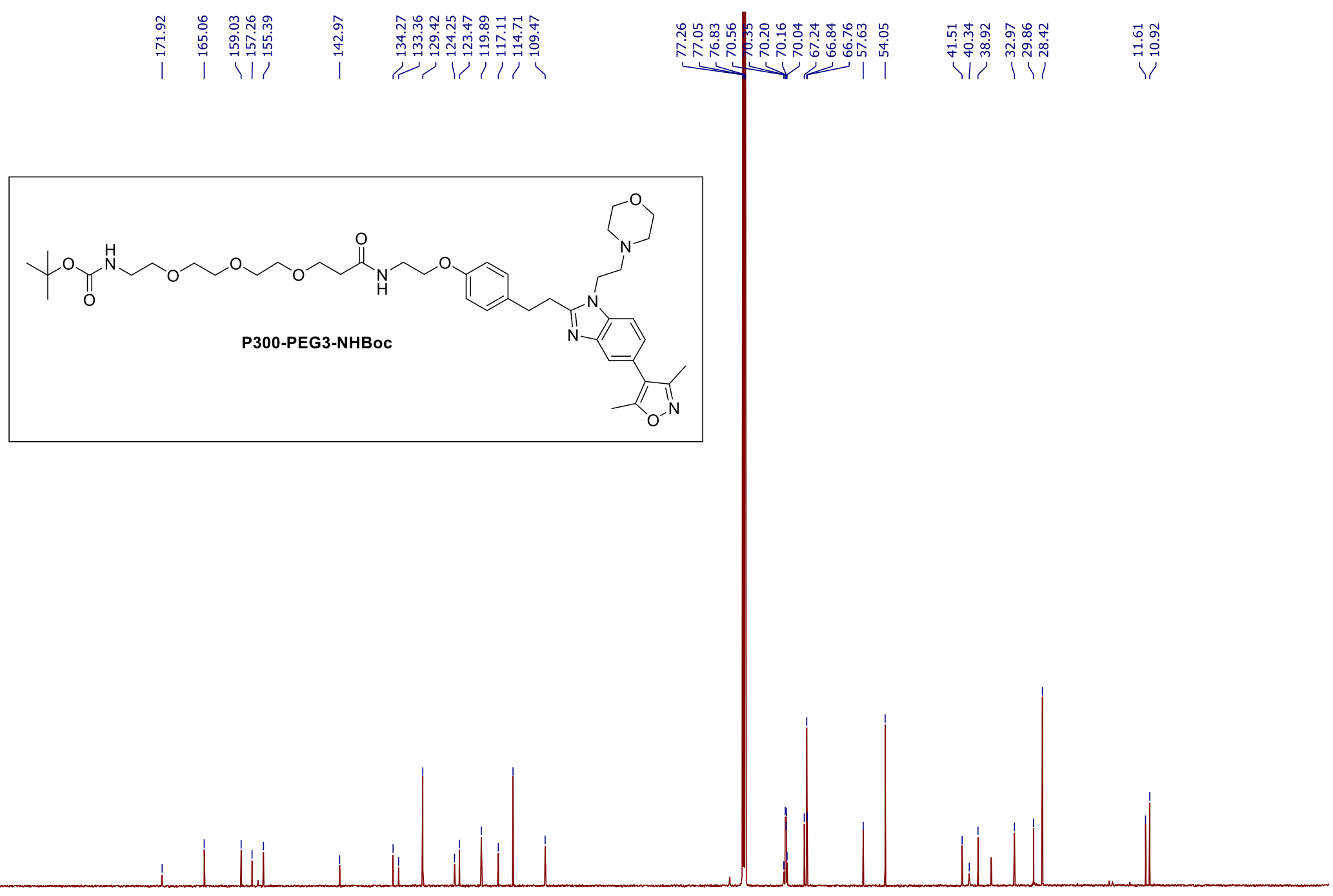

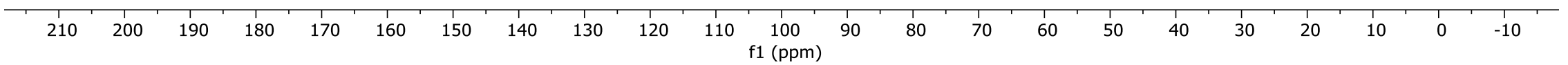

${ }^{13} \mathrm{C}$ NMR (P300-PEG3-NHBoc)

-S52- 


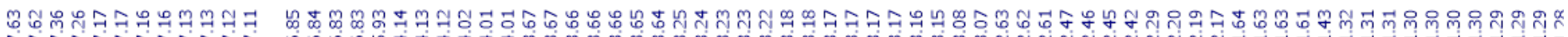

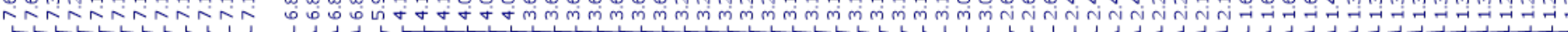
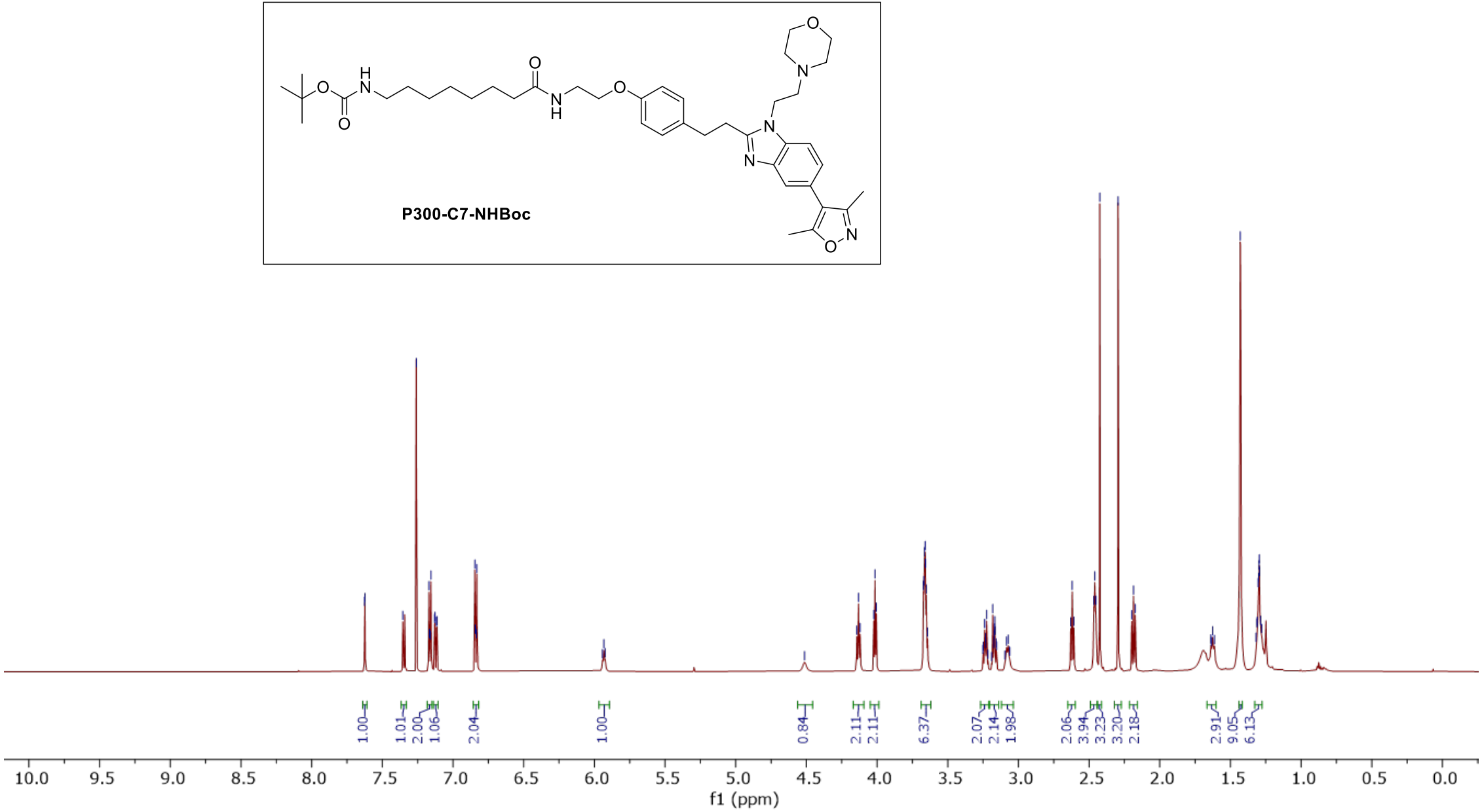

${ }^{1} \mathrm{H}$ NMR (P300-C7-NHBoc)

-S53- 

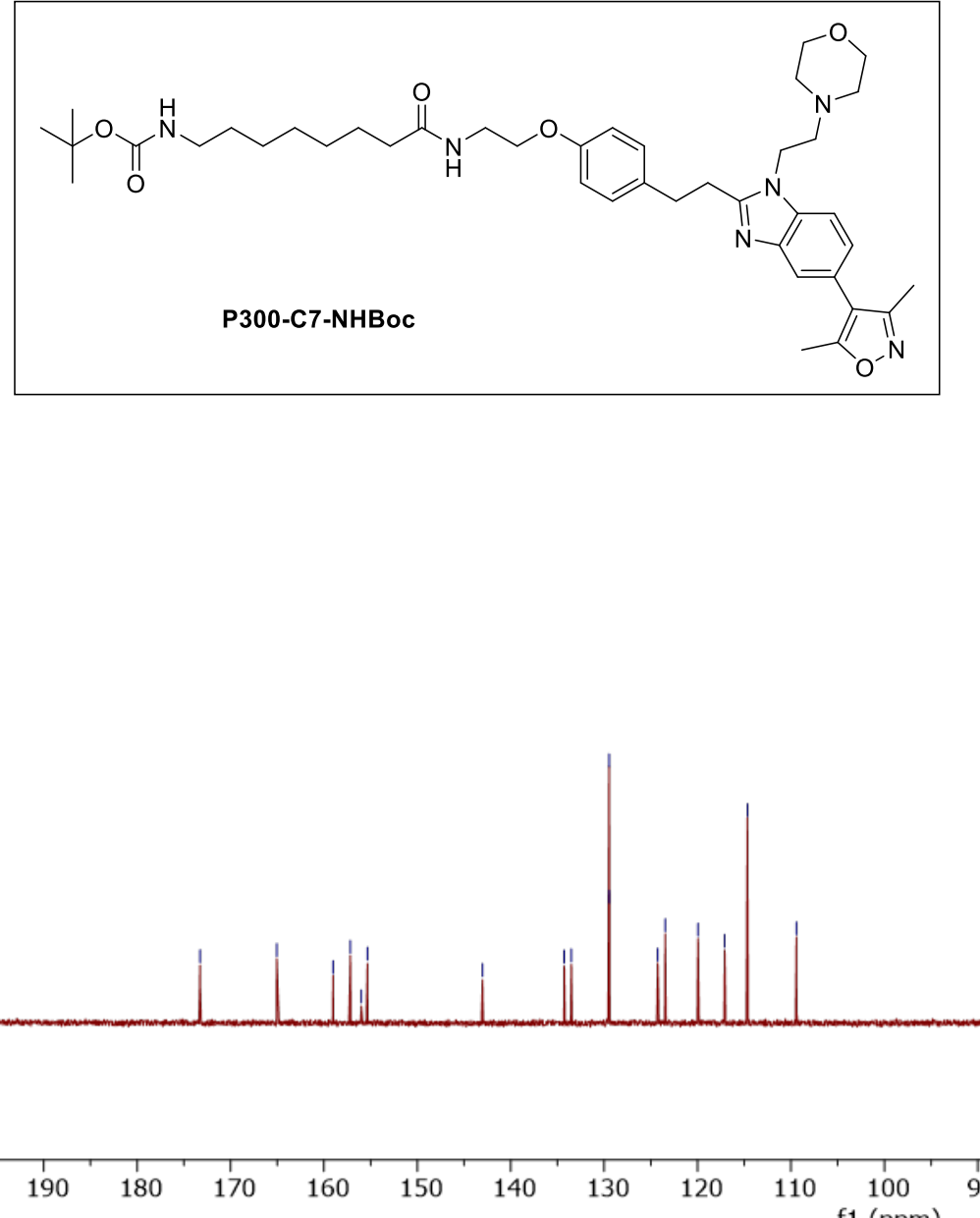
f1 (ppm)
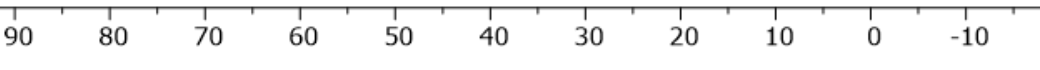

${ }^{13} \mathrm{C}$ NMR (P300-C7-NHBoc)

$-\mathrm{S} 54-$ 

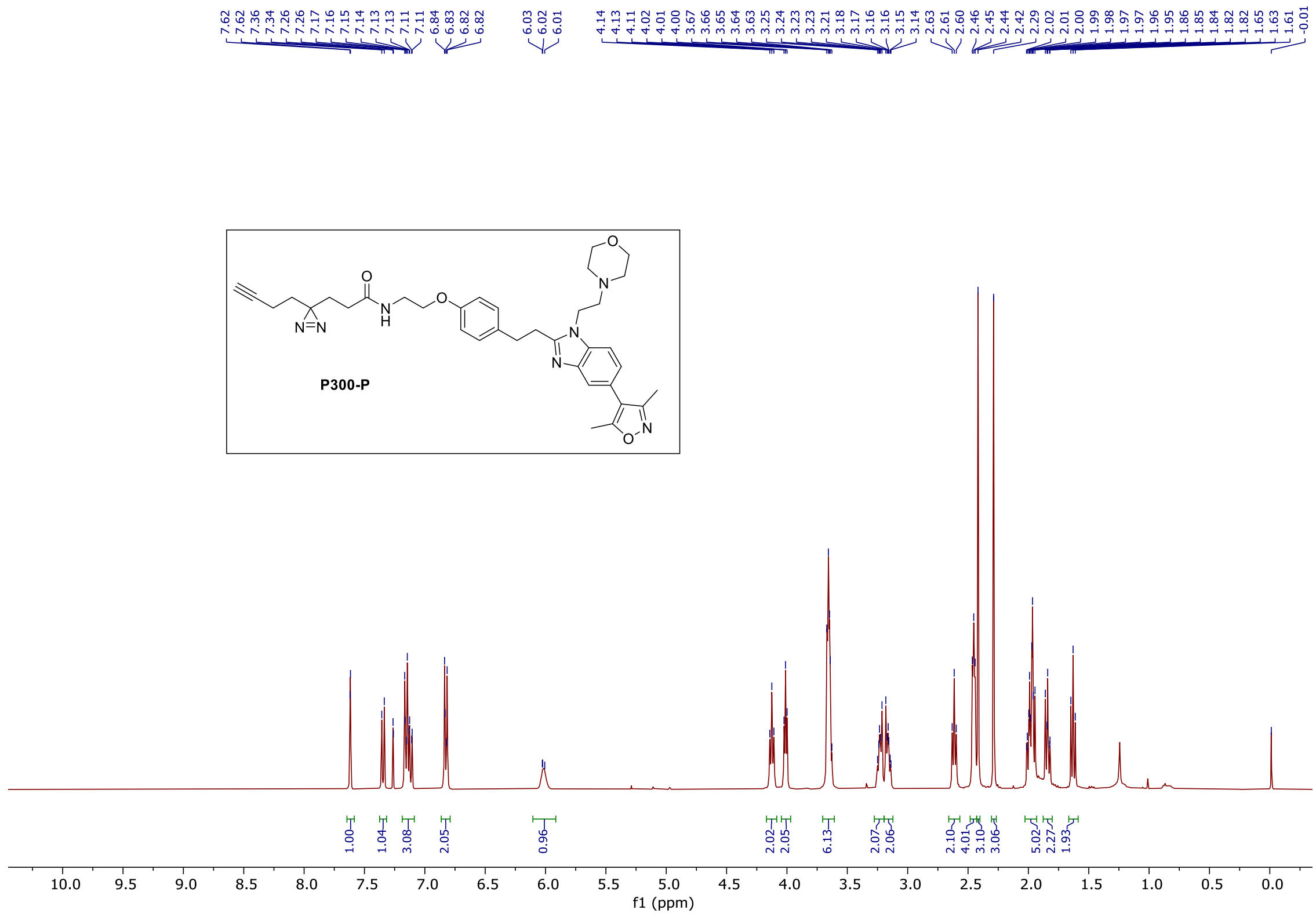

${ }^{1} \mathrm{H}$ NMR (P300-P)

-S55- 

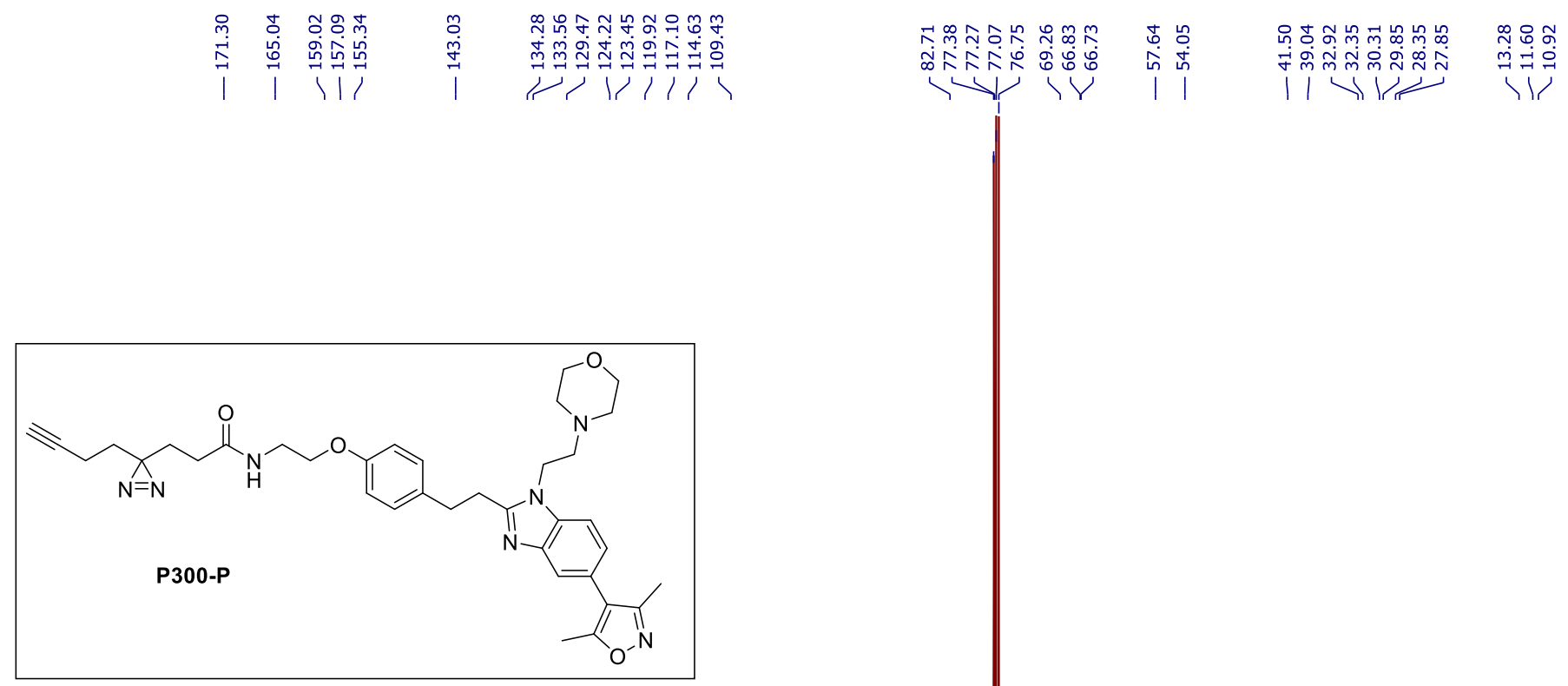

\begin{tabular}{|c|c|c|c|c|c|c|c|c|c|c|c|c|c|c|c|c|c|c|c|c|c|c|}
\hline 210 & 200 & 190 & 180 & 170 & 160 & 150 & 140 & 130 & 120 & 110 & $\begin{array}{c}100 \\
\text { f1 }(\mathrm{ppm})\end{array}$ & 90 & 80 & 70 & 60 & 50 & 40 & 30 & 20 & 10 & 0 & -10 \\
\hline
\end{tabular}




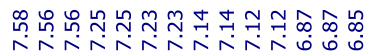

年

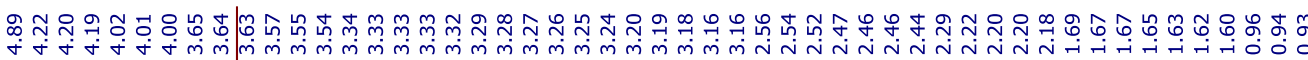
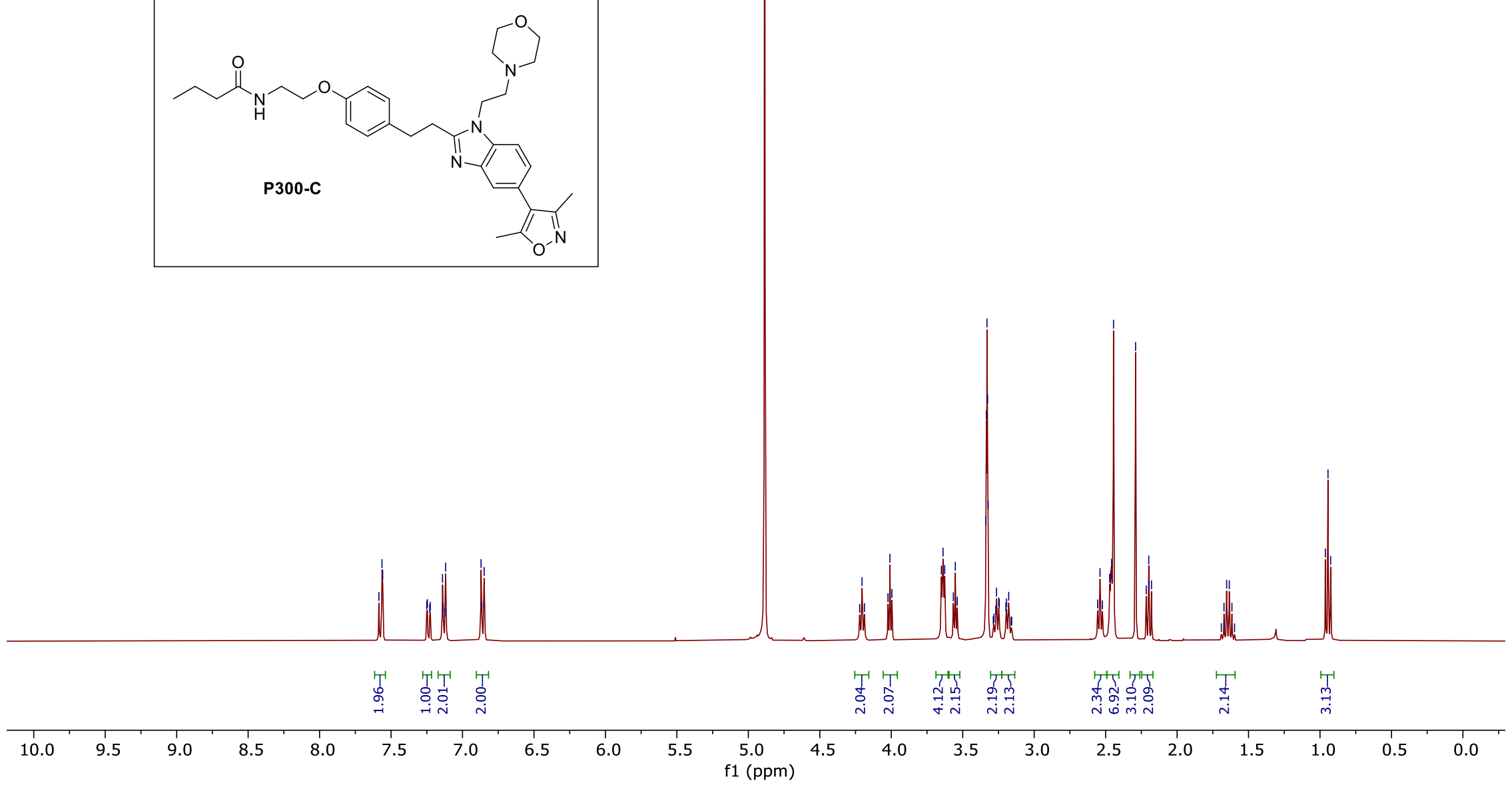

${ }^{1} \mathrm{H}$ NMR (P300-C)

-S57- 


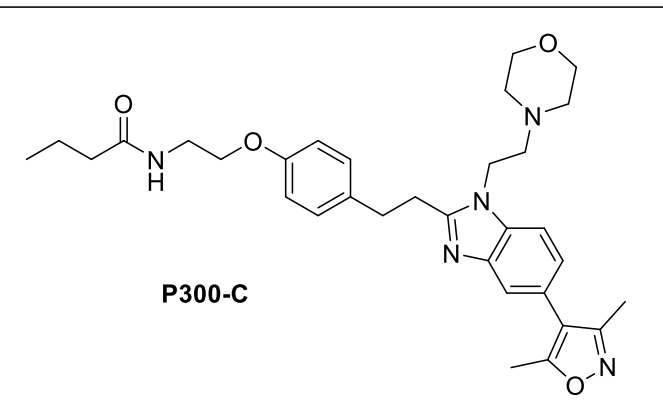

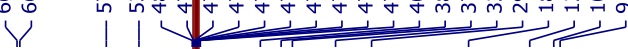

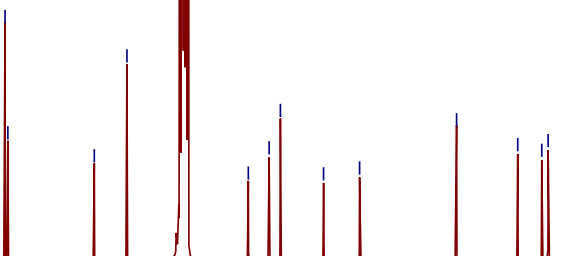

$\begin{array}{llllllllllll}210 & 200 & 190 & 180 & 170 & 160 & 150 & 140 & 130 & 120 & 110 & \begin{array}{c}100 \\ \mathrm{f} 1(\mathrm{ppm})\end{array}\end{array}$

-S58- 


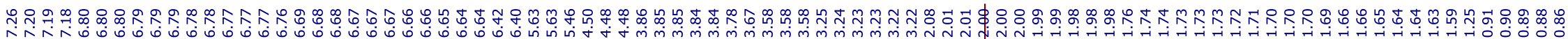

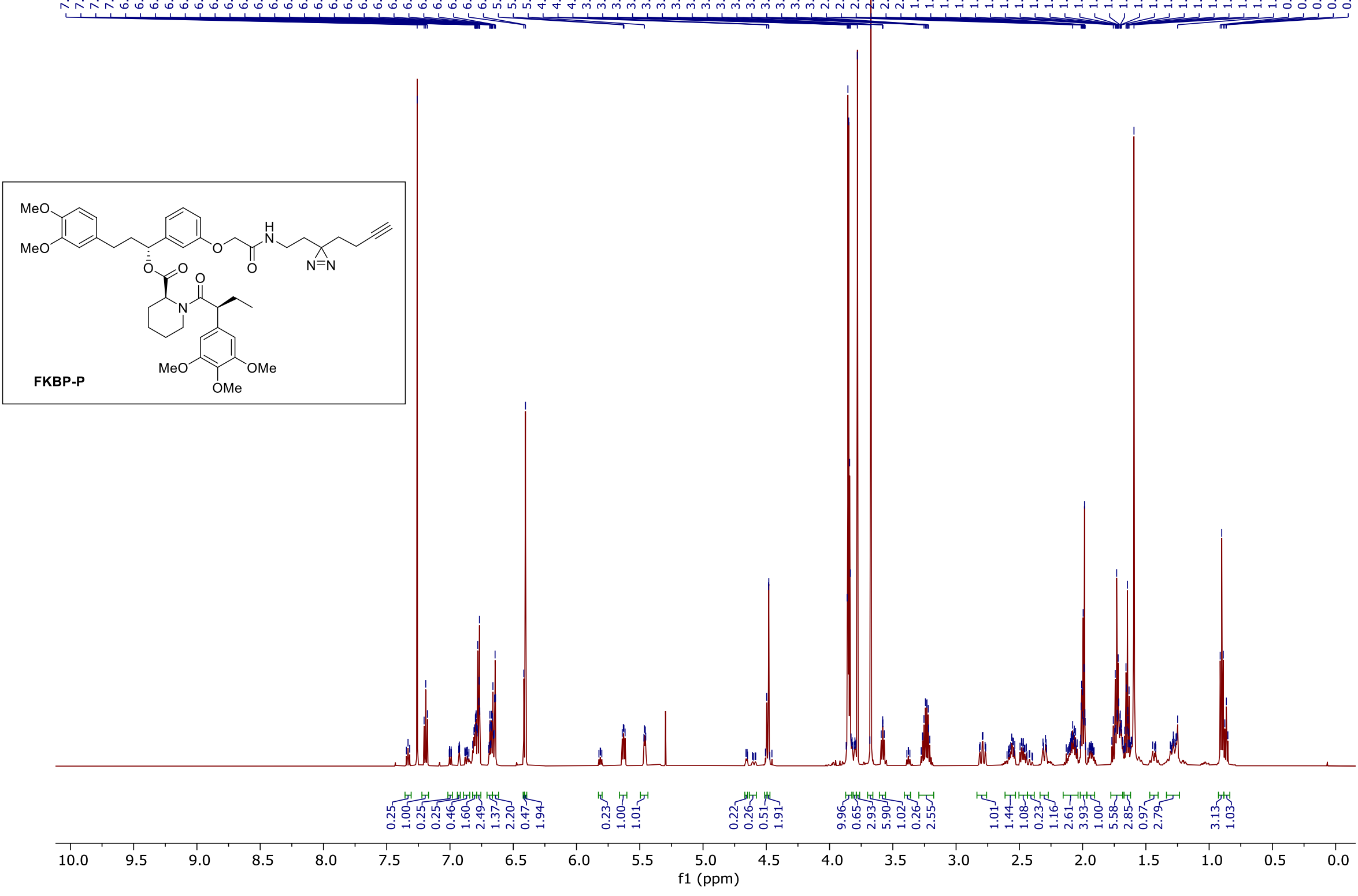

${ }^{1} \mathrm{H}$ NMR (FKBP-P)

-S59- 


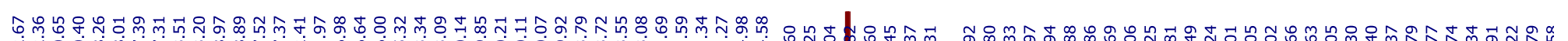

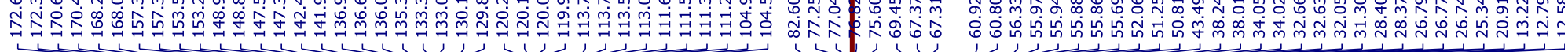

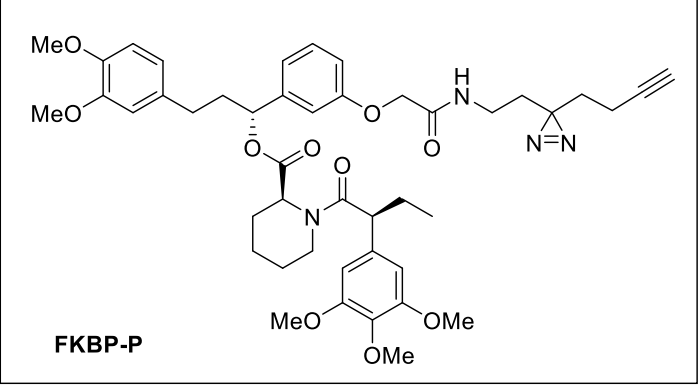

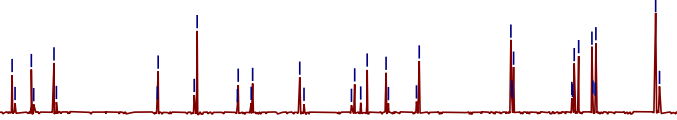

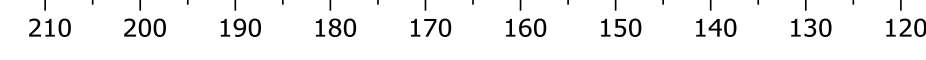

$110 \quad 100$ f1 (ppm)

${ }^{13} \mathrm{C}$ NMR (FKBP-P)

-S60- 


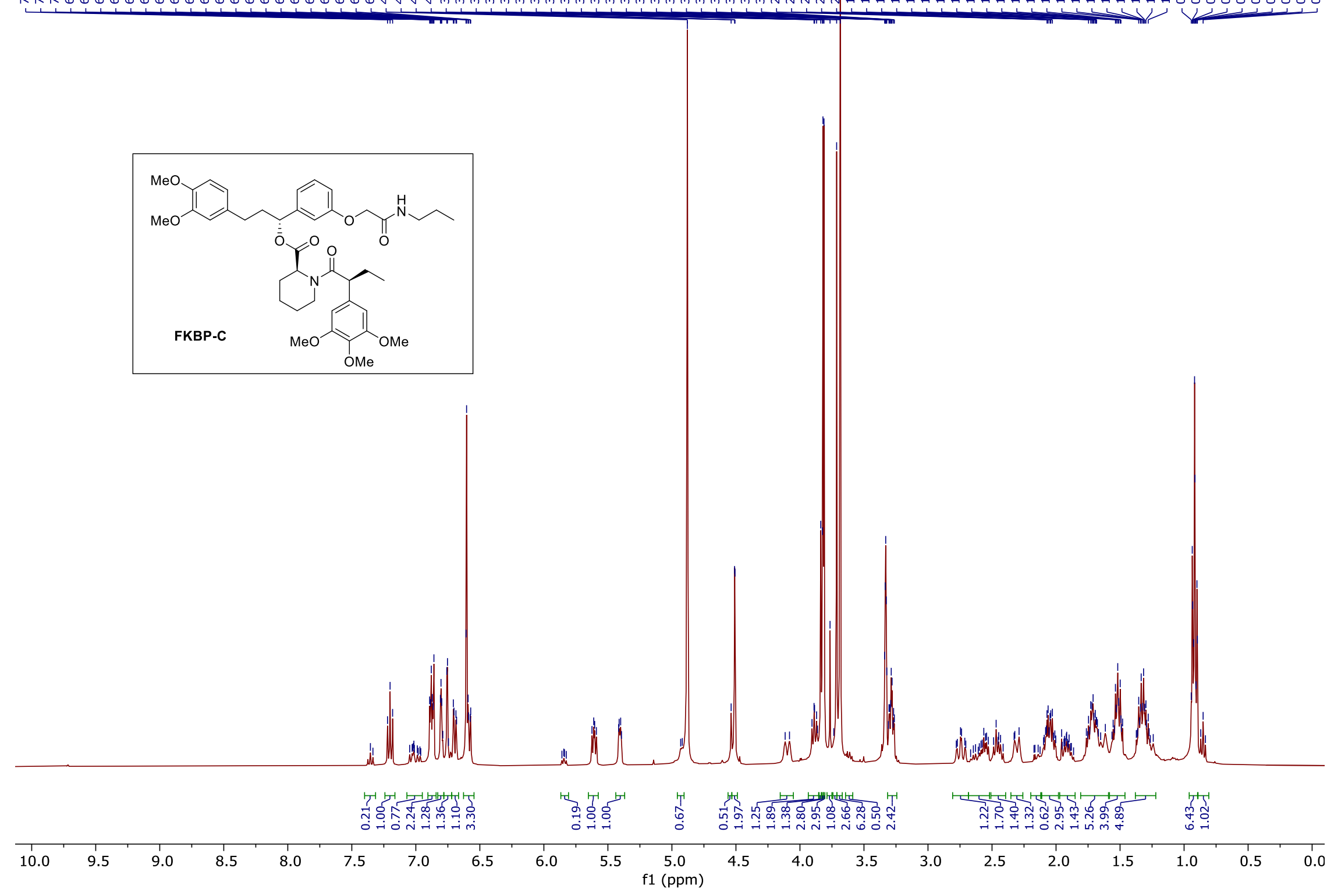

${ }^{1} \mathrm{H}$ NMR (FKBP-C)

$-S 61-$ 


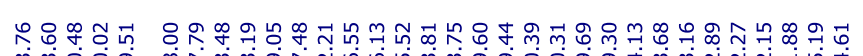

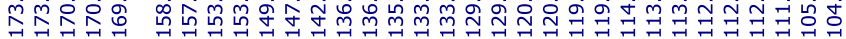

$4 V, Y<1$

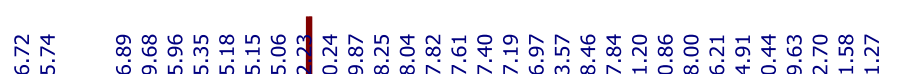

釷
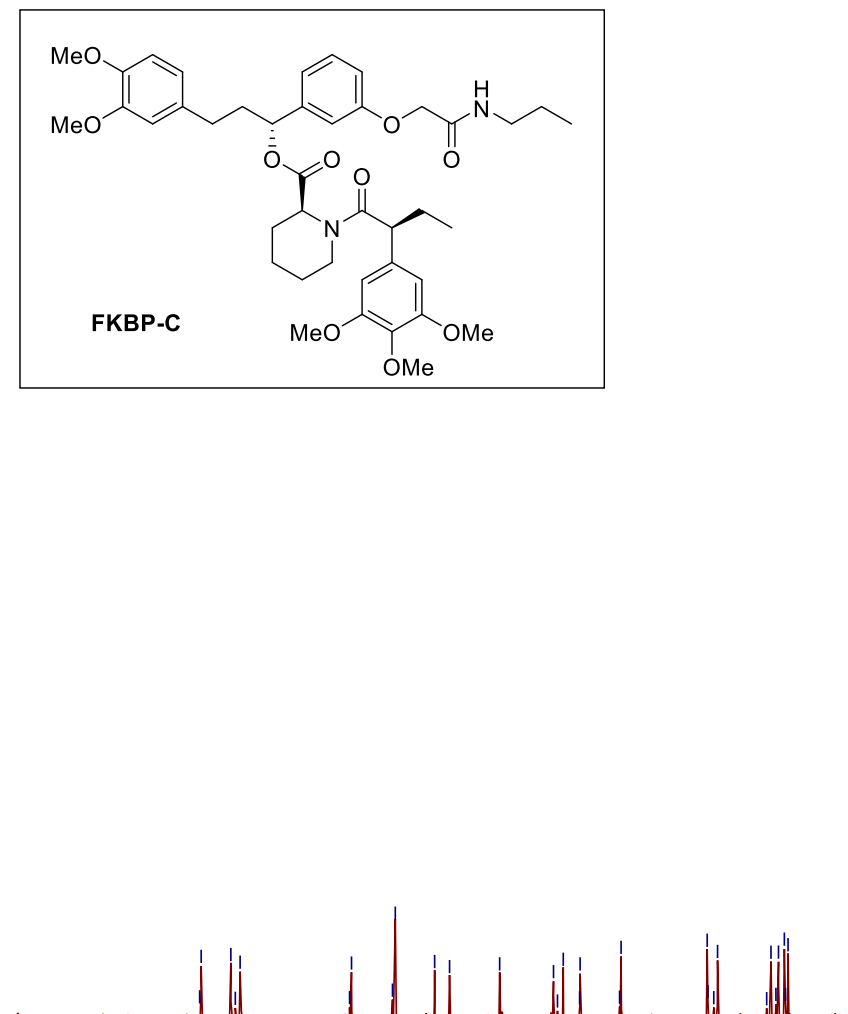

${ }^{13} \mathrm{C}$ NMR (FKBP-C)

-S62- 


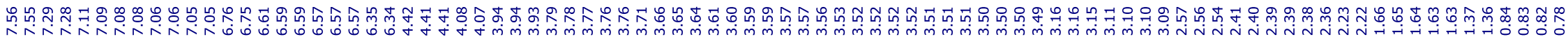

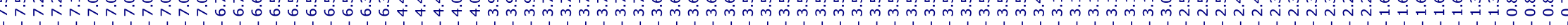

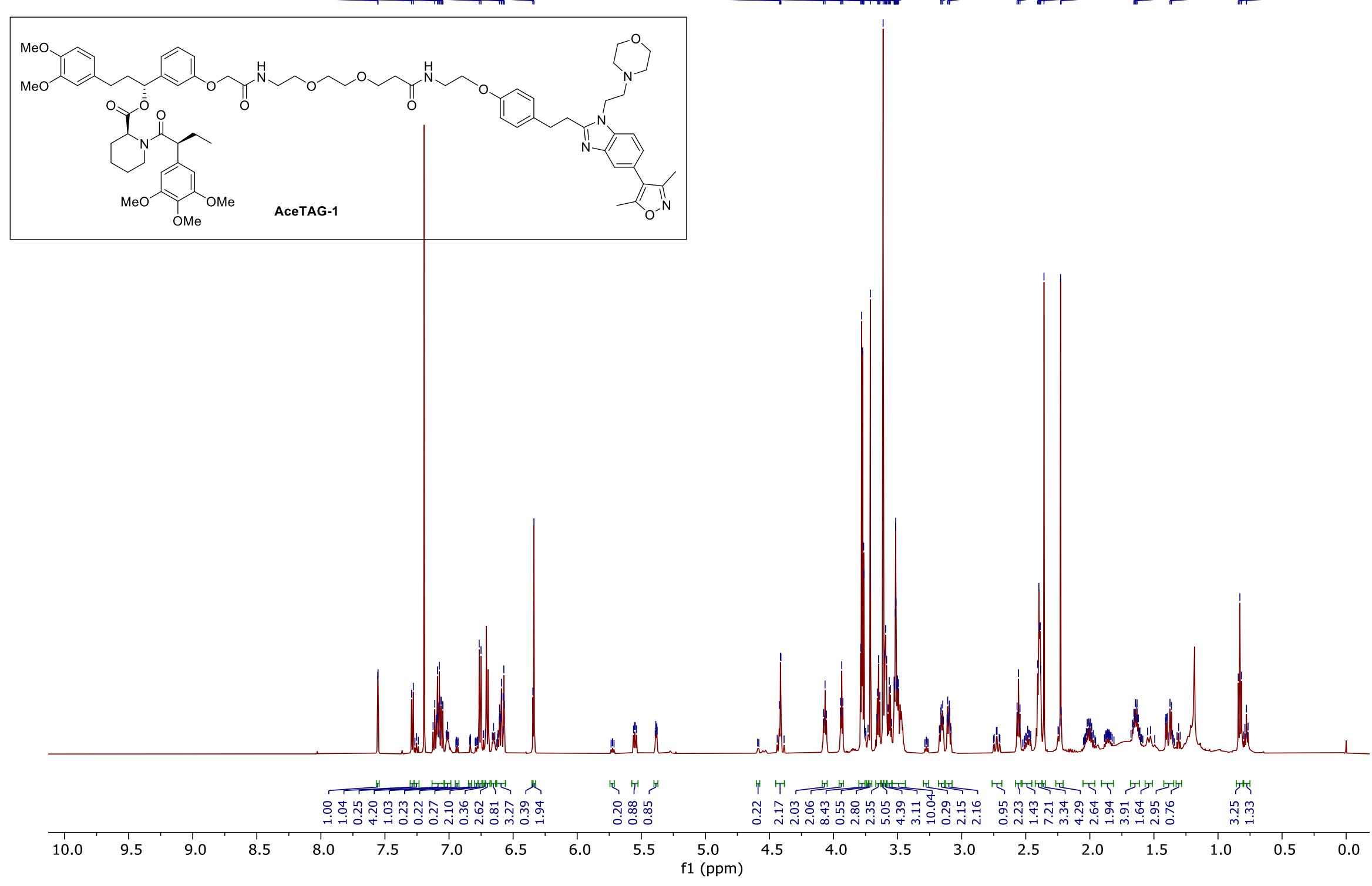

${ }^{1} \mathrm{H}$ NMR (AceTAG-1)

-S63- 


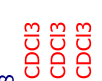

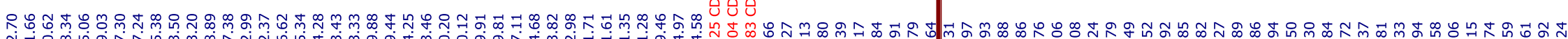

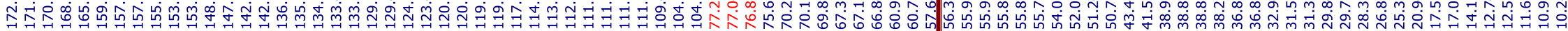
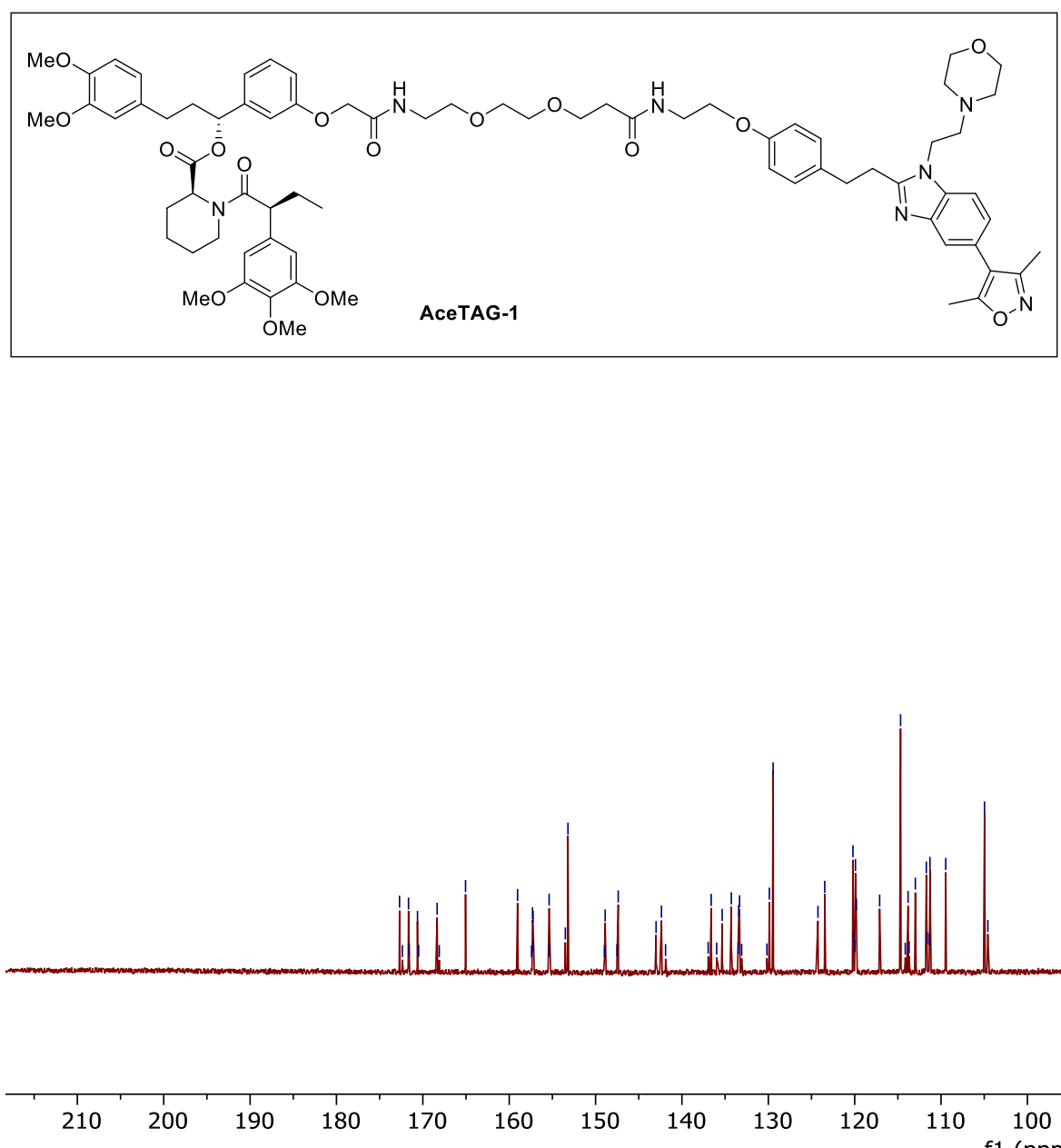

$210 \quad 200 \quad 190 \quad 180$

$170 \quad 160$

$150 \quad 140$

$130 \quad 120$

$110 \quad 100$ f1 (ppm)

$90 \quad 80$

70

$60 \quad 50$

$40 \quad 30$

20

$10 \quad 0$ $-10$

${ }^{13} \mathrm{C}$ NMR (AceTAG-1)

-S64- 


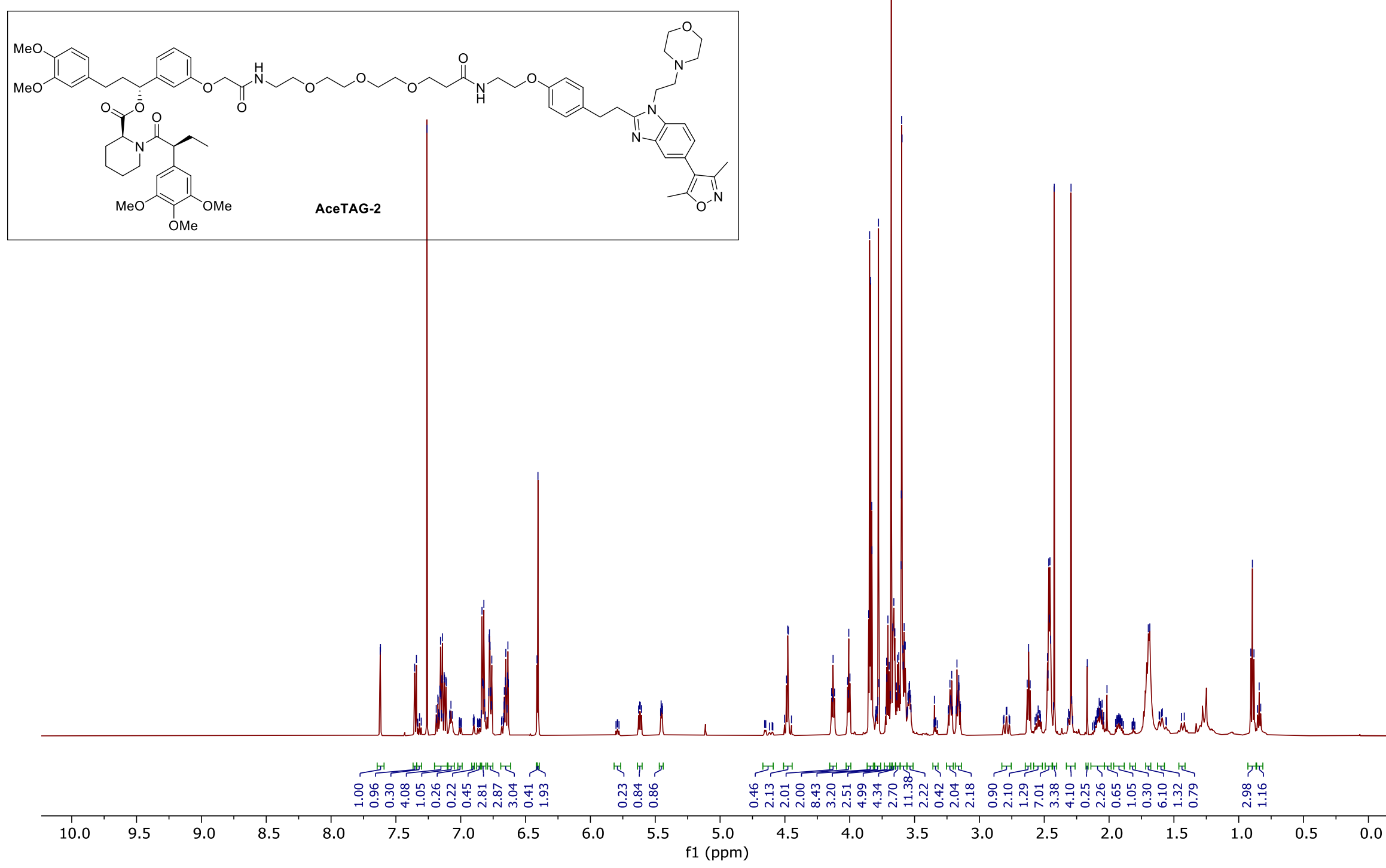

${ }^{1} \mathrm{H}$ NMR (AceTAG-2)

-S65- 


\section{8}

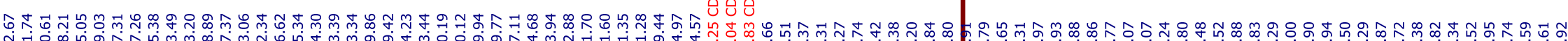

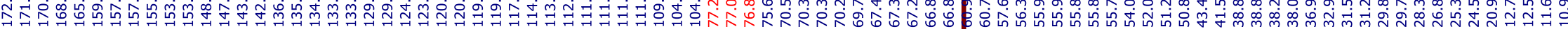
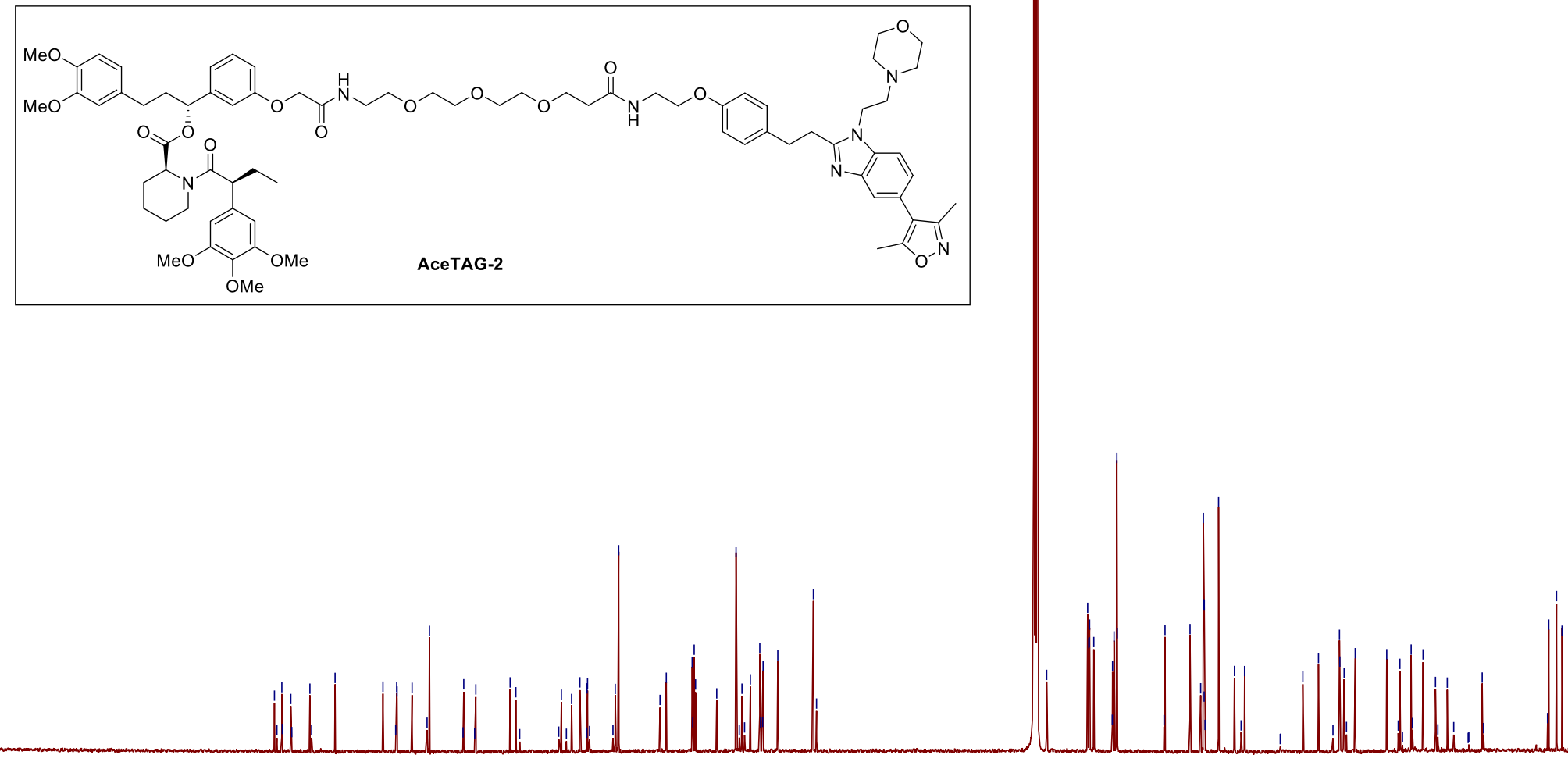

210

$200 \quad 190$

180

$160 \quad 150$

140

$130 \quad 120$

110100 f1 (ppm)

$90 \quad 80$

$70 \quad 60$

50

$40 \quad 30$

20

${ }^{13} \mathrm{C}$ NMR (AceTAG-2)

-S66- 


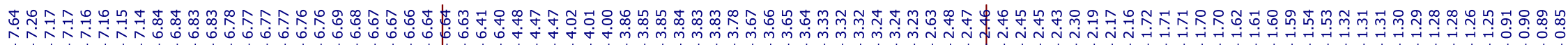
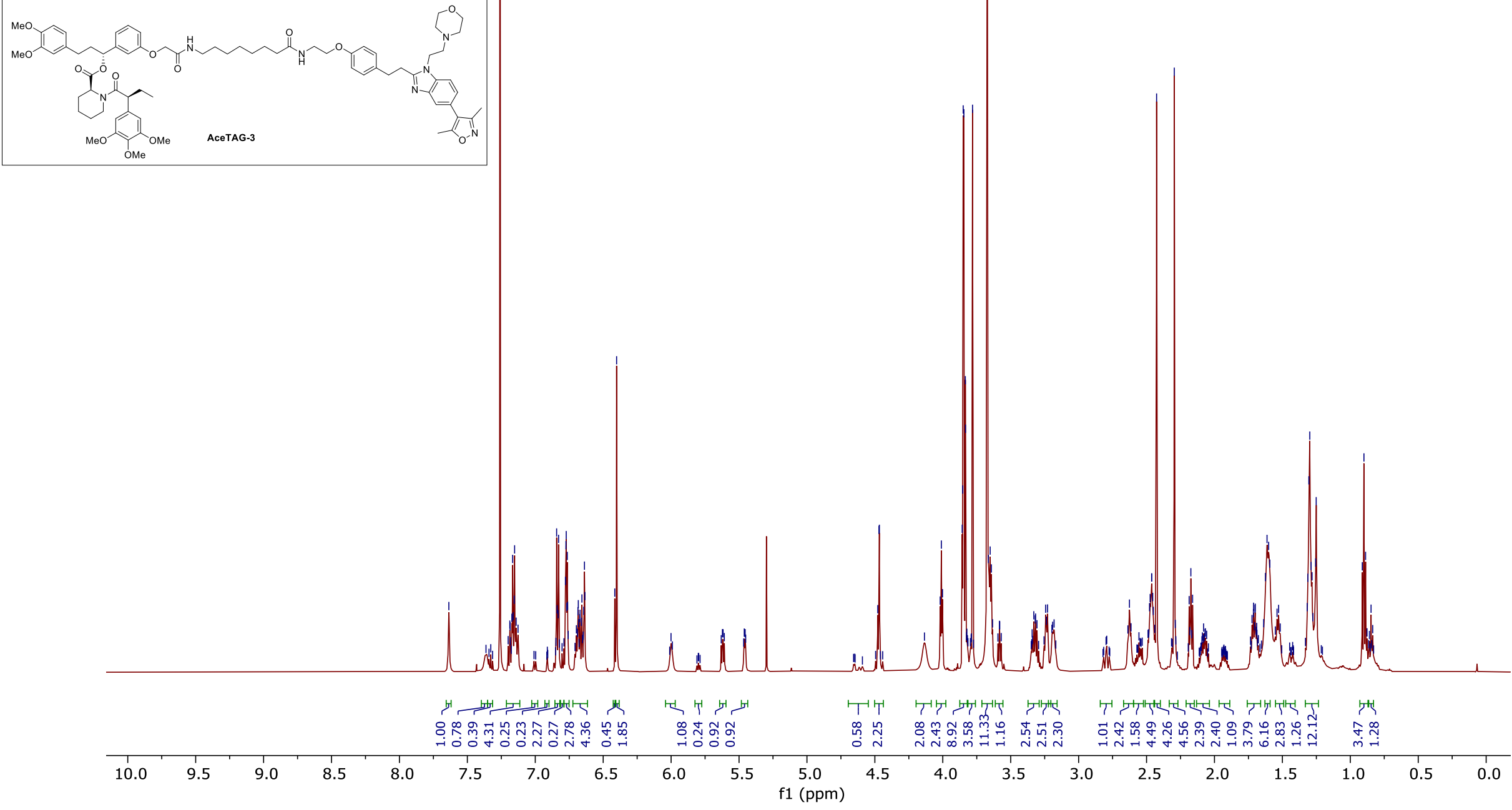

${ }^{1} \mathrm{H}$ NMR (AceTAG-3)

-S67- 


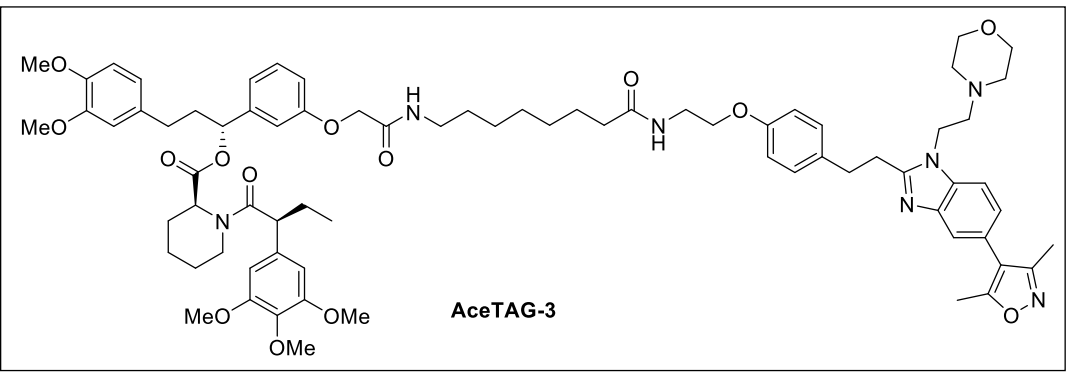

\begin{tabular}{|c|c|c|c|c|c|c|c|c|c|c|c|}
\hline 210 & 200 & 190 & 180 & 170 & 160 & 150 & 140 & 130 & 120 & $\begin{array}{cc}110 & 100 \\
\mathrm{f} 1(\mathrm{ppm})\end{array}$ & 90 \\
\hline
\end{tabular}

-S68- 